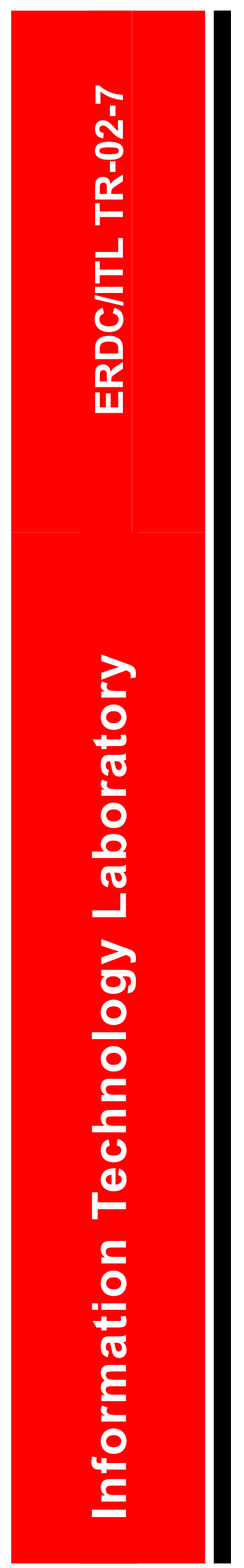

Innovations for Navigation Projects Research Program

Numerical Methods to Model Excavation of Soil Adjacent to Retaining Structures

Marte S. Gutierrez, Robert M. Ebeling,

November 2002 and George M. Filz 
The contents of this report are not to be used for advertising, publication, or promotional purposes. Citation of trade names does not constitute an official endorsement or approval of the use of such commercial products.

The findings of this report are not to be construed as an official Department of the Army position, unless so designated by other authorized documents. 


\section{Numerical Methods to Model Excavation of Soil Adjacent to Retaining Structures}

by Marte S. Gutierrez, George M. Filz

Virginia Polytechnic Institute and State University Blacksburg, VA 24061

Robert M. Ebeling

Information Technology Laboratory

U.S. Army Engineer Research and Development Center 3909 Halls Ferry Road

Vicksburg, MS 39180-6199

Final report

Approved for public release; distribution is unlimited 


\section{Contents}

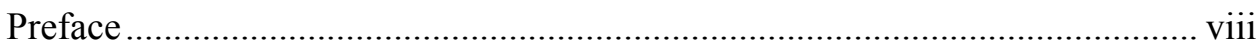

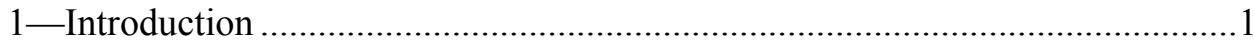

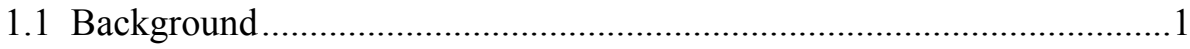

1.1.1 Common types of multi-anchored systems .................................. 1

1.1.3 Need for nonlinear finite element SSI analyses .............................

1.1.3 Need for nonlinear finite element SSI analyses ...........................6

1.2 Review of Previous Work on SSI Analysis ............................................

1.3 Bonneville Temporary Tieback Wall Analysis..........................................9

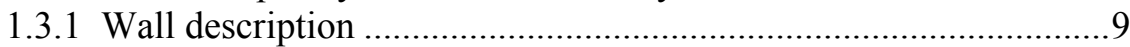

1.3.2 Overall design and evaluation process ......................................10

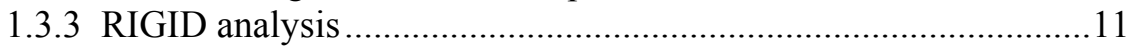

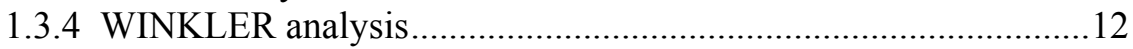

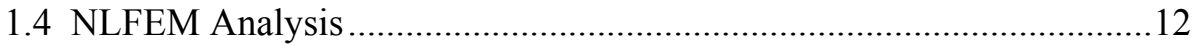

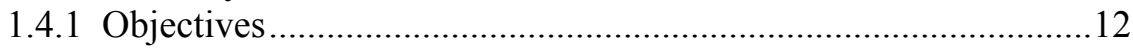

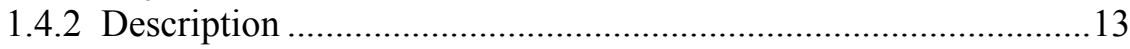

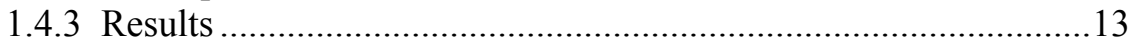

1.4.4 Comparison of the results of NLFEM, WINKLER, and

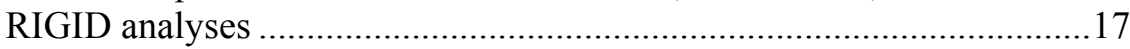

1.5 Overview of SOILSTRUCT-ALPHA Finite Element Program .............18

1.6 Need for Further Improvements in SOILSTRUCT-ALPHA .................20

1.6.1 Improvements in excavation procedure.......................................20

1.6.2 Accounting for soil-structure interface behavior in the

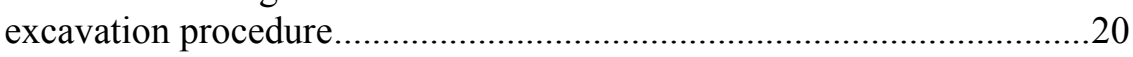

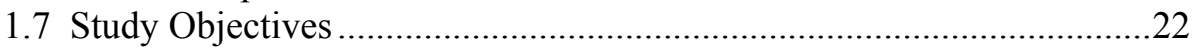

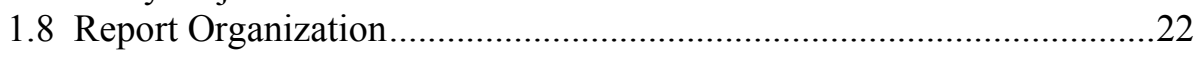

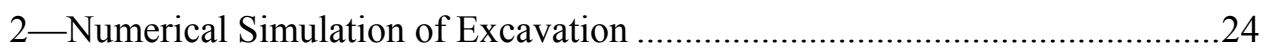

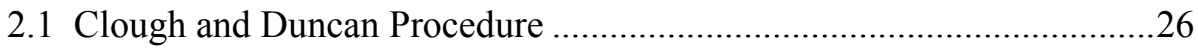

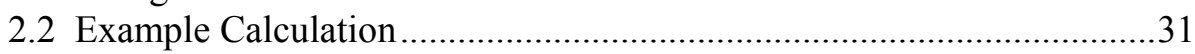

2.2.1 Existing ground condition (pre-excavation) .................................31

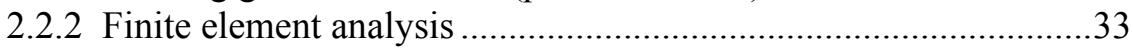

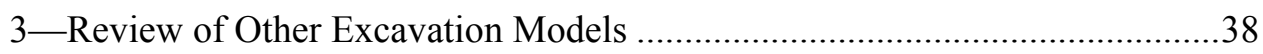

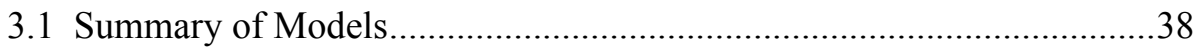

3.2 Methods Based on Force Residuals ..................................................4 43

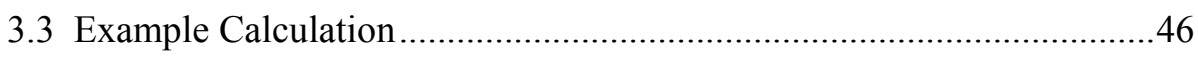

4-Assessment of Numerical Models for Excavation .........................................51

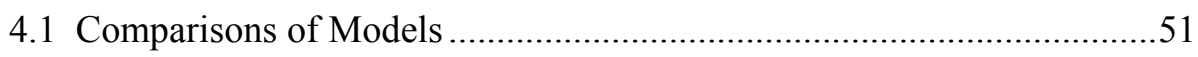


4.2 Performance of Numerical Procedures for Excavation Modeling ..........53

4.2.1 Uniqueness of solution for homogenous elastic regime................54

4.2.2 Force and moment equilibrium .................................................63

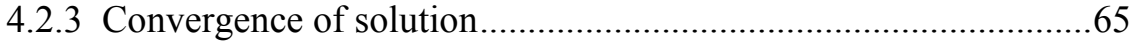

4.3 Implementation Issues in SOILSTRUCT-ALPHA.................................65

4.3.1 Implementation using QM5 or other element types .....................66

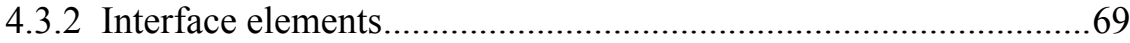

4.3.3 Nonlinear material properties and the ALPHA method ................73

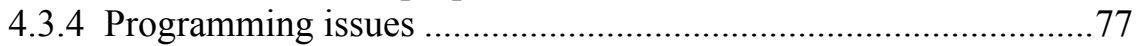

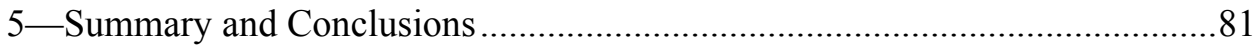

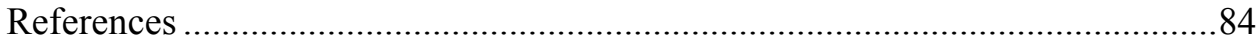

Appendix A: Internal and External Nodal Forces Using Isoparametric

Elements

Appendix B: Notation

B1

SF 298

\section{List of Figures}

Figure 1.1. Typical multi-anchored tieback wall system for Corps navigation projects .2

Figure 1.2. Typical construction sequence of a reinforced concrete

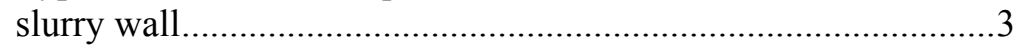

Figure 1.3. Typical construction and operation stages ...............................5

Figure 1.4. Bonneville navigation lock, temporary tieback wall-

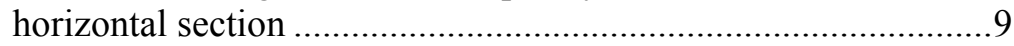

Figure 1.5. Bonneville navigation lock, temporary tieback wallvertical section

Figure 1.6. Overall design and evaluation process .....................................11

Figure 1.7. Deflections, moments, and earth pressures for Bonneville navigation lock, temporary tieback wall-

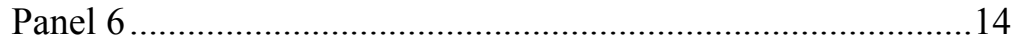

Figure 2.1. Steps in simulation of excavation ..........................................25

Figure 2.2. Normal and shear stresses and equivalent nodal forces along the excavated sides of an element .................................27

Figure 2.3. Equivalent nodal forces from surface stresses..........................28 
Figure 2.4. Interpolation procedures used to determine the stresses along the excavation boundaries

Figure 2.5. Three-dimensional representation of the Clough and

Duncan interpolation procedure

Figure 2.6. Flowchart for excavation modeling using the Clough and

Duncan procedure

Figure 2.7. Initial in situ stresses beneath a level ground surface.................33

Figure 2.8. Excavation of a single element................................................. 34

Figure 2.9. Nodal loads from self-weight ...................................................35

Figure 2.10. Stress distribution (a) along the excavation boundary

from the interpolated nodal stresses; (b) reversed

equivalent nodal forces

Figure 3.1. Values of errors in simulation of small layer onedimensional excavation for different values of $n$

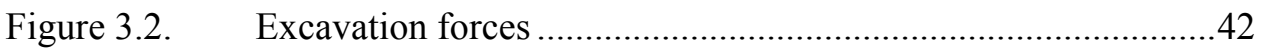

Figure 3.3. Flowchart for excavation modeling using the method of

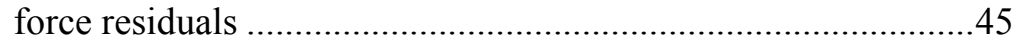

Figure 3.4. Nodal loads from self-weight ...............................................46

Figure 3.5. Calculation of reversed internal element nodal forces based on force equilibrium ......................................................

Figure 3.6. Reversed internal nodal forces from element stresses................48

Figure 3.7. Reversed total internal element forces along the

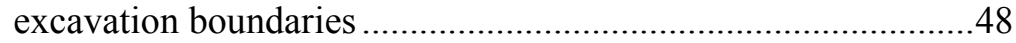

Figure 3.8. Total external nodal loads along the excavation boundaries

Figure 3.9. Excavation forces along the excavation boundaries..................50

Figure 4.1. Method of force residuals using four-nodal isoparametric quadrilateral elements - single-stage excavation

Figure 4.2. Method of force residuals using four-nodal isoparametric quadrilateral elements - two-stage excavation.....

Figure 4.3. Method of force residuals using eight-nodal isoparametric quadrilateral elements — single-stage excavation.

Figure 4.4. Method of force residuals using eight-nodal isoparametric quadrilateral elements - two-stage excavation. 
Figure 4.5. Comparison the results of a single-stage excavation using the Clough and Duncan procedure and the Method of Force Residuals

Figure 4.6. Clough and Duncan procedure-two-stage excavation

Figure 4.7. Comparison of the results of a single-stage and a twostage excavation using the Clough and Duncan

procedure

Figure 4.8. Interpolated stresses at element edges (a) and equivalent nodal forces (b) along the excavation boundaries from Element 2, calculated from the Clough and Duncan procedure

Figure 4.9. Nodal forces required to satisfy equilibrium of forces in the (a) vertical and (b) horizontal directions

Figure 4.10. Equivalent nodal forces based on minimization of force residuals.

Figure 4.11. Deformed mesh after excavation using the QM5 element with recovered internal displacements

Figure 4.12. Use of interface elements to model interaction between soil and structure .70

Figure 4.13. Simulation of excavation with interface elements. .73

Figure 4.14. Deformed mesh after excavation with $K_{s}=1 \cdot 10^{6} \mathrm{lb} / \mathrm{ft}$ .74

Figure 4.15. Deformed mesh after excavation with $K_{s}=1 \cdot 10^{3} \mathrm{lb} / \mathrm{ft} \ldots \ldots \ldots \ldots . . .74$

Figure 4.16. Deformed mesh after excavation with $K_{s}=1 \cdot 10^{2} \mathrm{lb} / \mathrm{ft} \ldots \ldots \ldots \ldots . . . .75$

Figure 4.17. ALPHA-method in factoring out load increments to avoid overshoot

Figure 4.18. Flowchart for implementing the method of force residuals in SOILSTRUCT-ALPHA using element stresses for calculating internal element forces

Figure 4.19. Flowchart for implementing the method of force residuals in SOILSTRUCT-ALPHA using incremental element displacements in calculating internal element forces

Figure A.1. One-dimensional isoparametric element showing

(a) local coordinates and (b) linear function approximation.

Figure A.2. Quadrilateral finite element (a) in the global coordinate system and (b) in the local (natural) coordinate system 


\section{List of Tables}

Table 1.1. Panel 6 Anchor Loads .............................................................. 10

Table 1.2. Loading Steps in SOILSTRUCT Analysis..................................13

Table 2.1. Calculated Element Stresses Due to Nodal Loads Shown

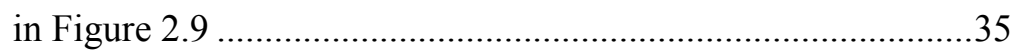

Table 3.1. Main Types of Numerical Procedures for Simulating Excavation Processes

Table 4.1. Advantages and Disadvantages of Different Types of Numerical Procedures for Simulating Excavation

Processes

Table 4.2. Calculated Maximum Heave at End of Excavation .62

Table 4.3. Summary of Advantages and Disadvantages of Finite Element Routines That Could Be Used in Implementing the Method of Force Residuals in SOILSTRUCTALPHA

Table 4.4. Effects of Interface Shear Stiffness on Maximum Heave at Base of Excavation 


\section{Preface}

The research described in this report was authorized by Headquarters, U.S. Army Corps of Engineers (HQUSACE), as part of the Innovations for Navigation Projects (INP) Research Program. The study was conducted under Work Unit (WU) 33272, "SSI Studies of Walls with Multiple Rows of Anchors." Principal Investigator of WU 33272 is Dr. Robert M. Ebeling of the U.S. Army Engineer Research and Development Center (ERDC) Information Technology Laboratory (ITL).

Dr. Tony C. Liu was the INP Coordinator at the Directorate of Research and Development, HQUSACE; Research Area Manager was Mr. Barry Holliday, HQUSACE; and Program Monitors were Mr. Mike Kidby and Ms. Anjana Chudgar, HQUSACE. Mr. William H. McAnally of the ERDC Coastal and Hydraulics Laboratory was the Lead Technical Director for Navigation Systems; Dr. Stanley C. Woodson, ERDC Geotechnical and Structures Laboratory (GSL), was the INP Program Manager.

Dr. Ebeling, ITL, was the author of the scope of work for the work unit and the scope of research discussed in this report. The research was performed and the report prepared by Professor Marte Gutierrez, Associate Professor, Virginia Polytechnic Institute and State University (VPI), Blacksburg, VA; Dr. Ebeling; and Professor George M. Filz, Associate Professor, VPI. Implementation and example calculations using the Method of Force Residuals and the Clough and Duncan Procedure to simulate excavation in a MATLAB Finite Element Code were performed with major assistance from Mr. Randall Hickman, graduate student, Geotechnical Group, Department of Civil and Environmental Engineering, VPI.

The research was monitored by Dr. Ebeling, under the supervision of Mr. H. Wayne Jones, Chief, Computer-Aided Engineering Division, ITL; Dr. Jeffery P. Holland, Director, ITL; and Dr. David W. Pittman, Acting Director, GSL.

At the time of publication of this report, Dr. James R. Houston was Director of ERDC, and COL John W. Morris III, EN, was Commander and Executive Director.

The contents of this report are not to be used for advertising, publication, or promotional purposes. Citation of trade names does not constitute an official endorsement or approval of the use of such commercial products. 


\section{Introduction}

\subsection{Background}

Multi-anchored or tieback wall systems are often used for temporary support of excavations that have space restrictions due to adjacent structures, highways, railroads, etc. In some cases, multi-anchored systems may remain as permanent structures after construction. In U.S. Army Corps of Engineers projects, permanent tieback wall systems are used as guide walls and approach walls on navigation projects, and as retaining walls on highway and railroad protection and relocation projects.

The behavior of multi-anchored systems may be strongly influenced by factors such as the sequence of excavation and installation of anchors, fluctuations in the water table, and the nonlinear stress-strain behavior of soils. Therefore, to obtain accurate predictions of the magnitudes of stresses and deformations in the structure and the surrounding soil, it is necessary to perform soil-structure interaction (SSI) analyses that model the construction and operation stages of the system. For such analyses, adequate modeling of the excavation process is required.

A substantial amount of research has been performed in recent years on another type of earth-retaining structure: lock walls for navigation. These studies have included SSI analyses of the Red River Lock and Dam No.1 (Ebeling et al. 1993; Ebeling and Mosher 1996; Ebeling, Peters, and Mosher 1997), the North Lock Wall at McAlpine Locks (Ebeling and Wahl 1997), and Locks 27 (Ebeling, Pace, and Morrison 1997). These are good examples of state-of-the-art techniques available for SSI analyses.

\subsubsection{Common types of multi-anchored systems}

Multi-anchored systems can be constructed using different materials and configurations. The following are the most common types found in practice:

- Vertical sheet-pile systems with wales and post-tensioned tieback anchors.

- Soldier beam systems with wood or reinforced concrete lagging and post-tensioned tieback anchors. 
- Secant cylinder pile systems with post-tensioned tieback anchors.

- Continuous reinforced concrete slurry wall systems with post-tensioned tieback anchors.

- Discrete concrete slurry wall systems (soldier beams with concrete lagging) with post-tensioned tieback anchors.

Figure 1.1 illustrates the use of a multi-anchored system for a typical navigation project. Because of the space restrictions imposed by an adjacent railroad, excavation for the expansion of the waterway requires use of a multi-anchored system. For simplicity, it is assumed that the multi-anchored system depicted in the figure corresponds to a continuous, reinforced concrete slurry wall with tieback anchors. Tiebacks consist of post-tensioned tendons with a grouted anchor region. A berm of granular material or riprap is placed at the toe of the wall to minimize erosion and improve stability.

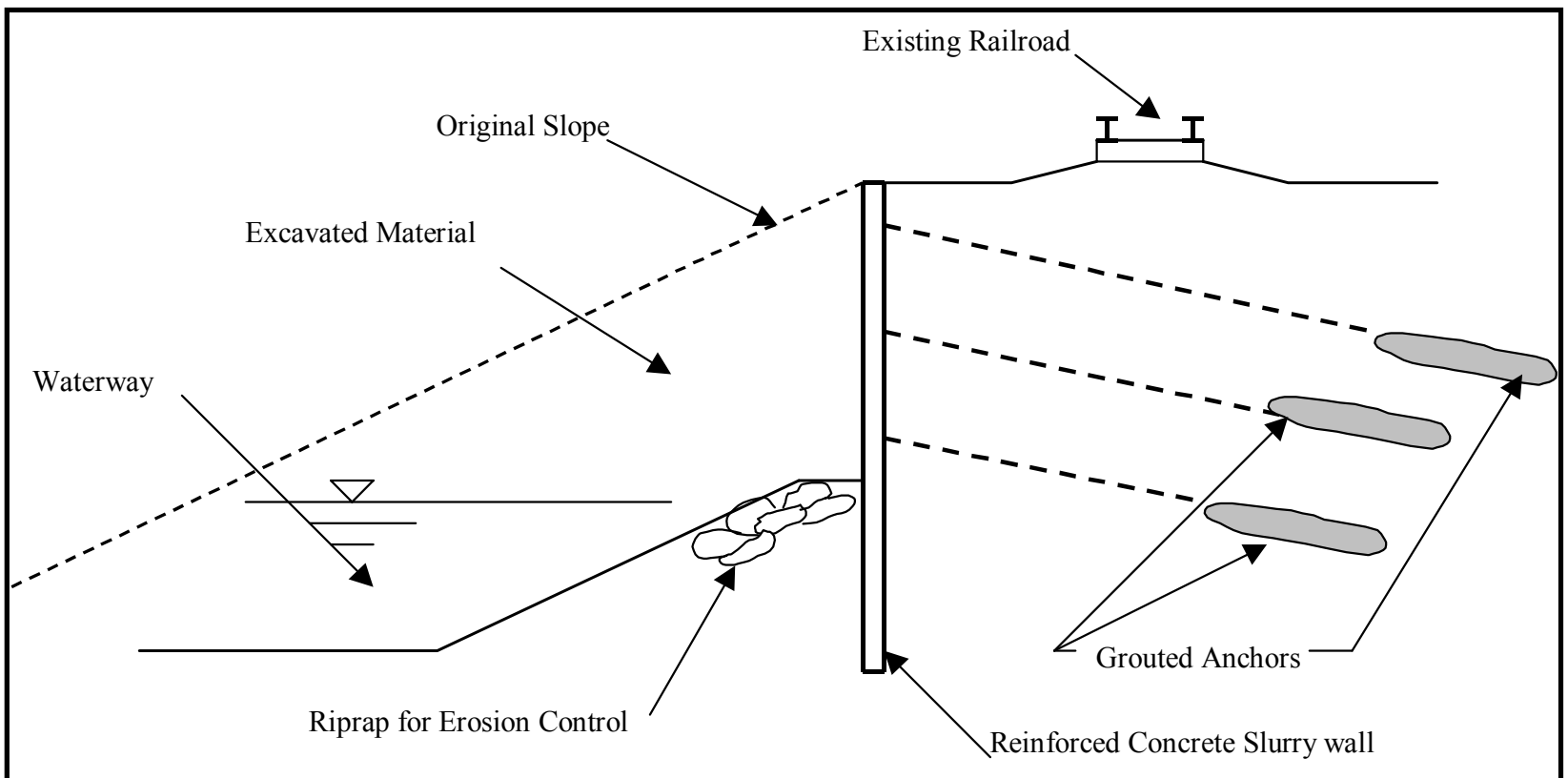

Figure 1.1. Typical multi-anchored tieback wall system for Corps navigation projects (from Gómez, Filz, and Ebeling 2000b)

Figure 1.2 illustrates the typical construction sequence of a reinforced concrete slurry wall. Initially, a trench is excavated using a clamshell-type tool. The excavation is stabilized by the use of mud slurry. The finished trench acts as formwork for the reinforced concrete panel. Placement of the concrete using a tremie pipe displaces the mud slurry and leaves a structural concrete wall that can be excavated and tied back in much the same manner as the other tieback wall systems. The walls are reinforced using preassembled cages, which are dropped into the slurry trench just before concrete placement. Slurry wall systems are usually 0.6 to $0.9 \mathrm{~m}(2$ to $3 \mathrm{ft})$ thick and can be placed to depths of $30 \mathrm{~m}(100 \mathrm{ft})$ or more. The construction process can be summarized as follows: 

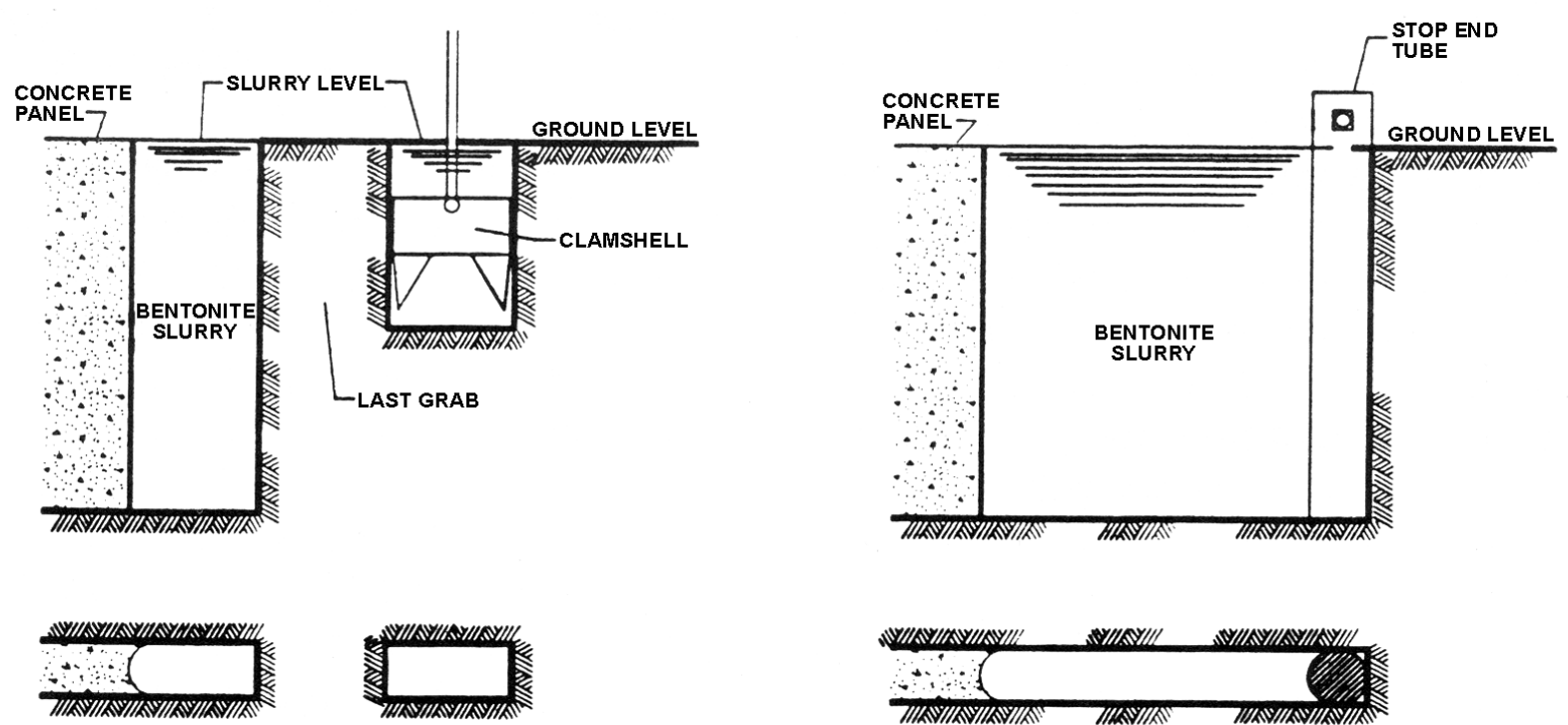

\section{a. Excavation under mud slurry}

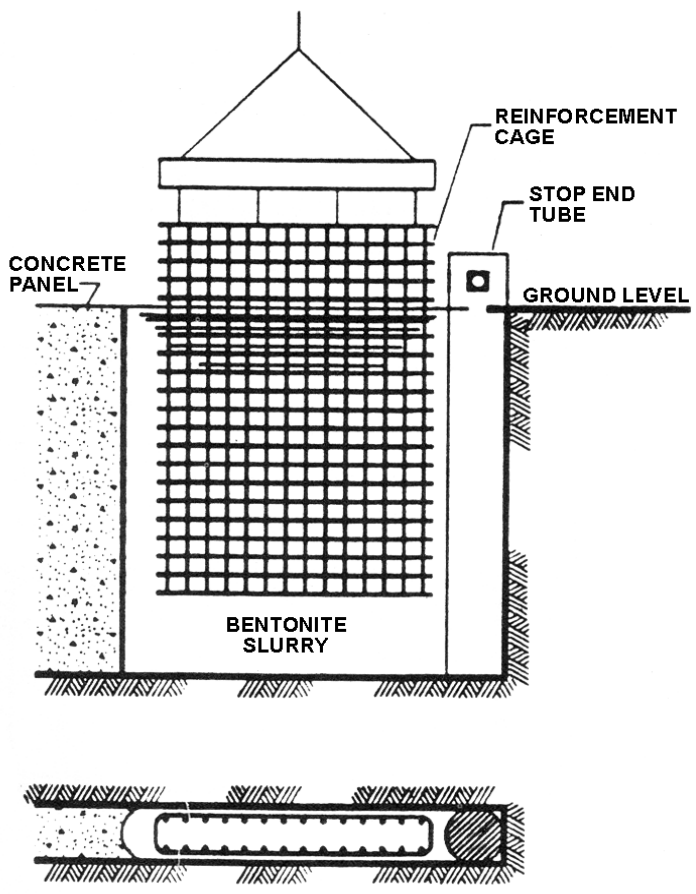

c. Placement of reinforcement cage

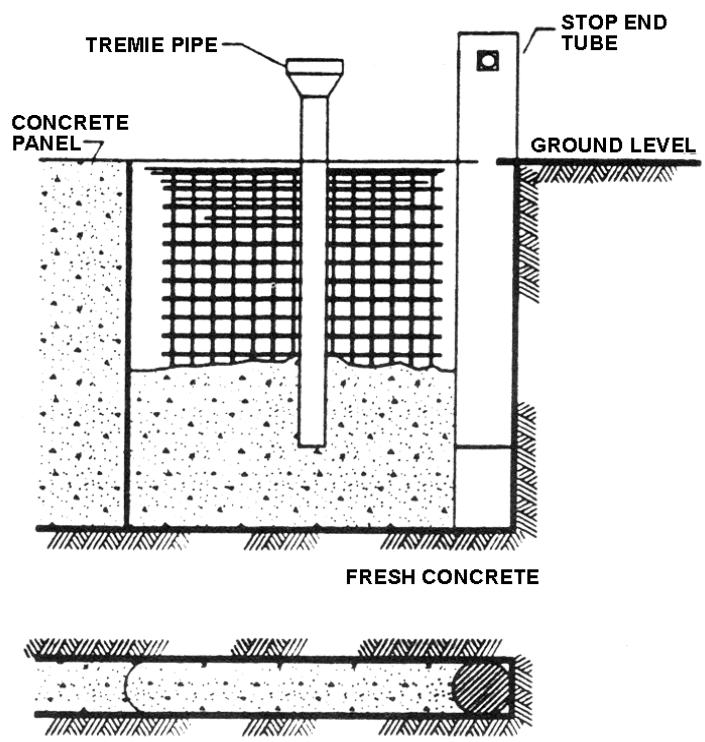

d. Placement of concrete

Figure 1.2. Typical construction sequence of a reinforced concrete slurry wall (from Strom and Ebeling 2001)

a. Guide walls are constructed to facilitate positioning and alignment of the clamshell during the excavation process. To stabilize the excavation, mud slurry is kept inside the excavation to a level above the water table. As illustrated in Figure 1.2a, the excavation for each panel follows a staggered sequence. Two end excavations are performed first, leaving a 
central core intact. After the end excavations are completed, the central core is removed.

$b$. A stop end tube is placed at one end of the panel excavation. This tube is extracted after concrete placement, leaving a semicircular indentation. This indentation serves as a guide for the excavation of the adjacent panel and allows the creation of a shear key between the panels.

c. Once the panel has been excavated to the desired depth and the slurry cleaned of fine excavation material (desanded), the reinforcement cage is lowered into the excavation.

d. One or more tremie pipes are used to place the concrete without contamination from the slurry.

$e$. Once the wall is finished and the concrete reaches its desired strength, the excavation and tieback installation process can begin.

Construction of the second navigation lock at Bonneville Lock and Dam required the use of concrete slurry walls to retain the foundation of an adjacent railroad line. Detailed descriptions of construction procedures for the continuous reinforced concrete slurry wall and for the discrete slurry wall systems used at Bonneville Lock are presented by Munger, Jones, and Johnson (1990) and Maurseth and Sedey (1992), respectively.

\subsubsection{Response of multi-anchored systems to excavation}

A waterway expansion project, such as that presented in Figure 1.1, requires SSI analyses to determine the magnitude of the deformations of the soil above the excavation, and the bending moments and stresses in the retaining wall. Such analyses require close modeling of the construction stages of the multi-anchored system. The finite element analyses performed by Mosher and Knowles (1990) for the tieback walls at Bonneville Lock and Dam are a good example of the available techniques that can be used in SSI analyses of multi-anchored systems.

Figure 1.3 illustrates some of the construction and operation stages of the hypothetical navigation project shown in Figure 1.1. For simplicity, it is assumed that construction is performed in the dry. After completion of the continuous reinforced concrete slurry wall (Figure 1.3b), the soil in front of the wall is excavated to an elevation slightly below the position of the first row of anchors. The anchors are then installed and tensioned according to the project specifications (Figure 1.3c). Once these anchors are tensioned and tested, excavation continues until reaching the position of the second row of anchors. The process is repeated until reaching the bottom of the excavation (Figures 1.3d and 1.3e). Once the excavation is completed, the granular toe berm is placed against the toe of the wall (Figure 1.3f). During operation of the navigation facility, the water level outside the wall reaches its normal elevation, which may fluctuate periodically during the life of the structure (Figure 1.3g). 


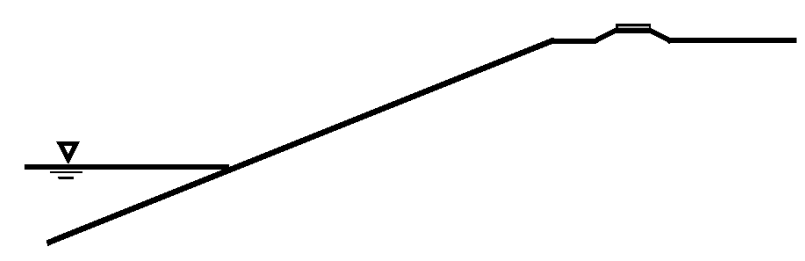

a. Initial state

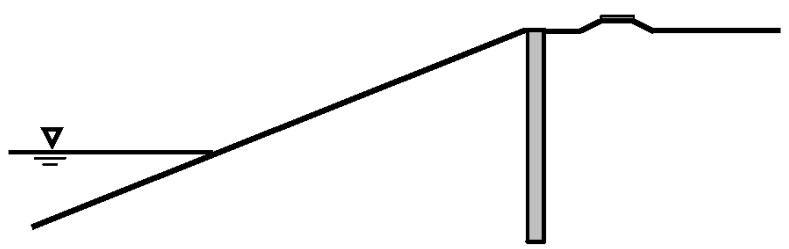

b. Construction of reinforced concrete slurry wall

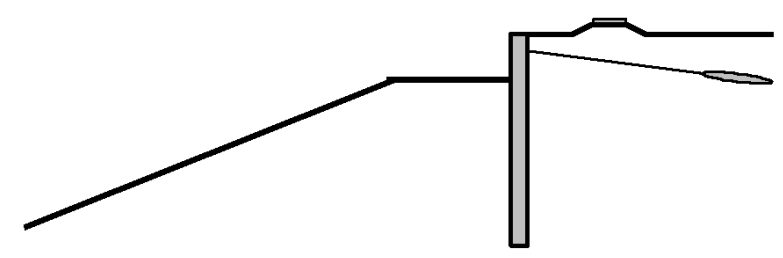

c. First stage of excavation and installation of anchors

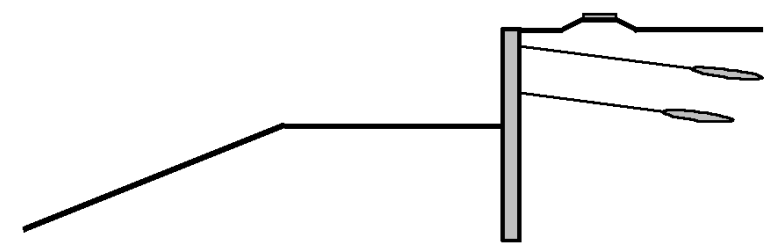

d. Intermediate stage of excavation and installation of anchors

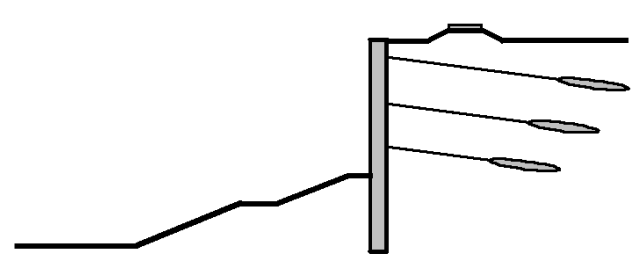

e. Final excavation and installation of bottom row of anchors

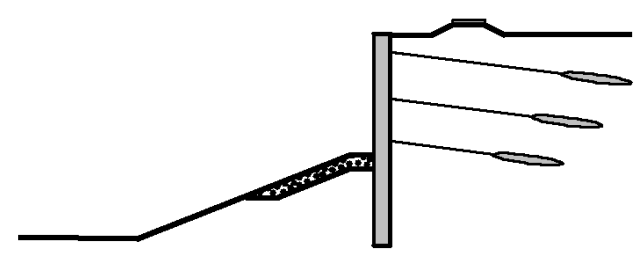

f. Construction of riprap blanket

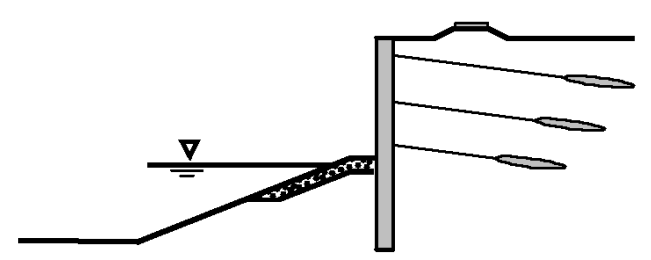

g. Operational stage

Figure 1.3. Typical construction and operation stages (from Gómez, Filz, and Ebeling 2000b) 


\subsubsection{Need for nonlinear finite element SSI analyses}

Excavation in soils is probably one of the few geotechnical problems that cannot be solved analytically, except in tunneling where the excavated region can be approximated by a circle. There are also analytical methods to determine the stability of natural slopes and estimate the magnitude of lateral earth pressures on structures. However, there are no simple and closed-form analytical solutions that can be used to estimate or predict the magnitudes of deformations expected from an excavation in soil, even if the soil is assumed to behave as a linear elastic material. The situation becomes more complicated when soil nonlinearity, the presence of water, interaction of the soils with structures, and construction effects are taken into consideration. In many cases, a reliable analysis of the response of soils and structures due to construction and operational loads can be obtained only by performing nonlinear finite element (NLFEM) soil-structure interaction analyses.

Two methods that have been used in Corps of Engineers projects are the beam on rigid supports (Strom and Ebeling 2001) and the WINKLER method. The beam on rigid support method, referred to as the RIGID analysis in this report, does not take soil deformations into account and, although widely used, has limited application for those circumstances in which actual loaddisplacement characteristics of the system are desired. The WINKLER method relates soil pressures to wall deformations and, for that reason, can be considered an improved method of analysis, especially when used in a staged construction analysis. However, it has not been a reliable tool for evaluating soil displacements that occur either in the soil mass or at the ground surface of the soil retained by the tieback wall. Wall displacement information provided by the WINKLER analysis is unreliable because the value of the coefficient of horizontal subgrade reaction is dependent on the extent of the zone of influence, a quantity that is difficult to properly establish. In addition, arching that takes place in the retained soil influences the soil displacement-pressure response, but this is not included in the WINKLER analysis.

The NLFEM can overcome the shortcomings of other analysis procedures, such as the RIGID and the WRINKLER methods, since it permits a complete and precise solution based on the stress-strain laws for the soils involved, the boundary conditions of the problem, and the basic equations of mechanics. Although the finite element method is the most suitable one, the complexities of the method are such that it is not routinely used in the design or evaluation of tieback wall systems.

In several cases, the NLFEM has been used with success to evaluate the performance of tieback wall systems. In particular, application with respect to the performance evaluation of a temporary tieback wall used to facilitate construction of the Bonneville navigation lock (Mosher and Knowles 1990) is described below. The NLFEM provided a detailed and accurate representation of the tieback wall-soil system response to various loadings that occurred prior to, during, and after wall construction. The objectives of the NLFEM were to confirm by incremental analysis that ground movements behind the wall during and after construction would meet stringent displacement requirements. The results of the analysis were confirmed by instrumentation. The Bonneville navigation lock 
NLFEM analysis is described in detail to demonstrate the differences between actual behavior and that usually assumed in the design of tieback wall systems. These differences are especially noticeable with respect to stiff wall systems with high anchor prestress loads.

\subsection{Review of Previous Work on SSI Analysis}

The first systematic SSI analyses of retaining wall behavior were presented by Clough and Duncan $(1969,1971)$ and Duncan and Clough (1971). These investigators used the hyperbolic constitutive relationship developed by Duncan and Chang (1970) to model the behavior of the backfill, and extended it to model the behavior of the wall-to-soil interfaces. Relative movement at the interfaces was achieved using the joint element developed by Goodman, Taylor, and Brekke (1968).

In their analyses of Port Allen and Old River U-frame locks, Clough and Duncan (1969) and Duncan and Clough (1971) demonstrated the importance of close modeling of the construction stages of the lock and backfill placement. They demonstrated that a simple linear elastic model for the soil and use of gravity turn-on analyses are not adequate to model the behavior of the soil-lock system. They also proved that the downdrag or vertical shear force exerted by the backfill on the wall has an important influence on the behavior of U-frame locks. Their work provided fundamental understanding of previously unknown aspects of lock wall behavior.

Clough and Duncan (1971) presented a systematic approach to SSI analyses of retaining wall behavior. They observed the importance of modeling the different stages of construction of the wall and placement of the backfill in the SSI analysis. They found that when the stages of placement of the backfill were closely modeled, the resulting horizontal and vertical loads acting on the wall were substantially larger than those obtained using classical earth pressure theories. The results of these analyses were consistent with some previous experimental work and field observations.

Ebeling, Duncan, and Clough (1990) performed a comparison between results from conventional equilibrium and finite element analyses of several hypothetical gravity walls founded on rock. Their analyses were performed with the backfill placement analysis option incorporated in SOILSTRUCT (Clough and Duncan 1969). A range of possible values of shear stiffness was assumed at the interfaces between the wall and the backfill, and between the backfill and the rock. Ebeling, Duncan, and Clough (1990) concluded that the magnitude of the downdrag force is significantly affected by the concrete-to-backfill and rock-tobackfill shear stiffness values. They also concluded that the conventional equilibrium analyses neglect the true process of soil-structure interaction and tend to yield very conservative results.

Ebeling et al. (1992) performed analysis of several hypothetical gravity walls founded on rock. The hypothetical walls were based on several representative examples of lock walls. Ebeling et al. (1992) found that conventional equilibrium analyses are very conservative because they do not account for the stabilizing 
effect of the downdrag forces generated by the settlement of the backfill. At the time of their work, it was not known whether these vertical shear forces persisted under field conditions nor whether they could be relied upon for the stability of the structure. These researchers also indicated that the behavior of retaining structures founded on soil might differ substantially from that of structures founded on rock. In soil-founded structures, the concrete-to-foundation interface is not bonded as in the case of concrete-to-rock interfaces, and relative interface displacements may occur, including more redistribution of the earth pressures.

Experimental data from the Instrumented Retaining Wall Facility at Virginia Tech (Filz 1992) showed that downdrag forces on the nonmoving test wall were significant and tended to either remain constant or increase with time after backfill placement.

Ebeling et al. (1993), Ebeling and Mosher (1996), and Ebeling, Peters, and Mosher (1997) presented the results of extensive SSI analysis for the soilfounded Red River Lock and Dam No. 1. A reinforced soil berm was recommended, among other alternatives, as a solution to problems induced by siltation of the lock. The SSI analysis procedures were validated against instrumentation measurements from the lock taken at the end of construction and several operational stages. Their analysis revealed that important changes in normal stresses may occur at the soil-to-structure interface during backfill placement and operation of the lock, and underscored the importance of selecting appropriate interface stiffness values for these loading conditions. They also noted that conventional equilibrium analyses are inadequate for the design of this type of structure.

Ebeling and Wahl (1997) presented the results of SSI analysis of the proposed North Lock Wall at McAlpine Locks. They determined that the downdrag force was significant, and that it could be substantially affected by the response of the interface to unload-reload cycles.

Filz and Duncan (1997) presented a theory to quantify the downdrag force on the back of nonmoving retaining walls. Filz, Duncan, and Ebeling (1997) presented a simplified method for incorporating downdrag forces in conventional analyses of nonmoving retaining walls. They also observed that postconstruction settlement causes an increase in the downdrag on the back of the wall. They cited measurements at Eibach Lock in Germany, where large vertical shear forces were persistent for 10 years under repeated filling and emptying cycles and temperature fluctuations. The measured $K_{v}$ remained at an approximately constant average value of 0.30 . These vertical shear forces cause an important reduction in the lateral earth pressures acting on the wall.

The simplified method in Filz, Duncan, and Ebeling (1997) is also described in Ebeling, Pace, and Morrison (1997). This method is shown to provide an improvement in accuracy over conventional analyses of nonmoving walls by producing downdrag values that are closer to the values from the other available sources of information: (a) theory, (b) finite element analyses, (c) data from pilotscale instrumented retaining wall tests, and (d) the field data from Eibach Lock. While more accurate than conventional analyses, the simplified method remains conservative for wall stability because the downdrag values from the simplified 
method are smaller than the values from the other available information.

Furthermore, the evidence from the instrumented retaining wall tests and Eibach Lock shows that downdrag forces either remain constant or increase over time after backfilling. The simplified method is restricted to backfill materials that do not exhibit creep.

\subsection{Bonneville Temporary Tieback Wall Analysis}

\subsubsection{Wall description}

Strom and Ebeling (2001) used the Bonneville temporary tieback wall to illustrate the importance of the NLFEM in the analysis and design of projects. Portions of their summary are contained in the following paragraphs. The temporary tieback retaining wall is approximately $134 \mathrm{~m}(440 \mathrm{ft})$ long. The wall is constructed by slurry trench methods in $6-\mathrm{m}(20-\mathrm{ft})$-long sections similar to those shown in the section view (horizontal) of Figure 1.4.

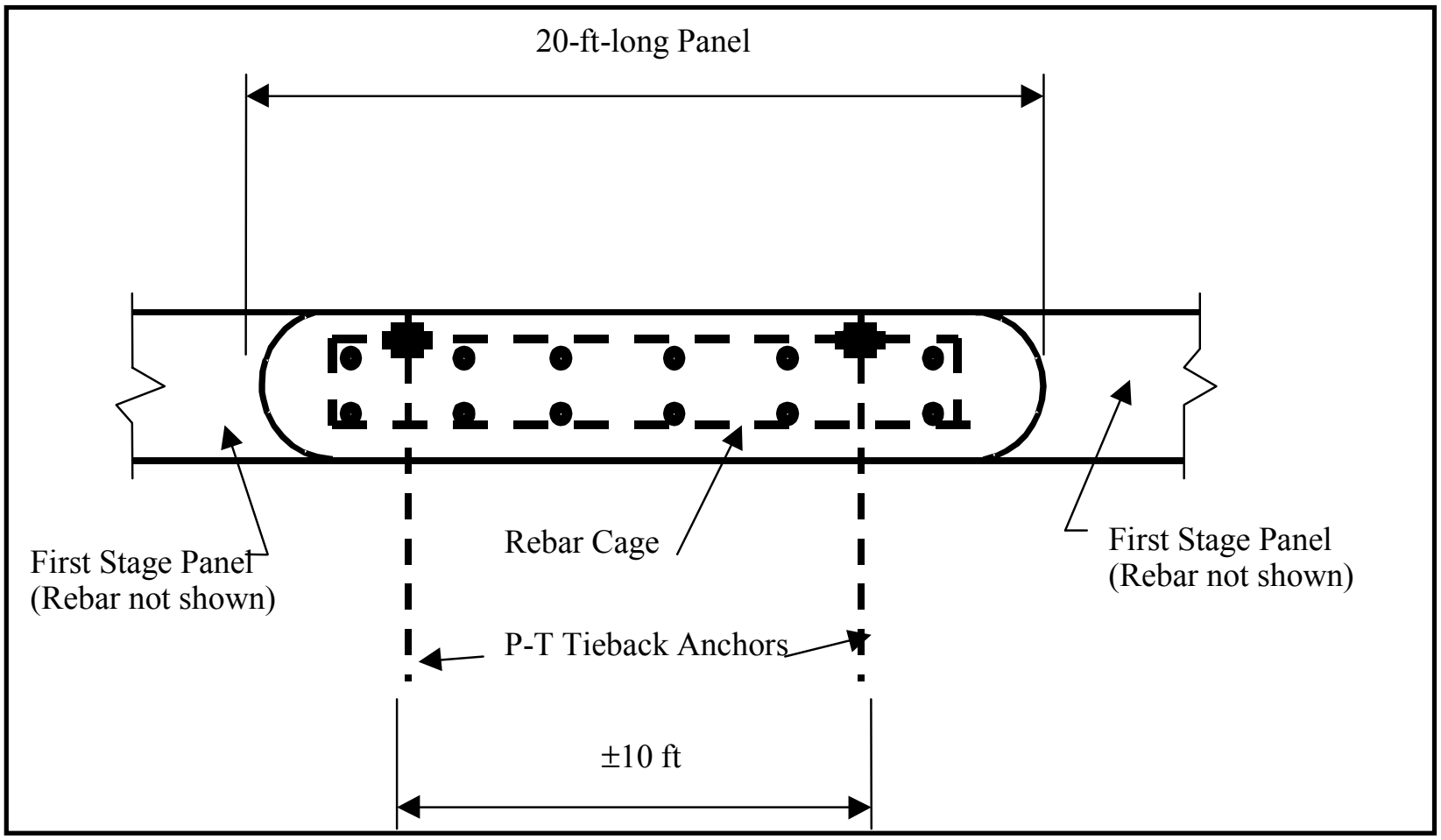

Figure 1.4. Bonneville navigation lock, temporary tieback wall-horizontal section (from Strom and Ebeling 2001)

The heights of the panels ranged from 6 to $34 \mathrm{~m}$ (20 to $110 \mathrm{ft})$. Excavation sequencing was similar to that shown in Figure 1.3. Anchors were installed in a grid pattern of approximately $3 \mathrm{~m}(10 \mathrm{ft})$ horizontal by $3.4 \mathrm{~m}(11 \mathrm{ft})$ vertical. Each tieback anchor was composed of nineteen 15-mm (0.6-in.)-diam strands with a guaranteed ultimate strength (GUTS) of 1,862 MPa (270 ksi). Each anchor was prestressed to 150 percent of its design load. The design loads are approximately 50 percent of the anchor ultimate load capacity. Panel 6 was the focus of 
the NLFEM analysis. A section view (vertical) of Panel 6 is shown as Figure 1.5.

The tieback anchor loads are summarized in Table 1.1.

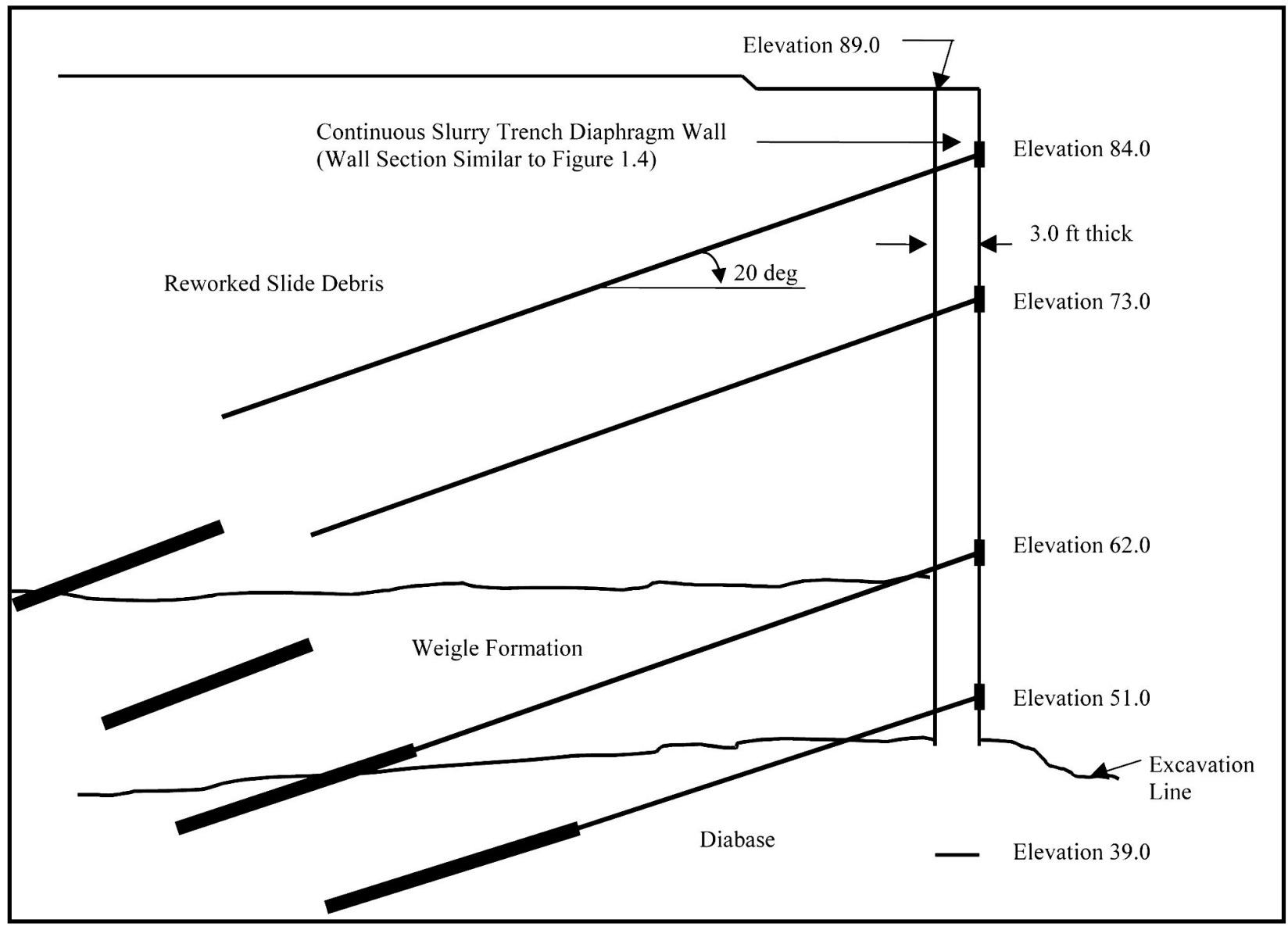

Figure 1.5. Bonneville navigation lock, temporary tieback wall-vertical section (from Strom and Ebeling 2001)

\begin{tabular}{|c|c|c|c|c|c|c|c|c|c|}
\hline \multicolumn{10}{|c|}{$\begin{array}{l}\text { Table } 1.1 \\
\text { Panel } 6 \text { Anchor Loads }\end{array}$} \\
\hline \multicolumn{2}{|c|}{ Anchor Elevation } & \multicolumn{2}{|c|}{ Anchor Length } & \multicolumn{2}{|c|}{ Design Load } & \multicolumn{2}{|c|}{$\begin{array}{l}\text { Prestress Load } \\
\text { at } 150 \text { percent } \\
\text { Design Load }\end{array}$} & \multicolumn{2}{|c|}{ Lock-Off Load } \\
\hline m & $\mathrm{ft}$ & $\mathbf{m}$ & $\mathrm{ft}$ & $\mathrm{kN}$ & kips & $\mathrm{KN}$ & kips & $\mathrm{kN}$ & kips \\
\hline 25.6 & 84 & 27.1 & 89 & $1,249.9$ & 281 & $1,874.9$ & 421.5 & $1,209.9$ & 272 \\
\hline 22.3 & 73 & 24.1 & 79 & $1,249.9$ & 281 & $1,874.9$ & 421.5 & $1,298.8$ & 292 \\
\hline 18.9 & 62 & 20.7 & 68 & $1,249.9$ & 281 & $1,874.9$ & 421.5 & $1,289.9$ & 290 \\
\hline 15.5 & 51 & 15.8 & 52 & $1,592.5$ & 358 & $2,388.7$ & 537.0 & $1,583.6$ & 356 \\
\hline
\end{tabular}

\subsubsection{Overall design and evaluation process}

The overall design and evaluation process for the Bonneville navigation lock temporary tieback wall involved a RIGID analysis and a WINKLER analysis, in 
addition to the NLFEM described in this chapter. The purposes and results of the RIGID and WINKLER analyses are described in general terms and illustrated using Figure 1.6.

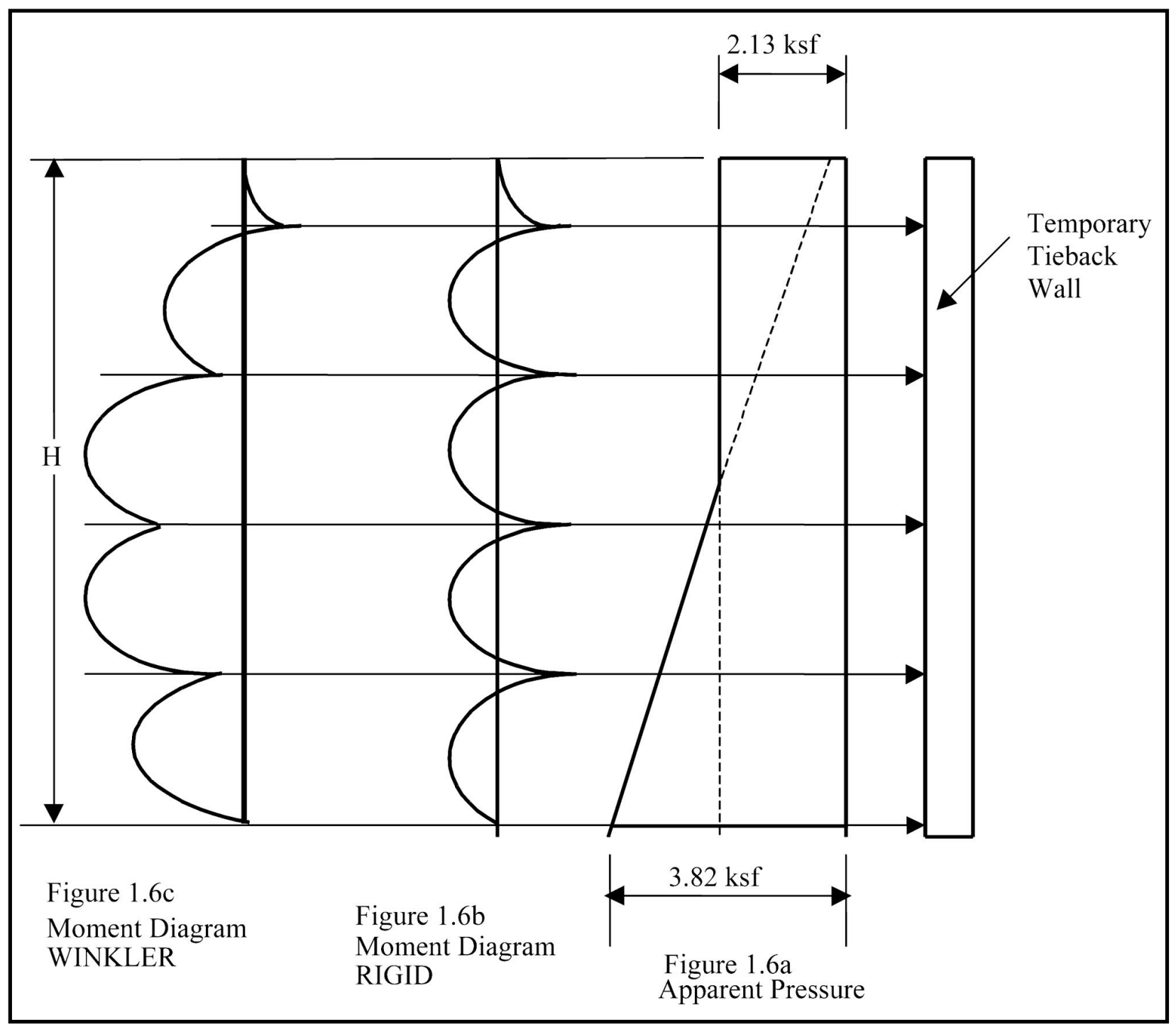

Figure 1.6. Overall design and evaluation process (from Strom and Ebeling 2001)

\subsubsection{RIGID analysis}

A simple preliminary analysis using the RIGID analysis procedure was employed to estimate the size and spacing of anchors. The RIGID analysis for Bonneville was based on a composite apparent pressure diagram, as shown in Figure 1.6a. The upper rectangular-shaped region is based on at-rest pressures, in accordance with Figure 29, Chapter 3, of Design Manual 7.2 (NAVFAC 1982). The lower triangular-shaped region is also based on at-rest pressures (Coulomb's equation with a factor of safety of 1.5 applied to the shear strength of the soil). This composite diagram assumed that wall displacements would be small, 
thereby keeping earth pressure near an at-rest state. The triangular lower portion of the diagram was considered to be appropriate since the upper anchors could possibly lose some tension during the life of the wall, thereby leading to higher loads at the base of the wall. Anchors sizes were estimated based on a continuous beam analysis using the pressure diagram loading of Figure 1.6a. There was very little difference between the anchor loads obtained from the continuous beam analysis and those determined using the tributary area method (Munger, Jones, and Johnson 1990).

The wall bending moment diagram resulting from a RIGID analysis is illustrated in Figure 1.6b. Because this type of analysis does not consider the wall displacement that occurs during prestressing and excavation, it will underestimate actual bending moment demands on the wall. Therefore, a WINKLER analysis was performed to estimate wall bending moments and to confirm anchor loads.

\subsubsection{WINKLER analysis}

The WINKLER analysis used to evaluate the Bonneville navigation lock temporary tieback wall is described in Munger, Jones, and Johnson (1990). The moment diagram for the wall was determined using a one-step analysis that modeled the final excavation condition only. The moment diagram for the WINKLER analysis is illustrated in Figure 1.6c. This analysis, because it accounts for wall displacements during anchor prestressing and excavation, does a reasonably good job of estimating moment demands on the wall. A RIGID analysis that considers construction staging and considers support displacements that accumulate during each stage of construction (yielding supports analysis) could also provide good results.

As illustrated in Figure 1.6c, the shape of the moment diagram obtained by the WINKLER analysis is quite different from that obtained by the standard RIGID analysis. Since the WINKLER analysis cannot give reliable information with respect to wall displacements, and since wall displacements and displacements of the ground retained by the wall were critical to performance, it was decided to perform a NLFEM analysis. The NLFEM analysis investigated wall displacements and bending moment demands for each stage of construction.

\subsection{NLFEM Analysis}

\subsubsection{Objectives}

The purpose of the NLFEM analysis was threefold: (1) to provide a means for additional confirmation of the procedure used in designing the wall, (2) to predict potential wall performance during excavation and tieback installation, and (3) to assist in the interpretation of instrumentation results. The results from the study depict wall behavior in terms of lateral deflection, bending moments, and earth pressures for each stage of construction. 


\subsubsection{Description}

The computer program SOILSTRUCT (Ebeling, Peters, and Clough 1992) was used for the analysis. A description of the finite element analyses can be found in Mosher and Knowles (1990). SOILSTRUCT is designed so that the actual construction process can be simulated. Simulation of the actual sequence of construction is important because the soil stress response is nonlinear and stress path dependent. SOILSTRUCT provides for simulation of initial stresses, fill placement, material excavation, dewatering, and placement of structural materials in a series of incremental load steps. Incremental stresses and displacements are computed after each load step. Table 1.2 lists the loading steps used to model the sequence for the wall construction and lock channel excavation.

\begin{tabular}{|c|c|}
\hline \multicolumn{2}{|c|}{$\begin{array}{l}\text { Table } 1.2 \\
\text { Loading Steps in SOILSTRUCT Analysis }\end{array}$} \\
\hline Step & Description \\
\hline 1 & Construct surcharge to pre-excavation grade (four increments) \\
\hline 2 & Excavate for railroad relocation \\
\hline 3 & Construct slurry trench temporary tieback wall \\
\hline 4 & Excavate in front of wall to el $78.5 \mathrm{ft}(23.9 \mathrm{~m})$ \\
\hline 5 & $\begin{array}{l}\text { Install upper tieback anchor at el } 84 \mathrm{ft}(25.6 \mathrm{~m}) \text { and prestress to } 150 \text { percent of the } \\
\text { design load }\end{array}$ \\
\hline 6 & Excavate in front of wall to el $67.5 \mathrm{ft}(20.6 \mathrm{~m})$ and lock off upper anchor at design load \\
\hline 7 & $\begin{array}{l}\text { Install second tieback anchor at el } 73 \mathrm{ft}(22.3 \mathrm{~m}) \text { and prestress to } 150 \text { percent of the } \\
\text { design load }\end{array}$ \\
\hline 8 & Excavate in front of wall to el $56.5 \mathrm{ft}(17.2 \mathrm{~m})$ and lock off second anchor at design load \\
\hline 9 & $\begin{array}{l}\text { Install third tieback anchor at el } 62 \mathrm{ft}(18.9 \mathrm{~m}) \text { and prestress to } 150 \text { percent of the design } \\
\text { load }\end{array}$ \\
\hline 10 & Excavate in front of wall to el $45 \mathrm{ft}(13.7 \mathrm{~m})$ and lock off third anchor at design load \\
\hline 11 & $\begin{array}{l}\text { Install fourth tieback anchor at el } 51 \mathrm{ft}(15.5 \mathrm{~m}) \text { and prestress to } 150 \text { percent of design } \\
\text { load }\end{array}$ \\
\hline 12 & Excavate to bottom of wall at el $39 \mathrm{ft}(11.9 \mathrm{~m})$ and lock off fourth anchor at design load \\
\hline
\end{tabular}

\subsubsection{Results}

The results for each stage of construction were studied, from the in situ state and wall construction through the excavation and tie installation procedure. The results for each stage of construction are illustrated in Figures 1.7a-1.7i and described below in terms of earth pressures, wall bending moments, and displacements.

1.4.3.1 Earth pressures. Lateral earth pressures on the wall for each stage of construction are illustrated in Figures 1.7a-1.7i. The initial pressure on the wall is approximately 50 percent greater than at-rest pressure. This increase can be attributed to overconsolidation and replacement of the soil by a concrete wall. The dotted line represents at-rest pressure increased by 50 percent. The earth pressure distribution changes throughout construction as a result of excavation and anchor prestressing. After the first excavation to elevation (el) $78.5 \mathrm{ft}$ $(23.9 \mathrm{~m})$, the soil behind and near the top of the wall is in an active state as a result of the wall moving toward the excavation. Farther down the wall, the 


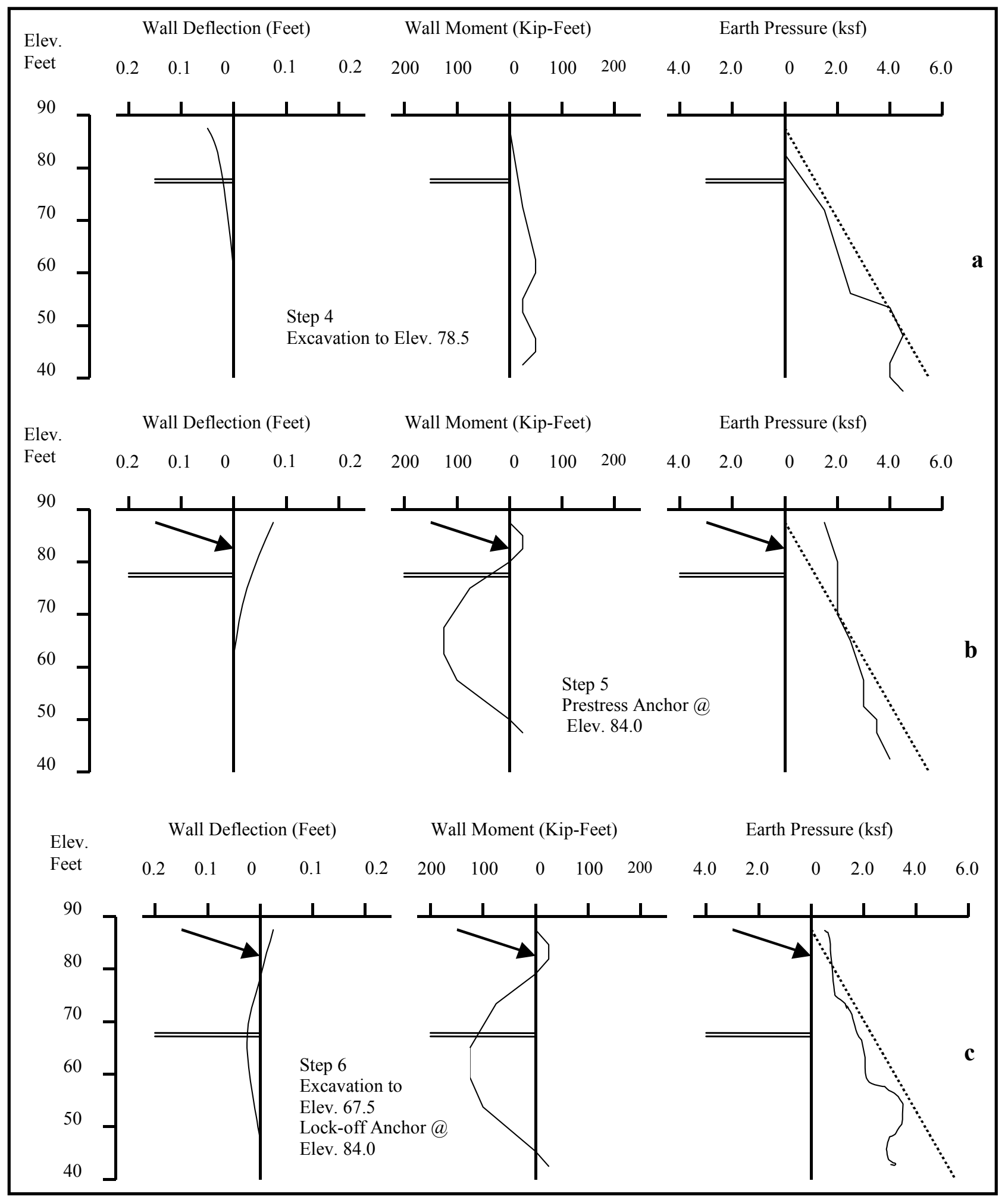

Figure 1.7. Deflections, moments, and earth pressures for Bonneville navigation lock, temporary tieback wall-Panel 6 (from Strom and Ebeling 2001) (Sheet 1 of 3) 


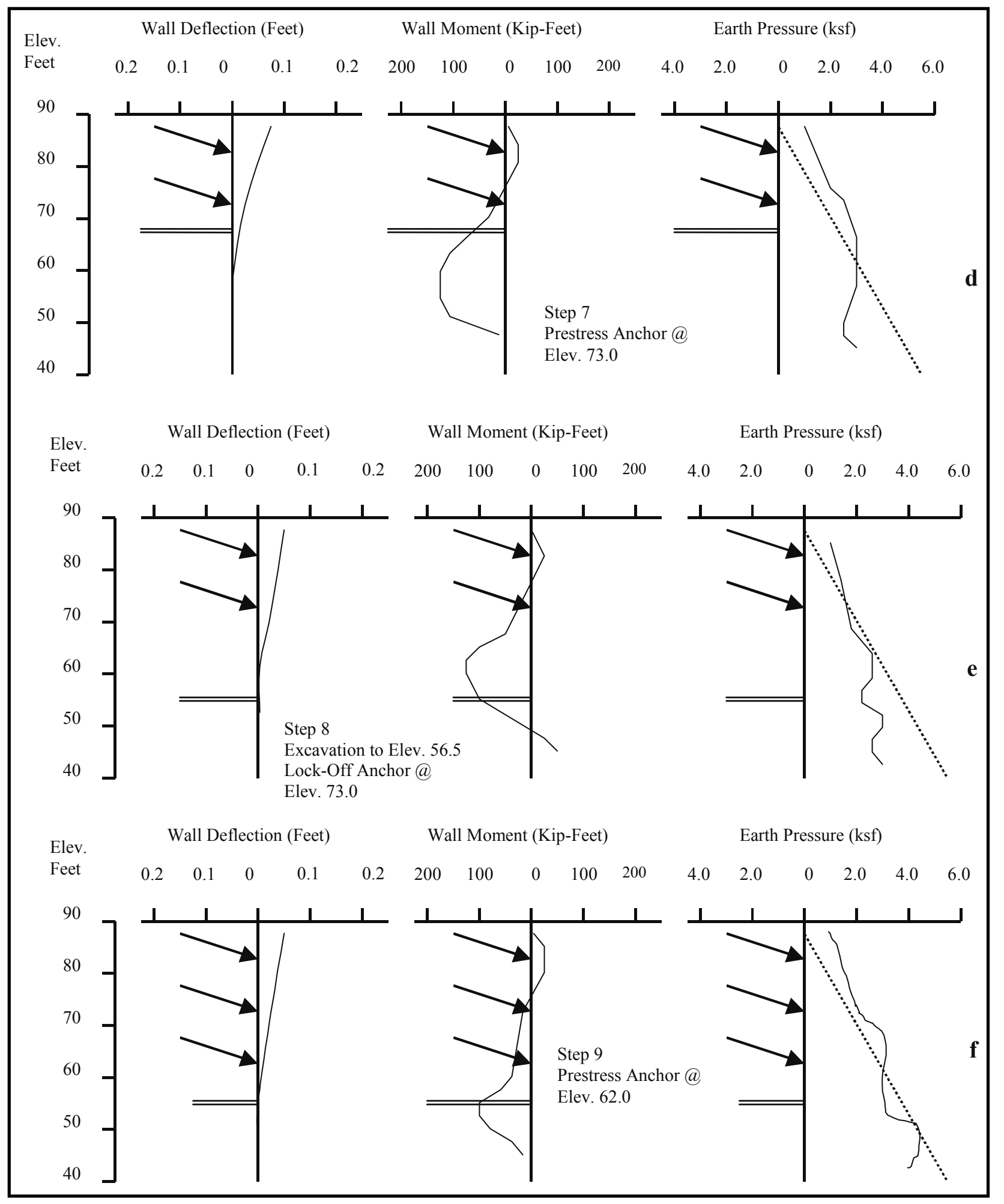

Figure 1.7. (Sheet 2 of 3 ) 


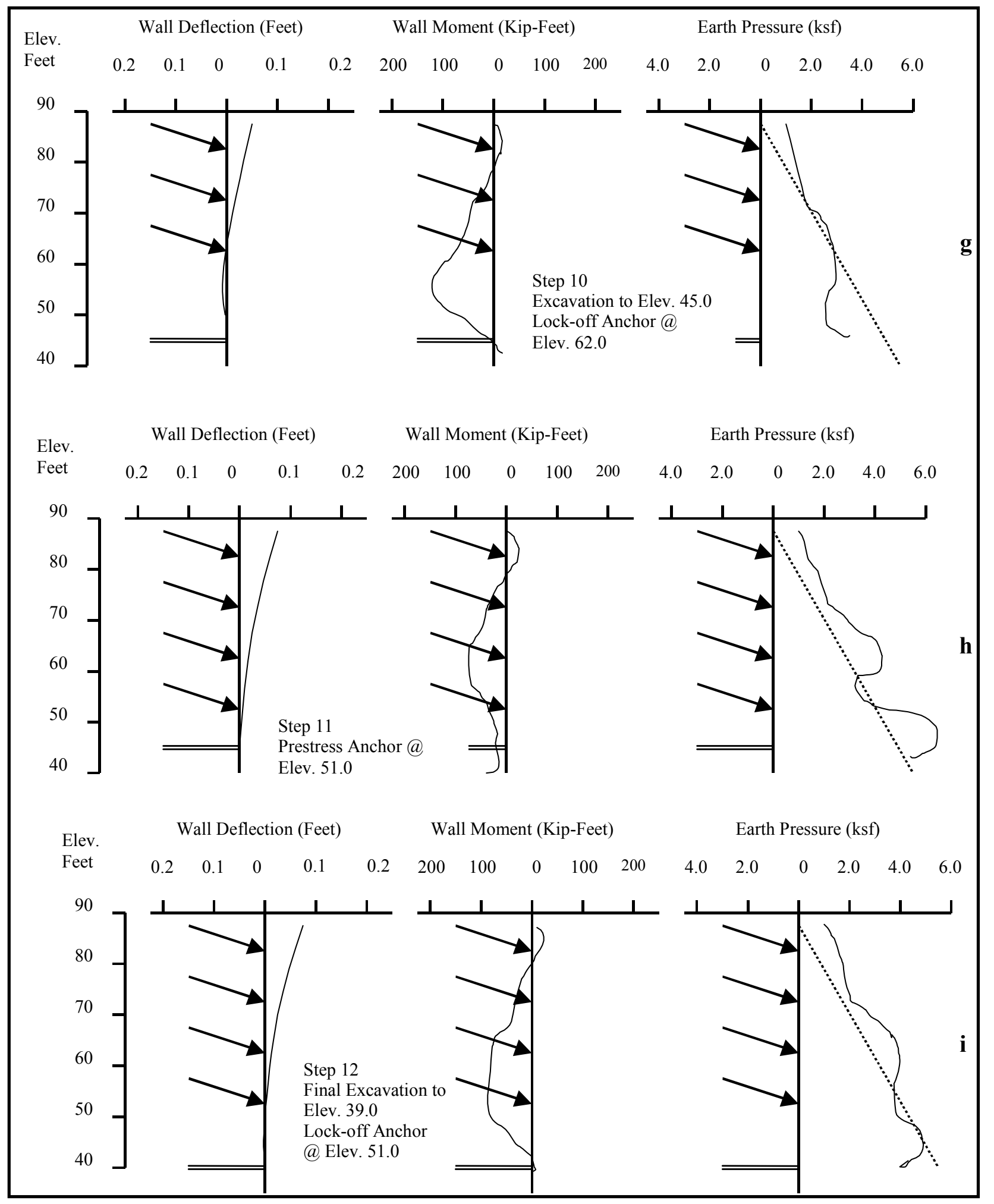

Figure 1.7. (Sheet 3 of 3 ) 
lateral earth pressure is greater than active, but less than the initial pressure on the wall. The analysis shows that, with prestressing of the first anchor, earth pressures increase to greater than initial pressures behind the upper one third of the wall. Subsequent excavations and anchor prestressings show decreases and increases, respectively, of the earth pressures along the wall. Bulging of pressures around the anchors appears in the lower one half of the wall. Although the shape of the pressure diagram is approximately trapezoidal during the initial stages of construction, it is closer to triangular for the later stages of construction.

1.4.3.2 Wall bending moments. Wall bending moments for each stage of construction are illustrated in Figures 1.7a-1.7i. Except for the first excavation, the moment diagram for the wall retains the same general form throughout construction. The region immediately behind the upper anchor experiences negative bending moment, and the lower region below the upper anchor experiences positive bending moment. The maximum moment is always positive and varies during construction with a maximum value of about $180 \mathrm{kN} . \mathrm{m}$ (133 ft-kips). The maximum moment develops during the intermediate stages of excavation after the second anchor is prestressed.

1.4.3.3 Wall displacements. Wall displacements for each stage of construction are illustrated in Figures 1.7a-1.7i. With the first excavation to el $78.5 \mathrm{ft}$ $(23.9 \mathrm{~m})$, the wall moves $0.5 \mathrm{in}$. $(13 \mathrm{~mm})$ toward the excavation. With prestressing of the upper tieback anchor, the wall is pulled back into the retained soil, resulting in a displacement of $0.78 \mathrm{in}$. $(20 \mathrm{~mm})$ past vertical in a direction away from the excavation. In subsequent construction steps, there is little change in the deflected position of the wall. In general, the wall moves into the soil when each anchor is prestressed and back toward vertical with each excavation.

\subsubsection{Comparison of the results of NLFEM, WINKLER, and RIGID analyses}

The analysis of the Bonneville navigation lock temporary tieback wall (presented above) demonstrates the significant differences in the results of the NLFEM, WINKLER, and RIGID approaches. This can be seen for instance in the assumed apparent earth pressure distribution behind the wall, and the moment diagrams calculated using the WINKLER and RIGID procedures (Figure 1.6). These diagrams are much different from those obtained from the NLFEM analysis (Figure 1.7), which shows a more complicated pattern of development of earth pressures and wall bending moments with construction stage. Prominent differences are in nonuniform development of earth pressure with depth and the continuing changes in the magnitudes of the earth pressure in every construction stage. In contrast, the WINKLER and RIGID procedures assume a uniform (until about half the excavation depth) then linearly varying earth pressure distribution with depth. There is no soil and wall interaction effect on the earth pressure distribution. The moment distributions are also very different with the NLFEM analysis, showing reduction in bending moment after installation of the prestressed anchors. As can be seen, both the WINKLER and RIGID procedures grossly simplify the loads acting on the tieback wall. There are several reasons for the differences shown in Figures 1.6 and 1.7; a few are cited below. 
- The wall is assumed to be stiff in the RIGID analysis rather than flexible.

- Prestressing to achieve stringent displacement control objectives results in total pressures in excess of at-rest conditions.

- Construction sequencing has a major impact on wall performance.

- Pressure distributions are approximately triangular, especially during the final stages of construction.

\subsection{Overview of SOILSTRUCT-ALPHA Finite Element Program}

Engineering application of soil-structure interaction modeling requires a balance between modeling realism and simplicity. There is now over 25 years of experience in modeling construction procedures by the finite element method, and the key ingredients in engineering applications are well known. One of the earliest successful applications of SSI analysis was performed by Clough and Duncan $(1969,1971)$ in their analysis of the two reinforced concrete U-frame locks at Port Allen and Old River. These two locks had been extensively instrumented. Prior to Clough and Duncan's analyses, the instrumentation data had been thought to be unreliable and contrary to the perceived understanding of the behavior of locks encountered during lock operation. Clough and Duncan's study showed that the best agreement between results computed using the finite element method and those obtained through instrumentation measurements is obtained when the actual construction process is simulated as closely as possible in the analysis.

During their study, Clough and Duncan developed what is referred to as the backfill placement analysis in which the loads exerted by the backfill on the lock wall are generated automatically during simulated placement of backfill behind the wall (i.e., predetermined earth pressure force distributions between the soil and the lock are not specified). This requires that the soil backfill and foundation soil strata be included in the finite element mesh. This procedure involves the use of incremental finite element analysis with nonlinear, stress-dependent, stressstrain behavior for the soil. An additional requirement is that interface elements be incorporated within the finite element mesh to allow for relative movement between the soil and structure.

Clough and Duncan developed the first version of the finite element program SOILSTRUCT, which implements this engineering modeling/analysis philosophy. SOILSTRUCT has been used successfully in the past decade on several engineering projects supported by field observations. Since 1969, several versions of SOILSTRUCT have been developed to analyze various types of earthretaining structures or to analyze specific problems that were not envisioned at the time of Clough and Duncan's original development. One of these updated versions, referred to as SOILSTRUCT-ALPHA, is the subject of this report. 
SOILSTRUCT-ALPHA (Ebeling, Duncan, and Clough 1990) is a specialpurpose, finite element program for two-dimensional (2-D), plane strain analysis of SSI problems. SOILSTRUCT calculates displacements and stresses resulting from incremental construction, backfilling, excavation, dewatering, rising water table, and/or load application. Nonlinear, stress-path dependent, stress-strain behavior of the backfill was approximated in the finite element analysis using the tangent modulus method. In the tangent modulus method, new values of tangent moduli are assigned to each soil element at each increment of loading (i.e., dewatering, lock construction, and backfilling) or unloading (i.e., excavation, rising water table). The modulus values assigned to each element are adjusted in accordance with their stresses to simulate nonlinear behavior.

Three types of finite elements are used to represent the behavior of different materials:

\section{Two-dimensional continua elements}

A 2-D, subparametric, quadrilateral element (QM5) is used to represent the soil and most structural materials. Structural supports, such as the struts or tieback components of an excavation support system, are typically modeled as a spring support using bar elements. However, 2-D elements have been used to model these supports in some cases.

\section{Interface elements}

SOILSTRUCT-ALPHA has the ability to model the interface region between the soil backfill and the structure using interface elements. This important feature allows for the movement of the softer continua elements used in modeling the backfill relative to (the movement of) the stiffer continua elements used in modeling the structure. This element is defined by four nodes, with each of the two pairs of nodes having the same coordinates; thus this element has no thickness.

\section{One-dimensional bar elements}

To model the behavior of a variety of structural systems, 1-D, two-node, bar or spring elements are used. This includes the modeling of structural supports such as braces or tiebacks or the modeling of reinforcement placed within a soil backfill.

SOILSTRUCT was expanded during the U.S. Corps of Engineers' Repair, Evaluation, Maintenance, and Rehabilitation Research Program to model the loss of contact between the base of a wall (a lock, in this case) and its rock foundation using a procedure called the ALPHA method (Ebeling, Duncan, and Clough 1990; Ebeling et al. 1992). Further details on the ALPHA method are given in Ebeling et al. (1992, pages 64-70). The ALPHA method was extended to soil elements by Regaldo, Duncan, and Clough (1992) to reduce numerical inaccuracies in soil elements that are at or near failure.

The continua elements used to model the soil and the soil-to-structure interface elements that may have failed in shear at one stage of loading have the ability to recover their shear stiffness and shearing resistance as a result of an increase in confining pressures at some later stage of loading in this version of SOILSTRUCT-ALPHA. Several other improvements have been made to the 
material models, including the new Gómez, Filz, and Ebeling (2000a, 2000b) extended load/unload/reload hyperbolic model for interfaces, and to the numerical procedures implemented within SOILSTRUCT-ALPHA based on experience gained at the U.S. Army Engineer Research and Development Center in conducting SSI analyses of different types of structures.

\subsection{Need for Further Improvements in SOILSTRUCT-ALPHA}

\subsubsection{Improvements in excavation procedure}

The Corps uses SOILSTRUCT-ALPHA to perform SSI analyses of multianchored or tieback retaining walls. Permanent multi-anchored walls have been used as guide walls and approach walls on navigation projects, and as retaining walls on highway and railroad protection and relocation projects (Mosher and Knowles 1990). Multi-anchored walls are constructed by first installing soldier elements for entire wall panels, and then beginning excavation. Anchors or tiebacks are installed as excavation proceeds. A critical aspect of SSI analysis of such structures is modeling the excavation process.

The excavation algorithm in SOILSTRUCT was developed in the late 1960s by Clough and Duncan (1969), and it has not been updated since that time, even though improved methods have been developed by Ghaboussi and Pecknold (1984), Borja, Lee, and Seed (1989), and others. The Clough and Duncan algorithm is based on extrapolation of stresses from nearby elements to the excavation boundary and integration of the extrapolated stresses to produce excavation unloading forces at element nodes. One of the weaknesses of the Clough and Duncan excavation algorithm is that the forces applied along the excavation boundary are not always consistent with the stresses in the excavated elements. Force equilibrium is not necessarily satisfied, and the resulting deformations can be either larger or smaller than they should be. The lack of force equilibrium can result in a distribution of excavation unloading force in which either too much or too little force is applied to the underlying soil and, correspondingly, either too little or too much force is applied to the structure. Moreover, it has been shown that the Clough and Duncan procedure may yield results that are dependent on the number of excavation stages used in simulations for linear elastic materials. For such materials, it has been shown that the results of the excavation should be independent of the number of steps and the sequence used to simulate the excavation.

\subsubsection{Accounting for soil-structure interface behavior in the excavation procedure}

A substantial amount of research has been performed in recent years on the interaction of soils and structures along their interface (Ebeling et al. 1993; Ebeling and Mosher 1996; Ebeling and Wahl 1997; Ebeling, Pace, and Morrison 1997; Ebeling, Peters, and Mosher 1997). These studies showed that the behavior of the soil-structure interface has a significant influence on the magnitudes of the 
loads acting against earth-retaining structures such as lock walls and soil reinforcements such as slurry walls. They also illustrated that the pre- and postconstruction stress paths followed by interface elements are complex, often involving simultaneous changes in normal and shear stresses, as well as unloading-reloading due to postconstruction rise of the groundwater level.

Gómez, Filz, and Ebeling (2000a) developed an extended hyperbolic model for interfaces and implemented it into the finite element program SOILSTRUCTALPHA. The model is based on the Clough and Duncan (1971) hyperbolic formulation, which was extended to model a variety of stress paths. Gómez, Filz, and Ebeling (2000a) performed a series of interface tests between uniform fine sands and concrete. Some of these tests followed complex stress paths that included unloading-reloading and simultaneous changes in normal and shear stresses.

Gómez, Filz, and Ebeling (2000a) also carried out a pilot-scale lock wall simulation that modeled placement and compaction of the backfill, surcharge application, and changes in the elevation of the water table behind the wall. By comparing model predictions to interface test results, and the results of SOILSTRUCT-ALPHA analyses to measurements from the lock wall simulation, these investigators concluded that the extended load/unload/reload hyperbolic model could provide accurate estimates of the response of backfill-to-lock wall interfaces.

Important similarities exist between the types of loading that occur at structure-to-soil interfaces in both multi-anchored systems and lock walls. Therefore, it is possible that the Gómez-Filz-Ebeling model for interfaces could also be used for SSI analyses of multi-anchored systems. However, because the model was developed based on the results of interface tests performed using uniform fine sands, additional testing was required to validate model performance for coarser soils.

Gómez, Filz, and Ebeling (2000b) performed a series of virgin shear tests under constant stress at the interface between a coarse sand and concrete. The results of these tests were used to determine the hyperbolic parameter values of the interface following the recommendations given by Gómez, Filz, and Ebeling (2000a). An interface test was performed following a complex stress path that included unloading-reloading as well as simultaneous changes in shear and normal stresses. The interface response measured during this test was compared with the response calculated using the extended hyperbolic model. It was found that the Gómez-Filz-Ebeling interface model provided accurate estimates of the response of this type of interface. Therefore, it can be concluded that the extended hyperbolic model can be used for prediction of the response of interfaces between concrete and a variety of granular soils. The hyperbolic parameter values of the interface tested also add to the database of interface properties available in the literature. The extended hyperbolic model, together with the interface data that have been generated, provides a useful tool for analyzing multi-anchored retaining systems and other Corps of Engineers structures.

The excavation algorithm in SOILSTRUCT-ALPHA was not developed with consideration of interface elements between the excavated soil and the retaining 
structure. Such interface elements are necessary for realistic modeling of earthretaining structures because the soil has a tendency to slip at its contact with the retaining structure, and interface elements allow slip to occur in finite element analyses. Consequently, it is important to upgrade SOILSTRUCT-ALPHA with an excavation procedure that correctly accounts for the presences of interface elements.

\subsection{Study Objectives}

The purpose of this report is to provide specific recommendations for improving the excavation algorithm in SOILSTRUCT, and to provide the information necessary for implementing these recommendations. The results will permit reliable and efficient improvement of the excavation algorithm in SOILSTRUCT-ALPHA. The objectives of the study described in this report are to

a. Complete a comprehensive literature review of numerical modeling of excavation.

$b$. Determine the suitability of existing excavation algorithms for their use in SOILSTRUCT.

c. Provide the information necessary to implement an improved excavation algorithm in SOILSTRUCT.

\subsection{Report Organization}

The report is organized in five chapters and one appendix. Chapter 1 provides a general background on the geotechnical issues addressed in the study and the motivation for the work carried out in the study.

Chapter 2 presents a detailed discussion of the general numerical procedure to simulate excavation. The chapter focuses on the Clough and Duncan procedure, and the use of the procedure is illustrated via an example problem.

Chapter 3 gives a review of the other available numerical procedures for simulating excavation. Four major types of numerical procedures are identified, and their main features are discussed. A detailed presentation of the method of force residuals is given by analyzing the example problem used in Chapter 2.

A comprehensive assessment and comparison of the available numerical models for excavation is given in Chapter 4. The models are compared in terms of practical and theoretical advantages and disadvantages. The Clough and Duncan procedure and the procedure based on force residuals are assessed with regard to how and whether they satisfy the requirements of force equilibrium, uniqueness of solution, and accuracy and convergence of solution. Chapter 4 also gives a detailed discussion of the issues related to the implementation of the method of force residuals in SOILSTRUCT-ALPHA. 
Chapter 5 summarizes the conclusions from the study and gives recommendations for updating and modifying the excavation algorithm used in SOILSTRUCT-ALPHA.

Finally, Appendix A gives a brief discussion on the determination of external surface tractions and internal element forces using isoparametric finite elements. 


\section{Numerical Simulation of Excavation}

Typical examples of excavation in soils were shown in Chapter 1. In finite element analysis, these excavations are simulated following the basic steps shown in Figure 2.1. The particular example used in the illustration is the excavation stage during construction of a slurry wall along a river embankment (see Figures $1.3 \mathrm{~b}-\mathrm{c}$ ). The portion of the soil to be excavated is shown as a shaded area. Prior to excavation, the soil to be excavated exerts stresses along the boundary between the soil to be excavated and the remaining soil (Figure 2.1a). As far as the remaining soil is concerned, the situation is the same as in Figure $2.1 \mathrm{~b}$ where the excavated soil is simply replaced by the stresses (or tractions) across the face of the excavated surface. The soil that will remain after the excavation would undergo no displacement or change in stress if the soil to be excavated were replaced by the boundary stresses. Since the systems shown in Figures 2.1a-b are equivalent, excavation simply involves removal of the boundary stresses from the remaining soil (Figure 2.1c). A stress-free surface would then result, and the displacements and stresses due to excavation would be produced by the removal of this load. In summary, simulation of excavation involves the following steps:

a. Find the tractions or boundary stresses transmitted to the remaining soil by the soil that will be excavated.

$b$. Remove the stiffness of the excavated region from the stiffness of the whole region.

c. Apply to the remaining soil the tractions or boundary stresses with magnitudes equal to those determined in Step 1 and opposite in sign.

d. Add the incremental displacements, strains, and stresses of Step 3 to the condition before excavation.

In finite element simulation, stresses induced by external loads and self-weight are converted to nodal forces. 


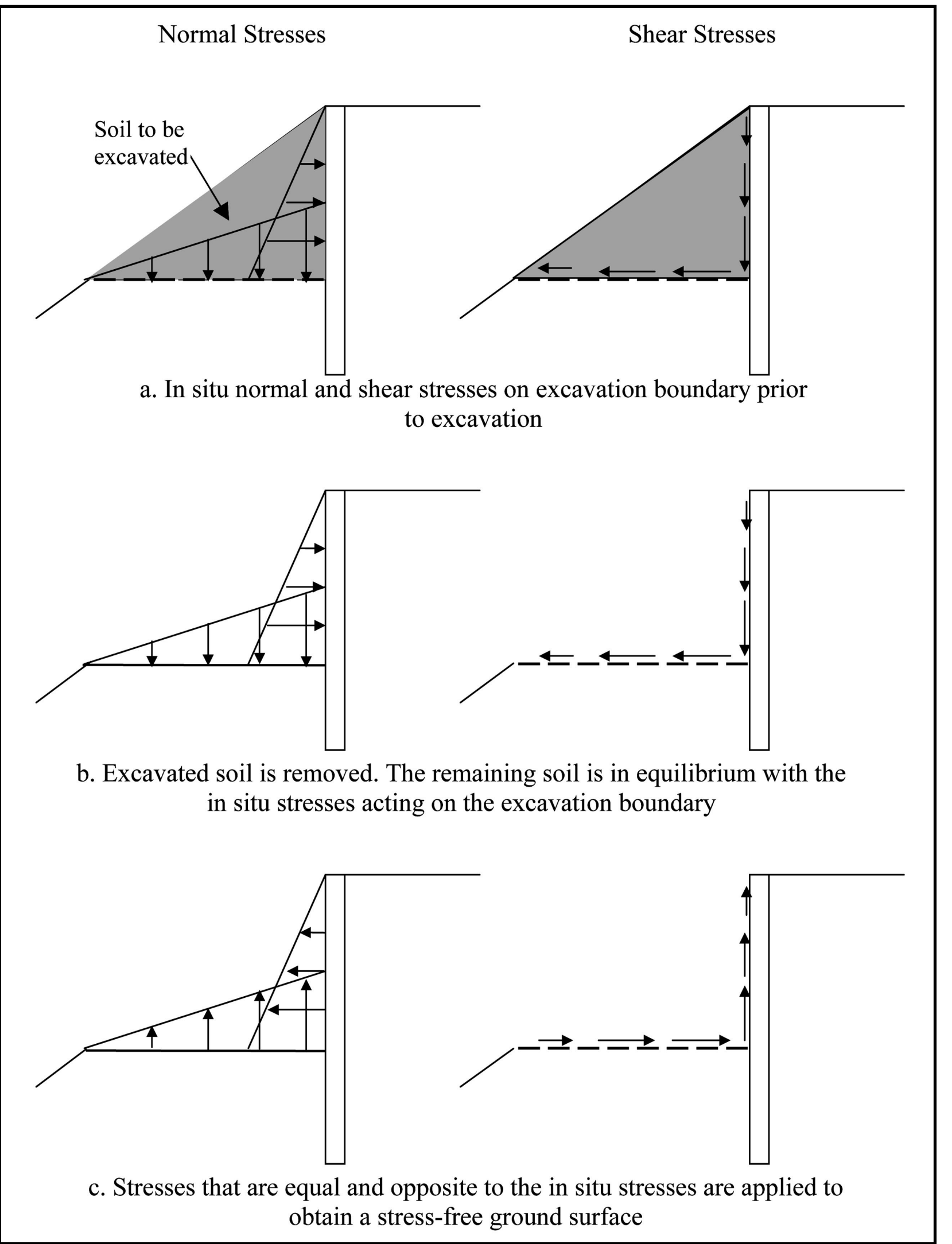

Figure 2.1. Steps in simulation of excavation 


\subsection{Clough and Duncan Procedure}

One of first finite elements procedures for simulating excavation in soils was developed by Clough and Duncan (1969). This is the simulation procedure used in the finite element code SOILSTRUCT and the latest version of SOILSTRUCT-ALPHA. Subsequent applications showed that the Clough and Duncan (1969) procedure suffers from certain limitations, which could have significant influence on the simulated results. Following the work of Clough and Duncan (1969), several other numerical procedures for modeling excavation have been developed that improved upon and removed the deficiencies in the Clough and Duncan procedure. This section gives a detailed review of the Clough and Duncan procedure. The review is presented to provide a starting point for assessing alternative methods for modeling excavation and determining how such alternative methods can be implemented in a modified and updated version of SOILSTRUCT-ALPHA.

Similar to many excavation procedures, the technique of Clough and Duncan is based on Figure 2.1 and consists of determining the stresses at the excavation boundary, calculating the equivalent nodal forces from the boundary stresses, and applying equal but opposite nodal loads to the finite element mesh. At the same time, the contributions of the excavated elements are taken out of the global stiffness matrix. This can be done by assigning minimal stiffness values to the excavated elements. The application of equal but opposite loads at the nodes along the excavation boundary ensures that the excavation boundary becomes stress free following the removal of the excavated elements.

To calculate the nodal loads on the excavation boundaries, the Clough and Duncan procedure uses the normal and shear stresses along the surface to be exposed by the excavation. Consider the case of a four-noded finite element with a linear distribution of normal and shear stresses along the excavation edges of the element, as illustrated in Figure 2.2. The normal stresses will produce nodal forces perpendicular to the excavation edge, while the shear stresses will produce nodal forces parallel to the excavation edge. Addition of all forces in the same $x$ and $y$ directions gives the total excavation forces $F_{x}$ and $F_{y}$ at each node.

The nodal forces for the case of uniform stress distribution along the excavation edge will be equal to one half the stress multiplied by the length of the excavated edge for both nodes (Figure 2.3). For quadrilateral elements with linear variation of stress along the edges, the nodal forces are calculated as shown in Figure 2.3. The nodal loads are obtained from simple static equilibrium and by integrating the area of the load over the length of side of the element. Appendix A presents a derivation of the equivalent nodal loads given in Figure 2.3.

In the finite element method, the stresses are generally determined only within the element (at the center of the elements or at the Gaussian quadrature points) and not along element edges. Since excavation boundaries pass between elements, several procedures were developed to determine the stresses on the excavation boundaries from the internal stresses of the elements adjacent to the excavation boundary. Dunlop, Duncan, and Seed (1968) determined the stresses on the boundaries by averaging the stresses in pairs of elements adjacent to the 


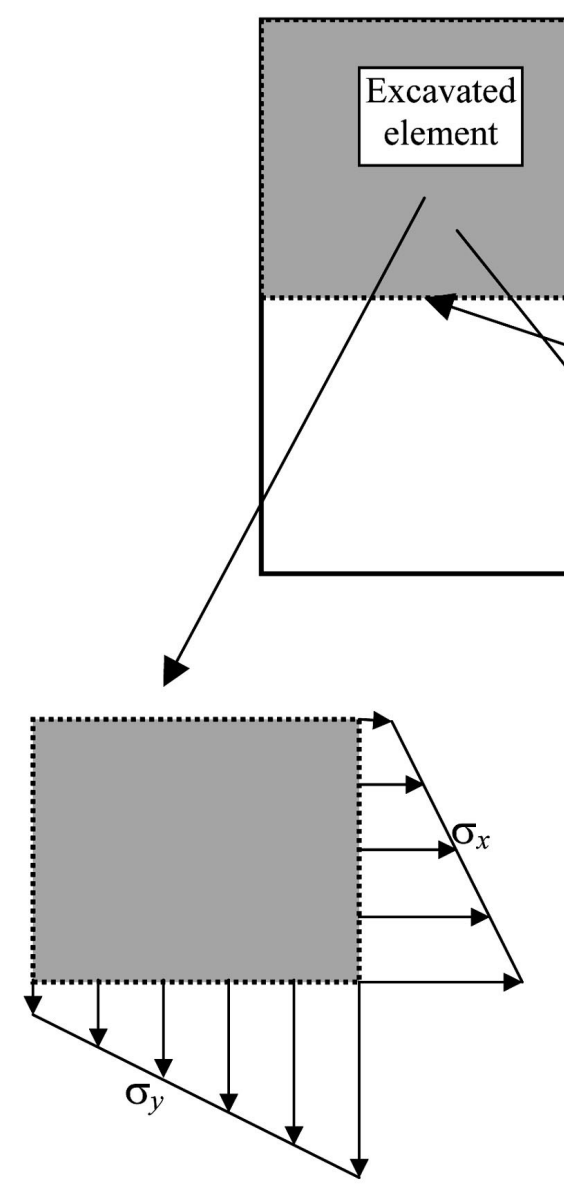

Normal stresses along excavation boundaries

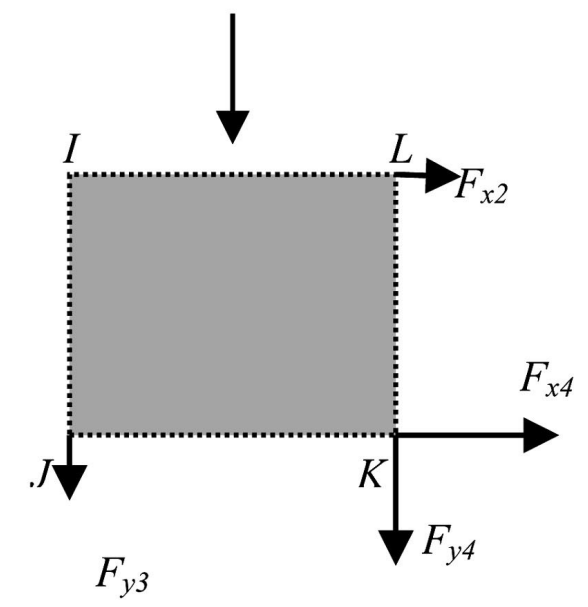

Equivalent nodal loads from normal stresses
Excavation boundaries

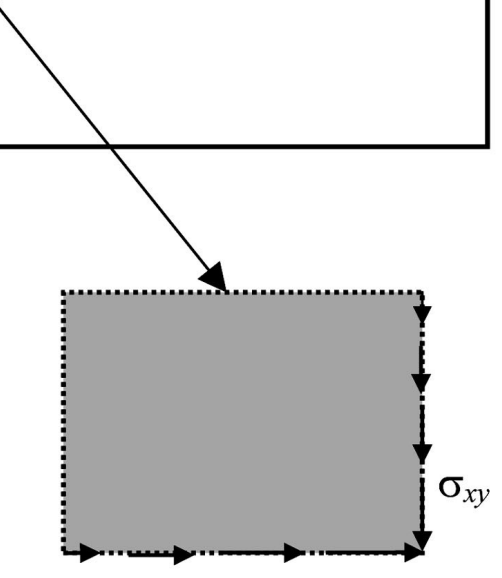

Shear stresses along excavation boundaries

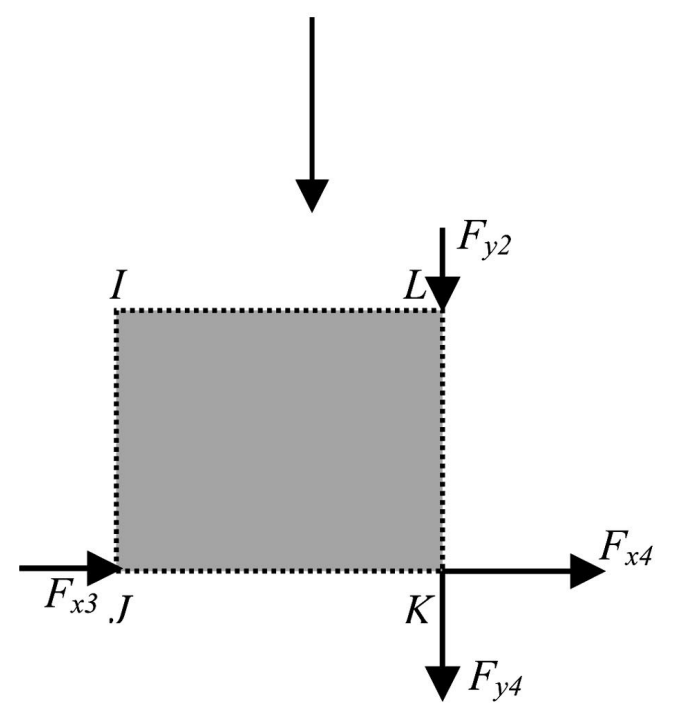

Equivalent nodal loads from shear stresses

Figure 2.2. Normal and shear stresses and equivalent nodal forces along the excavated sides of an element 

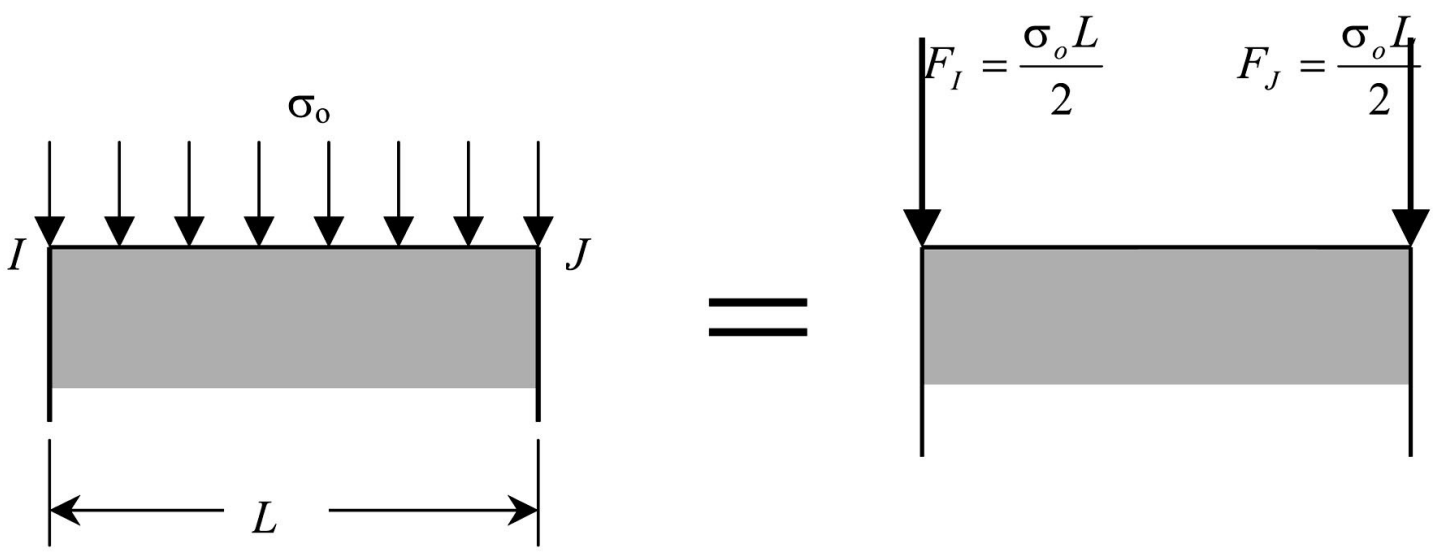

a. Uniform distribution

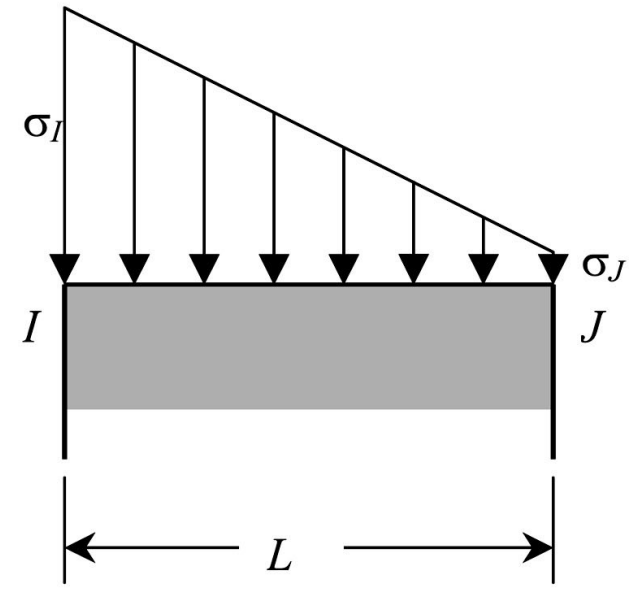

$$
F_{I}=L\left(\frac{\sigma_{I}}{3}+\frac{\sigma_{J}}{6}\right)
$$

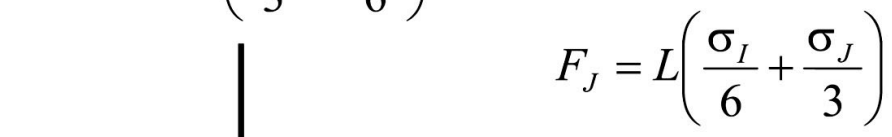

\section{b. Linear distribution}

Figure 2.3. Equivalent nodal forces from surface stresses

excavation boundary. Equivalent nodal forces were then calculated assuming that the average stresses are constant along the excavation boundary. In the case shown in Figure 2.4, the stresses along the excavation boundary $K-L$ are obtained from the average of the stresses in Elements 1 and 2, and for the boundary $J-K$ the stresses are calculated from Elements 1 and 4. This method was shown to be accurate only when the elements are of equal size. Chang (1969) improved on this method by using only the stresses above the boundary and correcting the nodal load according to an assumed gravity stress gradient within the elements.

Clough and Duncan generalized the techniques of Dunlop, Duncan, and Seed (1968) and Chang (1969) by interpolating the stresses along the excavation boundary from the stresses in the element to be excavated and the stresses in the three adjacent elements. This is the procedure that is currently used in SOILSTRUCT-ALPHA. Figure 2.4 illustrates the Clough and Duncan procedure. 


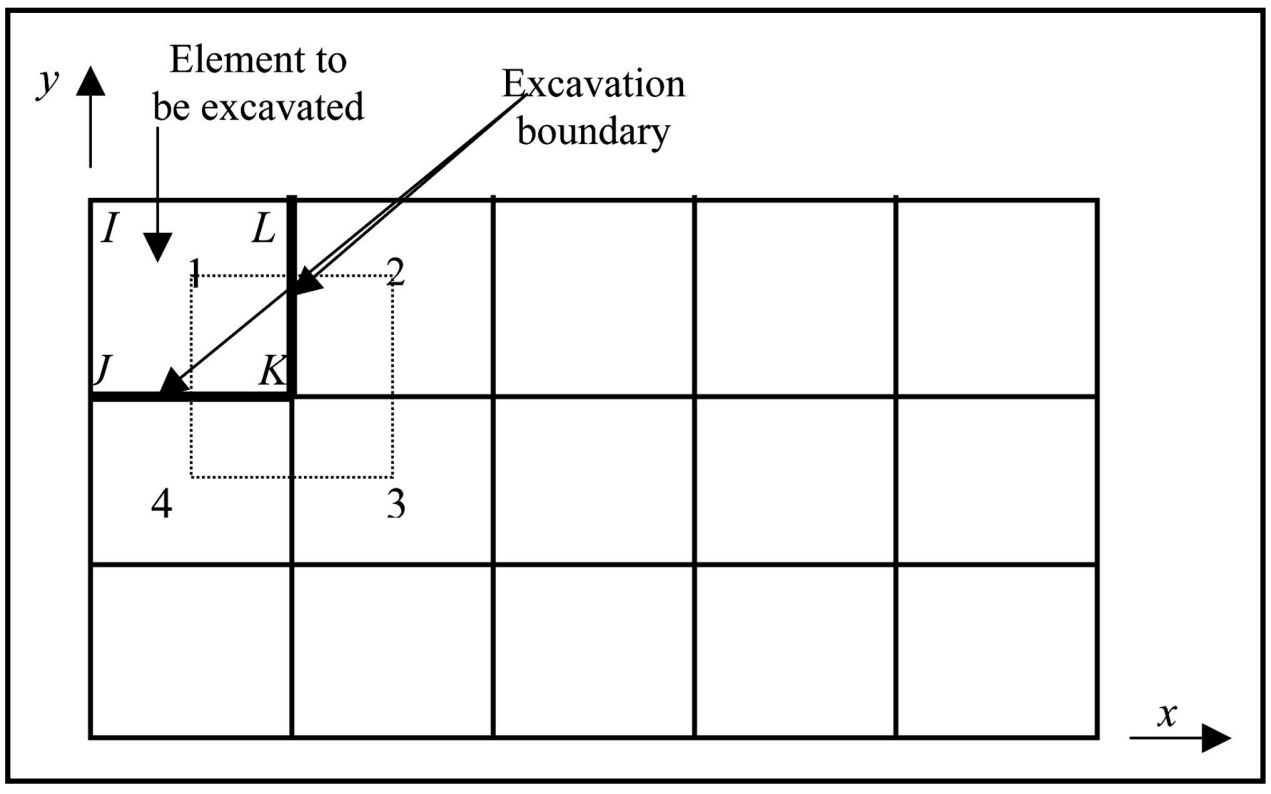

Figure 2.4. Interpolation procedures used to determine the stresses along the excavation boundaries. For the Dunlop, Duncan, and Seed (1968) procedure, stresses along $K-L$ are calculated from the stresses of Elements 1 and 2, and stresses along $J-K$ are calculated from the stresses of Elements 1 and 4. For the Clough and Duncan (1969) procedure, stresses at the nodal points $J, K$, and $L$ are interpolated from the stresses in the centers of the Elements 1, 2, 3, and 4. Elements 2, 3, and 4 adjacent to the excavated Element 1 are called interpolation elements

To interpolate the stresses along the excavation boundary, it is assumed that the stresses vary bilinearly in the region near the excavation boundary. An interpolation function of the following form is used to express the variation in stress:

$$
\sigma=a_{1}+a_{2} x+a_{3} y+a_{4} x y
$$

where $x$ and $y$ are the coordinates of a nodal point and $\sigma$ is any of the stress components $\sigma_{x}, \sigma_{y}$, and $\sigma_{x y}$. The interpolation coefficients $a_{1}, a_{2}, a_{3}$, and $a_{4}$ are determined from four known values of the stress $\sigma$ at four locations given by the coordinates $x$ and $y$. As mentioned above, these four locations are the centers of the excavated element and the three adjacent elements (the three adjacent elements are called the interpolation elements). Numbering the elements 1 to 4 , the stresses $\sigma(1), \sigma(2), \sigma(3)$, and $\sigma(4)$ in each element can be expressed in terms of the coordinates of the center of the elements $\left(x_{1}, y_{1}\right) \ldots\left(x_{4}, y_{4}\right)$ and the interpolation coefficients $a_{1}, a_{2}, a_{3}$, and $a_{4}$ as

$$
\begin{aligned}
& \sigma(1)=a_{1}+a_{2} x_{1}+a_{3} y_{1}+a_{4} x_{1} y_{1} \\
& \sigma(2)=a_{1}+a_{2} x_{2}+a_{3} y_{2}+a_{4} x_{2} y_{2} \\
& \sigma(3)=a_{1}+a_{2} x_{3}+a_{3} y_{3}+a_{4} x_{3} y_{3} \\
& \sigma(4)=a_{1}+a_{2} x_{4}+a_{3} y_{4}+a_{4} x_{4} y_{4}
\end{aligned}
$$


These equations can be written in matrix form as

$$
\{\sigma\}_{e}=[m]\{a\}
$$

where $\{\sigma\}_{e}=\left\{\begin{array}{llll}\sigma(1) & \sigma(2) & \sigma(3) & \sigma(4)\end{array}\right\}^{T},\{a\}=\left\{\begin{array}{llll}a_{1} & a_{2} & a_{3} & a_{4}\end{array}\right\}^{T}$, and

$$
[m]=\left[\begin{array}{cccc}
1 & x_{1} & y_{1} & x_{1} y_{1} \\
1 & x_{2} & y_{2} & x_{2} y_{2} \\
1 & x_{3} & y_{3} & x_{3} y_{3} \\
1 & x_{4} & y_{4} & x_{4} y_{4}
\end{array}\right]
$$

The unknown interpolation coefficients $\{a\}=\left\{\begin{array}{llll}a_{1} & a_{2} & a_{3} & a_{4}\end{array}\right\}^{T}$ can be obtained from Equation 2.2 as

$$
\{a\}=[m]^{-1}\{\sigma\}_{e}
$$

The values of the interpolation coefficients can now be used to extrapolate the stresses at each of the nodes of the element to be excavated. Denoting the four nodes of the element to be excavated as $I, J, K$, and $L$, the stresses at the nodes $\{\sigma\}_{n}=\left\{\begin{array}{llll}\sigma_{I} & \sigma_{J} & \sigma_{K} & \sigma_{L}\end{array}\right\}^{T}$ can be determined as

$$
\{\sigma\}_{n}=[n]\{a\}
$$

where $[n]$ is the coordinate matrix for the nodes $I, J, K$, and $L$ :

$$
[n]=\left[\begin{array}{cccc}
1 & x_{I} & y_{I} & x_{I} y_{I} \\
1 & x_{J} & y_{J} & x_{J} y_{J} \\
1 & x_{K} & y_{K} & x_{K} y_{K} \\
1 & x_{L} & y_{L} & x_{L} y_{L}
\end{array}\right]
$$

Finally, the nodal forces at the excavation boundary nodes can be calculated from the nodal stresses assuming the stresses vary linearly along the sides of the element. The calculations of the nodal forces from the surface tractions are the same as those shown in Figure 2.3.

A three-dimensional presentation of the Clough and Duncan interpolation procedure is shown in Figure 2.5. Essentially, the procedure fits a bilinear distribution of stresses from the interpolation elements and uses the interpolation parameters in finding the stresses at the nodes of the excavated element. This means that the interpolated surface is extended from the interpolation elements to the region occupied by the excavated elements. 


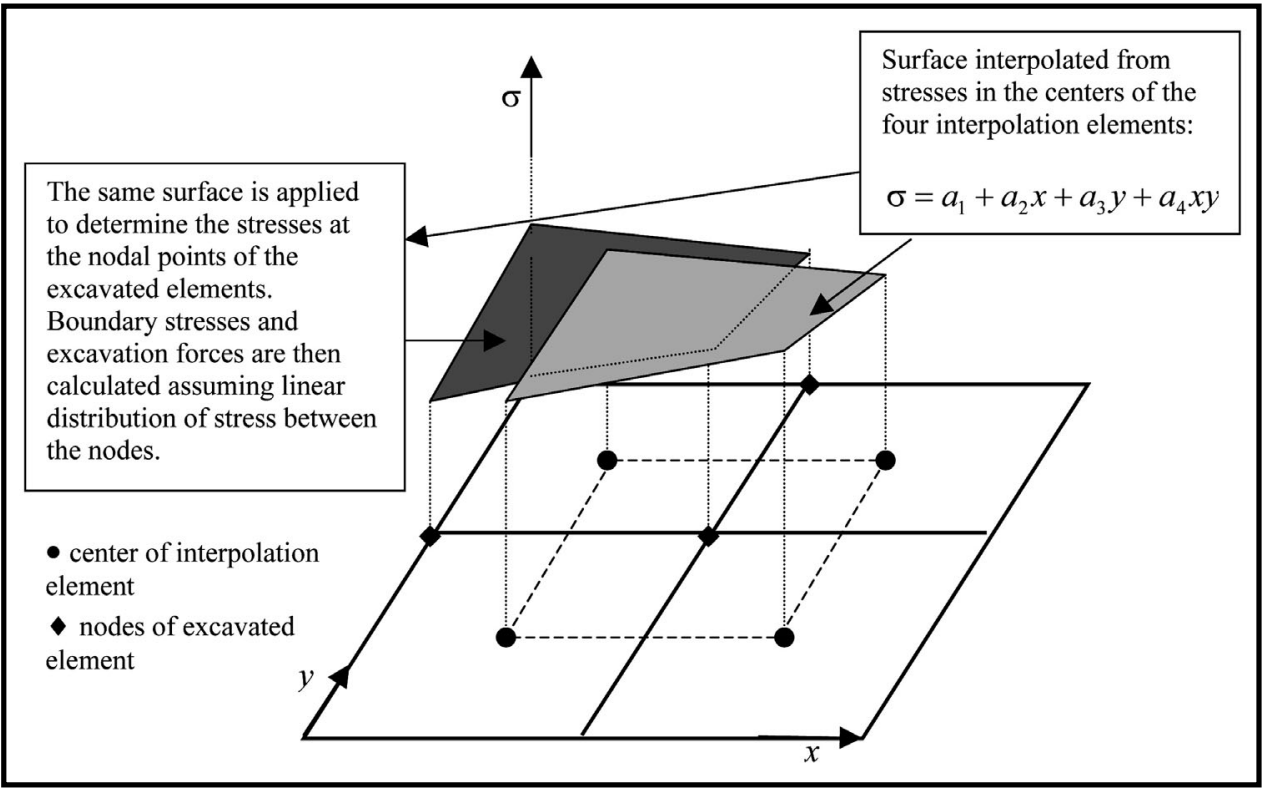

Figure 2.5. Three-dimensional representation of the Clough and Duncan interpolation procedure

The Clough and Duncan procedure is illustrated in the flowchart shown in Figure 2.6.

\subsection{Example Calculation}

To illustrate the Clough and Duncan procedure, the simple problem shown in Figure 2.7, which consists of an excavation in level ground, will be used. For convenience, constant stress rectangular elements will be used. The same problem will also be used in Section 3.3 to illustrate methods based on the calculation of excavation forces using internal element stresses.

\subsubsection{Existing ground condition (pre-excavation)}

The ground consists of a 2-m horizontal layer of homogenous, normally consolidated loose sand underlain by stiff rock. For convenience, the unit weight of the soil is assumed to be $\gamma=20 \mathrm{kN} / \mathrm{m}^{3}$. The initial in situ vertical and horizontal stresses are due to the self-weight of the soil. The in situ vertical stress $\sigma_{y}$ varies linearly with depth $y$ :

$$
\sigma_{y}=\gamma y
$$




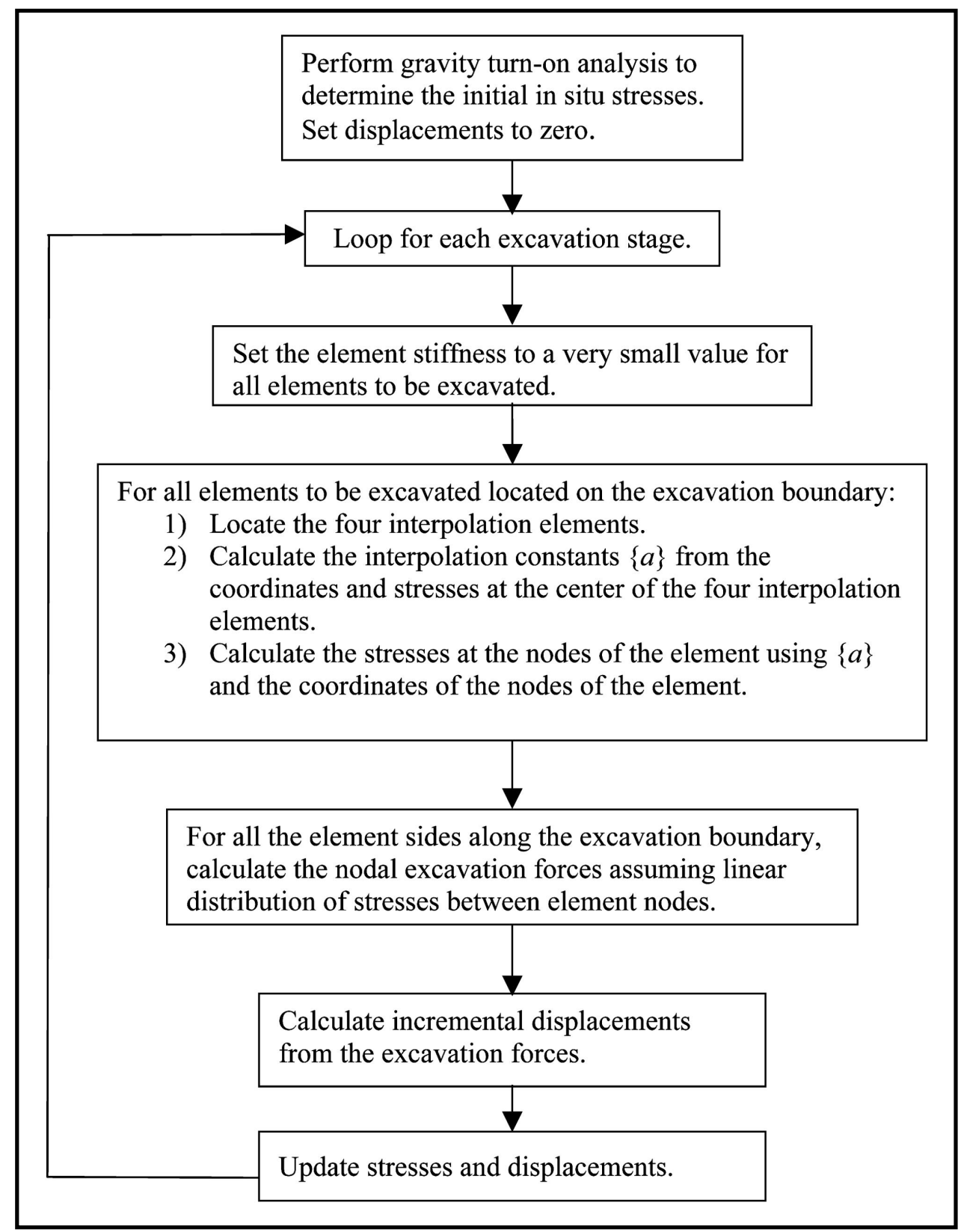

Figure 2.6. Flowchart for excavation modeling using the Clough and Duncan procedure

Assuming an infinite horizontal extent, uniaxial oedometric conditions apply. Consequently, the horizontal $\sigma_{x}$ is related to the vertical stress according to

$$
\sigma_{x}=K_{o} \sigma_{y}
$$

where $K_{o}$ is the at-rest ratio of horizontal to vertical stress. This ratio is estimated from Jaky's equation for normally consolidated deposits as 


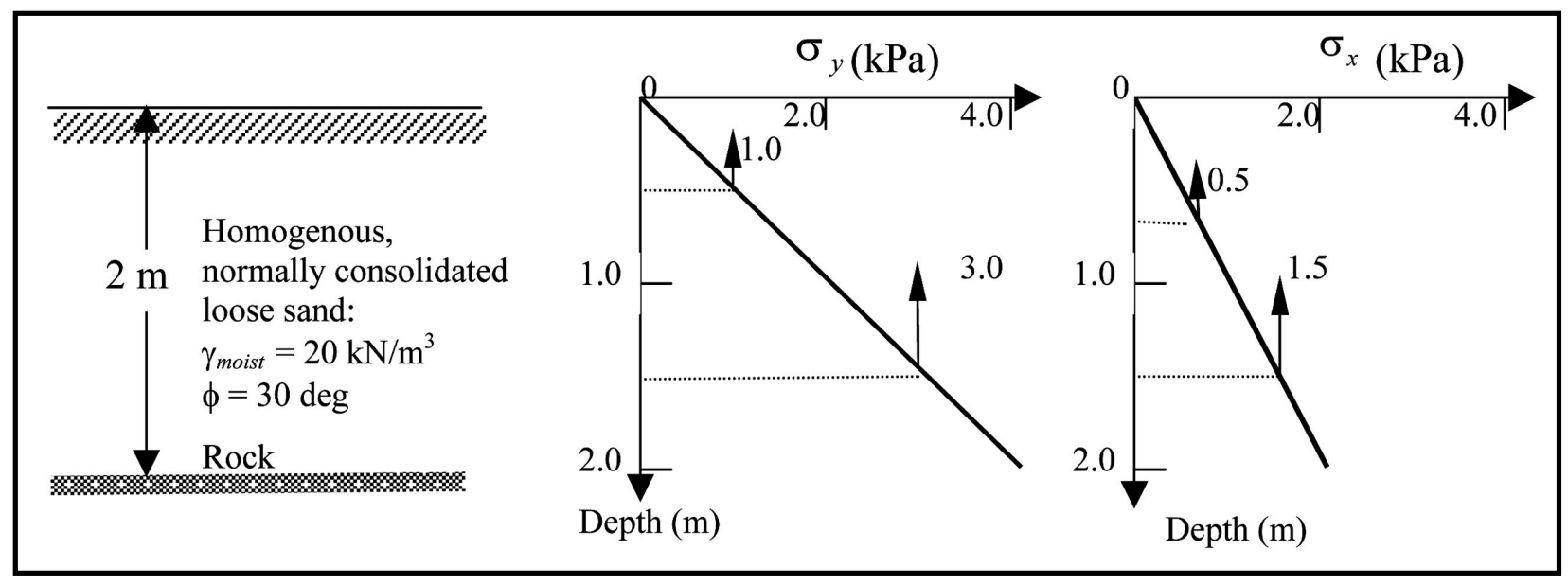

Figure 2.7. Initial in situ stresses beneath a level ground surface

$$
K_{o}=1-\sin \phi
$$

Assuming the friction angle $\phi$ is equal to $30 \mathrm{deg}$ gives $K_{o}=0.5$. Using $\gamma=$ $20 \mathrm{kN} / \mathrm{m}^{3}$ and $K_{o}=0.5$ gives the in situ vertical and horizontal stress distributions shown in Figure 2.7.

\subsubsection{Finite element analysis}

Step 1: Gravity turn-on analysis. The first step is the simulation of the ground conditions of the site before the start of the construction operations. In finite element programs such as SOILSRUCT and SOILSTRUCT-ALPHA, the standard procedure involves representing the initial conditions by an initial state of stress in each element in which the vertical stress is equal to the overburden stress, and the horizontal stress is a fraction of the vertical stress given by Equation 2.9. Assuming level ground, the initial shear stresses on the horizontal and vertical planes are assumed to be zero. Also, the displacements and strains from the initial stresses are set to zero once the gravity turn-on analysis is completed. However, the stresses calculated in subsequent incremental loadings are cumulatively superimposed on the initial stresses. It is important to account for the initial stresses, particularly in cases where stress-dependent deformation moduli are used. This gravity turn-on procedure does not explicitly model the influence of stress history on material behavior.

A simplified finite element model of the level ground shown in Figure 2.7 is given in Figure 2.8. The finite element model consists of two layers of constant stress elements and a total of six elements. The calculation involves the determination of the nodal loads at the excavation boundaries due to the removal of Element 2. To simulate an infinite horizontal extent, no lateral displacements are allowed along the two sides. Also since the layer is underlain by rock, the vertical displacement of the base of the model is assumed to be zero. The size of all 


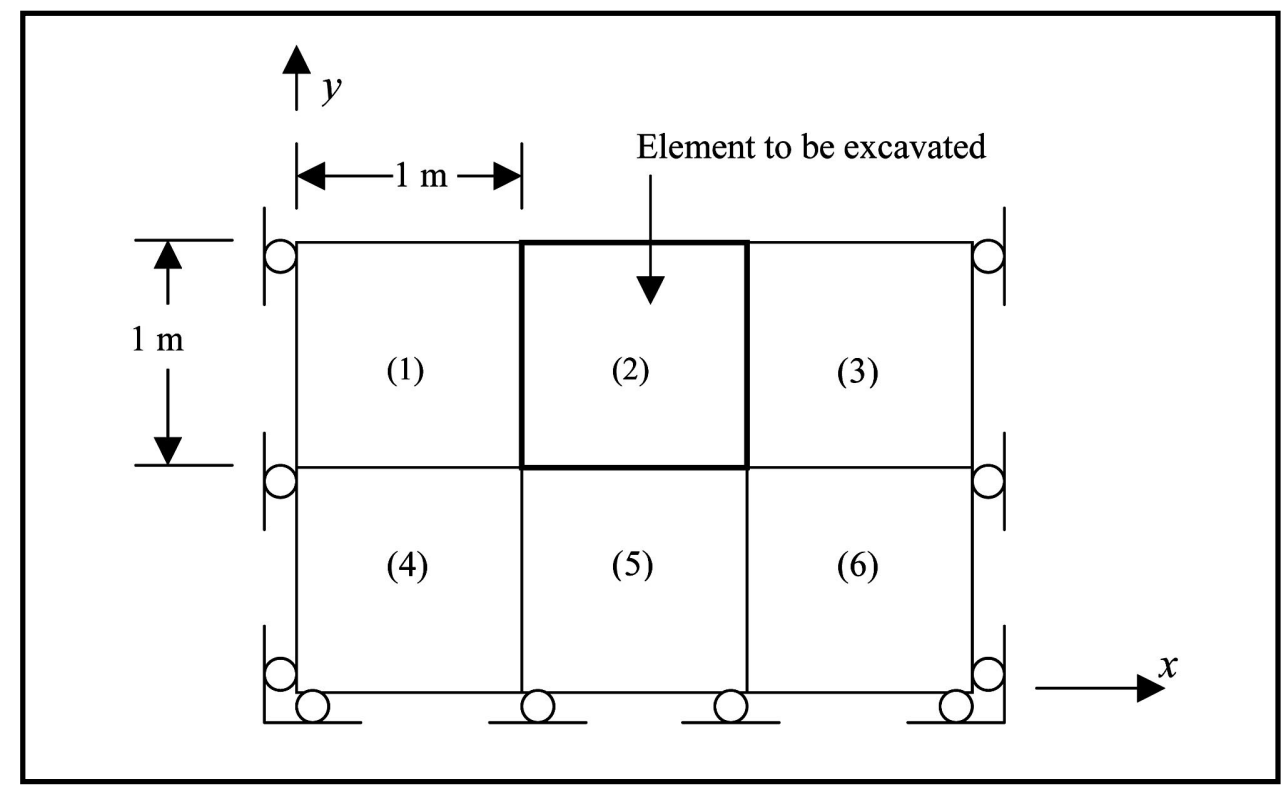

Figure 2.8. Excavation of a single element

elements is 1 by $1 \mathrm{~m}^{2}$, and a unit thickness is assumed. Elastic properties are assumed (see below).

Because loading in finite element analysis can only be represented by the application of nodal forces, the self-weights of the elements have to be converted to vertical nodal forces. Again, assuming a unit thickness of the model, the selfweight of each element $W$ shown in Figure 2.8 is equal to

$$
W=\gamma L^{2}=\left(20 \mathrm{kN} / \mathrm{m}^{3}\right)(1 \mathrm{~m})(1 \mathrm{~m})(1 \mathrm{~m})=20 \mathrm{kN}
$$

For a rectangular mesh, the equivalent nodal loads from the element self-weights are obtained by adding one quarter of the weight of each element and summing the weights of all elements connected to a node (Cook, Malkus, and Plesha 2002). For the problem shown in Figures 2.7 and 2.8, the self-weight induces the vertical nodal load vectors given below (Figure 2.9). For example, the vertical load of $10 \mathrm{kN}$ for node 2 comes from one quarter the weight of Element 1 (equal to $5 \mathrm{kN}$ ) and one quarter the weight of Element 2 (equal to $5 \mathrm{kN}$ ). The summation of element weights is carried out for all the nodes.

Step 2: Results of gravity turn-on analysis. Having prescribed the vertical loads due to the element self-weights, a finite element analysis can now be carried out to calculate the initial stresses in the elements. Normally, this will also require that the material parameters be prescribed. For an elastic material, a Young's modulus $E$ and a Poisson's ratio $v$ are required. For the situation shown in Figure 2.9, the analysis of the element vertical stresses is trivial and can be done solely based on vertical equilibrium. The Young's modulus is assumed to be $10 \mathrm{MPa}$. 


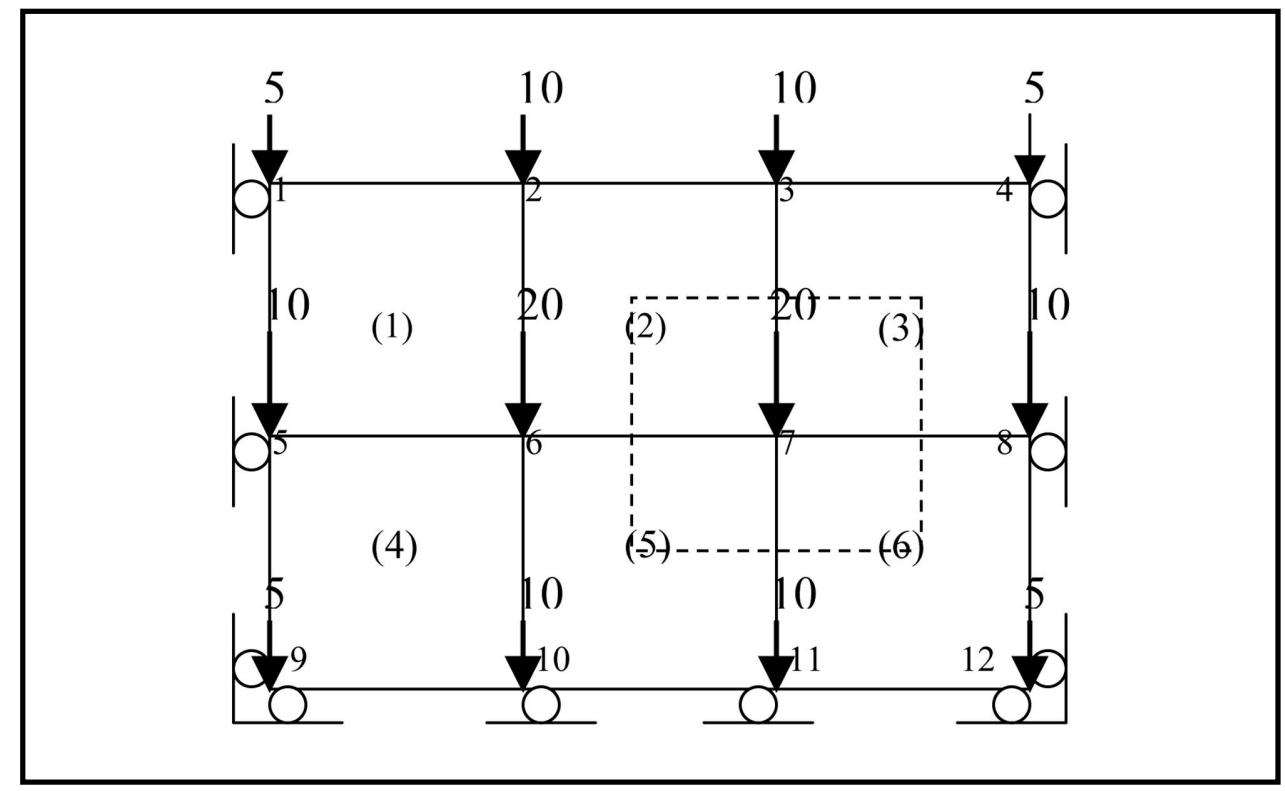

Figure 2.9. Nodal loads from self-weight (forces shown are in kilonewtons)

The horizontal stresses can be obtained from an elastic stress-strain relation assuming the horizontal strain $\varepsilon_{x}$ is equal to zero. The horizontal stresses from this elastic stress-strain solution follow Equation 2.9, where $K_{o}$ is related to the Poisson's ratio $v$ of the material by the following relation:

$$
K_{o}=\frac{v}{1-v}
$$

Thus, to achieve a $K_{o}$ value consistent with the value obtained from Equation 2.10, the Poisson's ratio $v$ can be solved from Equation 2.9 as

$$
v=\frac{K_{o}}{1+K_{o}}
$$

This gives $v=0.33$ for $K_{o}=0.5$. Based on vertical equilibrium and the solution of the horizontal elastic stress-strain relation, the vertical and horizontal stresses at the centers of the elements (due to the self-weight vertical loads shown in

\begin{tabular}{|c|c|c|c|}
\hline \multicolumn{4}{|c|}{$\begin{array}{l}\text { Table 2.1 } \\
\text { Calculated Element Stresses Due to Nodal Loads Shown in } \\
\text { Figure } 2.9\end{array}$} \\
\hline Elements & Depth, $y(\mathrm{~m})$ & $\begin{array}{l}\text { Vertical Stress, } \\
\sigma_{y}(\mathrm{kPa})\end{array}$ & $\begin{array}{l}\text { Horizontal Stress, } \\
\sigma_{x}(\mathrm{kPa}) \\
\end{array}$ \\
\hline $1,2,3$ & 0.5 & "10 & " \\
\hline $4,5,6$ & 1.5 & 30 & 15 \\
\hline
\end{tabular}
Figure 2.9) are given in Table 2.1 below. 
These element stresses correspond to the stresses shown in the stress profiles in Figure 2.7. Note that, due to the nature of the loading, shear stresses $\sigma_{x y}$ are zero.

Step 3: Determination of excavation forces using Clough and Duncan procedure. To determine the stresses along the excavation boundaries, the stresses at the nodal points 2, 3, 6, and 7 are first determined following the interpolation procedure discussed above. The interpolation is carried out using Elements 2, 3, 5, and 6 as the interpolation elements and the stresses in the centers of these elements. The interpolation is, therefore, carried out using the region connected by the dashed lines in Figure 2.9. For illustration, the calculations are first carried out for the horizontal stresses along the excavation boundary between Elements 2 and 3 (line connecting nodes 3 and 7). Substituting the horizontal stresses and the coordinates of the centers of Elements 2, 3, 6, and 5 in Equation 2.2 gives the following interpolation equation:

$$
\left\{\begin{array}{c}
5 \\
5 \\
15 \\
15
\end{array}\right\}=\left[\begin{array}{llll}
1 & 1.5 & 1.5 & 2.25 \\
1 & 2.5 & 1.5 & 3.75 \\
1 & 2.5 & 0.5 & 1.25 \\
1 & 1.5 & 0.5 & 0.75
\end{array}\right]\left\{\begin{array}{l}
a_{1} \\
a_{2} \\
a_{3} \\
a_{4}
\end{array}\right\}
$$

Solving for $\{a\}=\left\{\begin{array}{llll}a_{1} & a_{2} & a_{3} & a_{4}\end{array}\right\}^{T}$ in Equation 2.14 gives $\{a\}=\{20,0,-10$, $0\}$. Substituting these values in Equation 2.6, together with the coordinates of nodes $2,3,6$, and 7 , gives the following stresses at these nodal points:

$$
\left\{\begin{array}{l}
\sigma_{x}(2) \\
\sigma_{x}(3) \\
\sigma_{x}(6) \\
\sigma_{x}(7)
\end{array}\right\}=\left[\begin{array}{llll}
1 & 1 & 2 & 2 \\
1 & 2 & 2 & 4 \\
1 & 2 & 1 & 2 \\
1 & 1 & 1 & 1
\end{array}\right]\left\{\begin{array}{c}
20 \\
0 \\
-10 \\
0
\end{array}\right\}
$$

Solving Equation 2.15 gives

$$
\left\{\begin{array}{l}
\sigma_{x}(2) \\
\sigma_{x}(3) \\
\sigma_{x}(6) \\
\sigma_{x}(7)
\end{array}\right\}=\left\{\begin{array}{c}
0 \\
0 \\
10 \\
10
\end{array}\right\}(\mathrm{kPa})
$$

Following the same procedures, the vertical stresses $\sigma_{y}$ at nodes $2,3,6$, and 7 can be obtained as 


$$
\left\{\begin{array}{l}
\sigma_{y}(2) \\
\sigma_{y}(3) \\
\sigma_{y}(6) \\
\sigma_{y}(7)
\end{array}\right\}=\left\{\begin{array}{c}
0 \\
0 \\
20 \\
20
\end{array}\right\}(\mathrm{kPa})
$$

Assuming linear distribution of stresses along the sides of the elements between the nodes, the stresses along the excavation boundaries corresponding to the interpolated nodal stresses are plotted in Figure 2.10. The boundary stresses are then converted to nodal forces following the procedures shown in Figure 2.3.

The reversed equivalents of these nodal forces are also shown in Figure 2.10. These are the forces that will be applied to simulate the excavation of Element 2 following the Clough and Duncan procedure. Further discussions of the results of the Clough and Duncan procedure are given in Section 4.2.

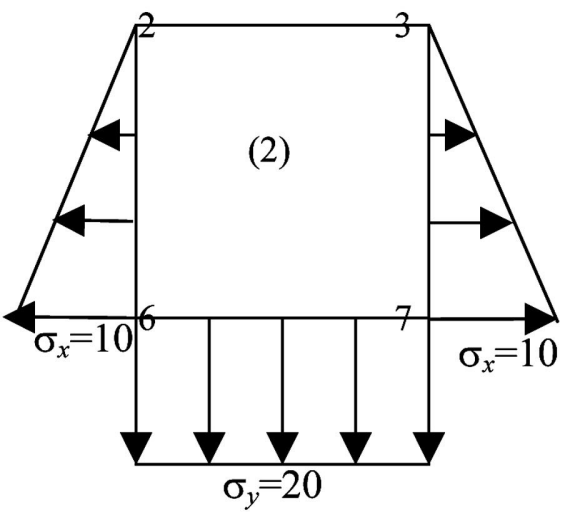

(a)

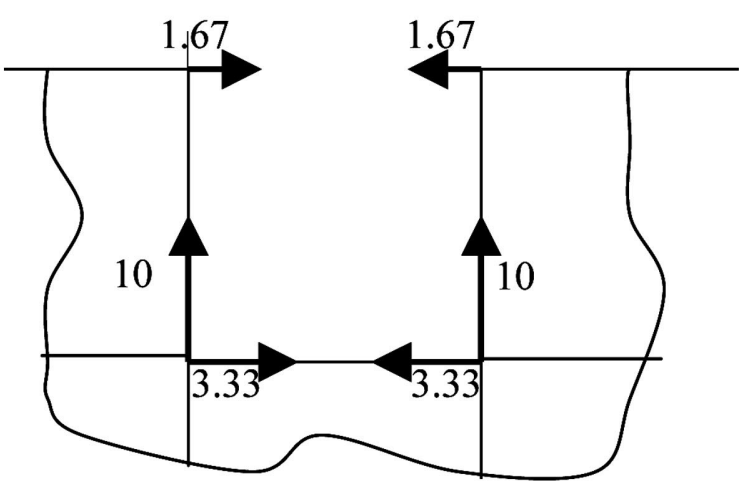

(b)

Figure 2.10. Stress distribution (a) along the excavation boundary from the interpolated nodal stresses; (b) reversed equivalent nodal forces (stresses are in kilopascals; forces are in kilonewtons) 


\section{Review of Other Excavation Models}

As noted in Chapter 2, several procedures for modeling excavation processes have been developed since Clough and Duncan presented their excavation algorithm in 1969. In this chapter, the main features of the different numerical models for simulating excavation processes are described and reviewed.

\subsection{Summary of Models}

The method of using stresses or surface traction along the excavation boundaries appears to have been proposed first by Brown and King (1966). The Clough and Duncan model itself was an improvement of the models proposed by Dunlop, Duncan, and Seed (1968) and Chang (1969). The difficulties associated with the Clough and Duncan procedure had not been rigorously analyzed until Christian and Wong performed a detailed analysis of the different excavation procedures available in 1973. At that time, Clough and Duncan (1969) and Ishihara (1970) had already demonstrated that, for linear elastic materials, the results of the excavation must be independent of the number of steps used in the excavation.

Clough and Duncan (1969) performed a numerical analysis of the effects of number of layers in simulation of one-dimensional (1-D) excavation and fill placement. Curves of error (in percent) in vertical displacement were developed where the error was defined as the ratio of the vertical displacement for a given number of increments to the vertical displacement obtained for the solution using layers of infinitesimal thickness. The analysis was carried out for both linear and nonlinear material behavior. For nonlinear material response, the Young's modulus $E$ was modeled as a power function of the confining stress $\sigma_{3}$. Clough and Duncan's results are shown Figure 3.1 in terms of the values of errors in simulation of small layers of excavation for different values of the exponent $n$ used to model the dependency of $E$ to $\sigma_{3}$. As can be seen, there are no simulation errors for linear elastic material with $n=0$, which shows that 1-D excavation is independent of the number of layers used in the simulation. 


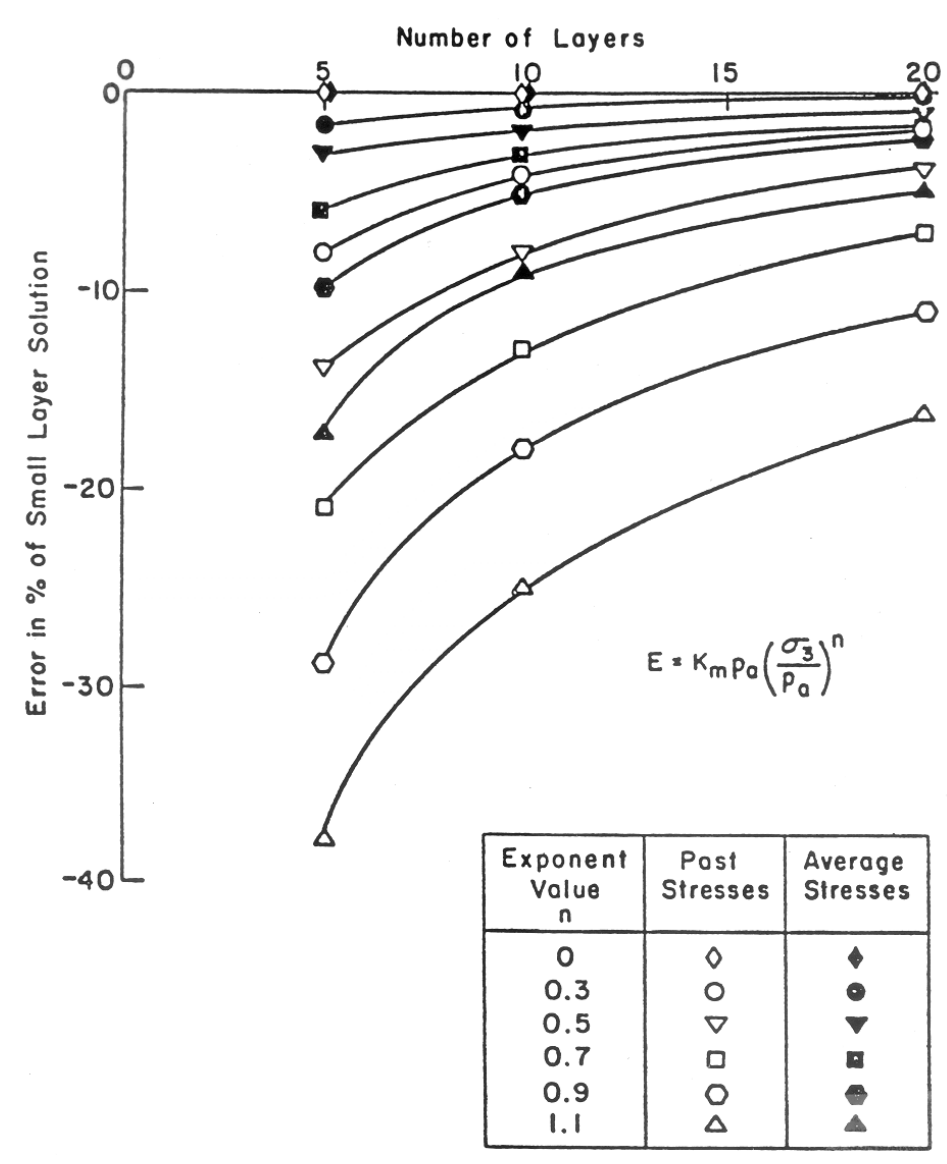

Figure 3.1. Values of errors in simulation of small layer one-dimensional excavation for different values of $n$ (Clough and Duncan 1969)

Ishihara (1970) presented a more formal and mathematical proof that, for elastic materials, the result must be independent of the number of stages used in general 2- and 3-D excavation problems. This follows from the principle that the response of elastic materials is independent of the load or displacement path taken by the material. Uniqueness of the solution for excavation in elastic materials should, therefore, be one of the main criteria in determining the validity of a numerical procedure for simulating excavation.

Christian and Wong (1973) studied the performance of three numerical procedures: (a) the Clough and Duncan procedure of interpolating stresses from four elements near the excavation boundary; (b) the Dunlop, Duncan, and Seed (1968) procedure of averaging the stresses of the two elements adjacent to the excavation boundary; and (c) using the stresses of the excavated element as the boundary stresses. It was found that the results of these three finite element procedures could be in serious error. In particular, the different procedures yielded displacements at the top of a vertical cut which were dependent on the number of steps of excavation in an elastic soil. For the problem Christian and Wong (1973) analyzed, the calculated vertical displacements at the top of the excavation varied from -0.6 to $0.8 \mathrm{ft}(-0.2$ to $0.2 \mathrm{~m})$ when the number of 
excavation lifts was changed from 1 to 8 . Clearly, this discrepancy shows the difficulty of using the three procedures in predicting displacements from excavations, as the results are heavily influenced by the number of steps used in the simulation.

Christian and Wong (1973) argued that the errors are largely due to the inability of the finite elements to model adequately the stress gradients at the toe of the excavation. They proposed a modified model and recommended that simulations of excavations should be done in as few steps as possible. In their modified procedure, the stresses at the excavation boundary are extrapolated using a fifth- or sixth-order polynomial fitted through the stresses at the element centers in the same horizontal row of elements. Although better results were obtained with this modified procedure, there were still differences in the calculated displacements for different numbers of excavation steps used.

Following the work of Christian and Wong (1973), Chandrasekaran and King (1974) developed a procedure that does not rely on interpolation of the stresses along the excavation boundary. The procedure is based on the individual calculations of the excavation loads for each stage of excavation based on earth pressure assumptions and the displacement functions used for the elements. The individual sets of loads are calculated before the different stages of excavation are carried out. Each set of loads is modified to account for the changes in load from the previous excavation stage. These changes are equal to the product of the stiffness matrix of the unexcavated elements and the displacements from the previous stage. The procedure is shown to yield numerically identical results for different numbers of excavation stages. Another attempt at solving the nonuniqueness problem shown by Christian and Wong (1973) is the procedure developed by Desai and Sargand (1984). A hybrid finite element procedure, in which the finite element degrees-of-freedom include both displacements and stresses, was proposed.

Over the years, a numerical solution that has found wide acceptance among modelers is the procedure based on calculating excavation forces from element stresses at the Gaussian points (or at the element center for constant stress elements). Clough and Mana (1976) appeared to be first to propose this procedure. However, the most rigorous proof of the uniqueness of the solution based on the use of internal element stresses for elastic materials was given by Ghaboussi and Pecknold (1984). A generalized formulation was presented in which the excavation forces are treated in the context of the Newton-Raphson family of solution techniques widely used in nonlinear analysis. In the solution technique, unbalanced forces from excavation are simply treated as part of the force residuals that need to be balanced for a given load or excavation stage. In addition, Ghaboussi and Pecknold accounted for the stresses from the material self-weight. The selfweight stresses were not included in the Clough and Mana (1976) procedure.

The validity of the Ghaboussi and Pecknold (1984) procedure was also demonstrated by Chow (1985). Using this procedure, Chow showed that the Desai and Sargand (1984) method does not account for the body forces. Brown and Booker (1986) performed further studies showing the uniqueness of the solution using the Ghaboussi and Pecknold procedure for linearly elastic 
materials. It was also shown that the procedure does not require a large degree of mesh refinement to obtain accurate results for linear elastic materials.

Borja, Lee, and Seed (1989) extended the Ghaboussi and Pecknold (1984) procedure to nonlinear materials using a variational formulation that accounts for time-varying problem domain and boundaries. Independence of the solution from the number of construction stages was shown not only for elastic materials but also for a certain class of elastoplastic materials with a shrinking elastoplastic zone. Similar to the Ghaboussi and Pecknold procedure, changes due to excavation are treated as part of the nonlinear problem, although a different numerical strategy is used to resolve the force residuals from the unbalanced forces.

Based on this review, the methods can be grouped into four main types of numerical procedures for modeling excavation processes, as summarized in Table 3.1 and Figure 3.2. Chapter 4 presents an evaluation of these procedures, their advantages and disadvantages, and the requirements for implementing the recommended procedure in SOILSTRUCT-ALPHA.

\begin{tabular}{|c|c|}
\hline \multicolumn{2}{|c|}{$\begin{array}{l}\text { Table } 3.1 \\
\text { Main Types of Numerical Procedures for Simulating Excavation } \\
\text { Processes }\end{array}$} \\
\hline Numerical Procedure & Summary of the Procedure and Variants \\
\hline $\begin{array}{l}\text { Excavation forces from } \\
\text { stresses along the } \\
\text { excavation boundary } \\
\text { (Figure } 3.2 a \text { ) }\end{array}$ & $\begin{array}{l}\text { Originally developed by Brown and King (1966). } \\
\text { Excavation boundary stresses are determined from the boundary } \\
\text { stresses of the excavation element (Christian and Wong 1973). } \\
\text { Excavation boundary stresses are determined from the average of } \\
\text { the element stresses of two elements adjacent to the excavation } \\
\text { boundary (Dunlop, Duncan, and Seed 1968). } \\
\text { Stresses at the nodes of the excavated element are determined from } \\
\text { interpolation of element stresses from four elements adjacent to the } \\
\text { excavation boundary. Nodal stresses are then converted to } \\
\text { excavation forces along the excavation boundary (Clough and } \\
\text { Duncan 1969). } \\
\text { Excavation boundary stresses are extrapolated using a fifth- or sixth- } \\
\text { order polynomial fitted through the stresses at the element centers in } \\
\text { the same horizontal row of elements (Christian and Wong 1973). }\end{array}$ \\
\hline $\begin{array}{l}\text { Accumulation of } \\
\text { excavation forces } \\
\text { (Figure } 3.2 b)\end{array}$ & $\begin{array}{l}\text { Individual sets of excavation loads are calculated before the different } \\
\text { stages of excavation are carried out. Each set of loads is modified to } \\
\text { account for the changes in the load from the previous excavation } \\
\text { stage. These changes are equal to the product of the stiffness matrix } \\
\text { of the unexcavated elements and the displacements from the } \\
\text { previous stage (Chandrasekaran and King 1974). }\end{array}$ \\
\hline $\begin{array}{l}\text { Hybrid finite element } \\
\text { procedure (Figure } 3.2 \mathrm{c} \text { ) }\end{array}$ & $\begin{array}{l}\text { Uses finite elements with displacement and stress degrees-of- } \\
\text { freedom (Desai and Sargand 1984). }\end{array}$ \\
\hline $\begin{array}{l}\text { Excavation forces from } \\
\text { force residuals } \\
\text { (Figure } 3.2 \mathrm{~d} \text { ) }\end{array}$ & $\begin{array}{l}\text { Excavation forces are calculated from stresses at the Gaussian } \\
\text { points (Clough and Mana 1976). } \\
\text { Body forces are included along with the internal stresses in the } \\
\text { calculation of excavation forces (Ghaboussi and Pecknold 1984, } \\
\text { Chow 1985, Brown and Booker 1986). } \\
\text { The procedure is a generalization of the Newton-Raphson procedure } \\
\text { to minimize force residuals from unbalanced (difference between } \\
\text { internal and external) forces (Ghaboussi and Pecknold 1984). } \\
\text { The procedure is generalized for nonlinear materials behavior (Borja, } \\
\text { Lee, and Seed 1989). }\end{array}$ \\
\hline
\end{tabular}




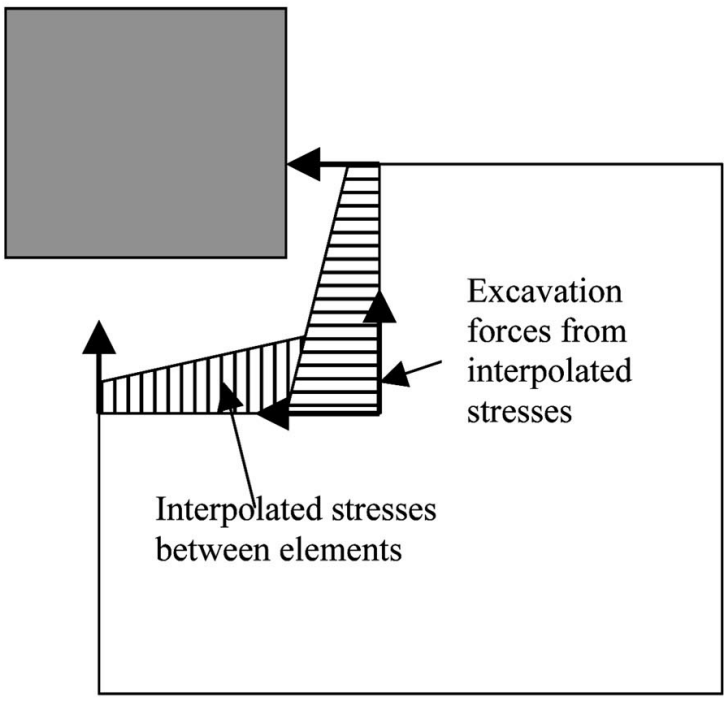

a. Excavation forces from interpolated stresses along the excavation boundary

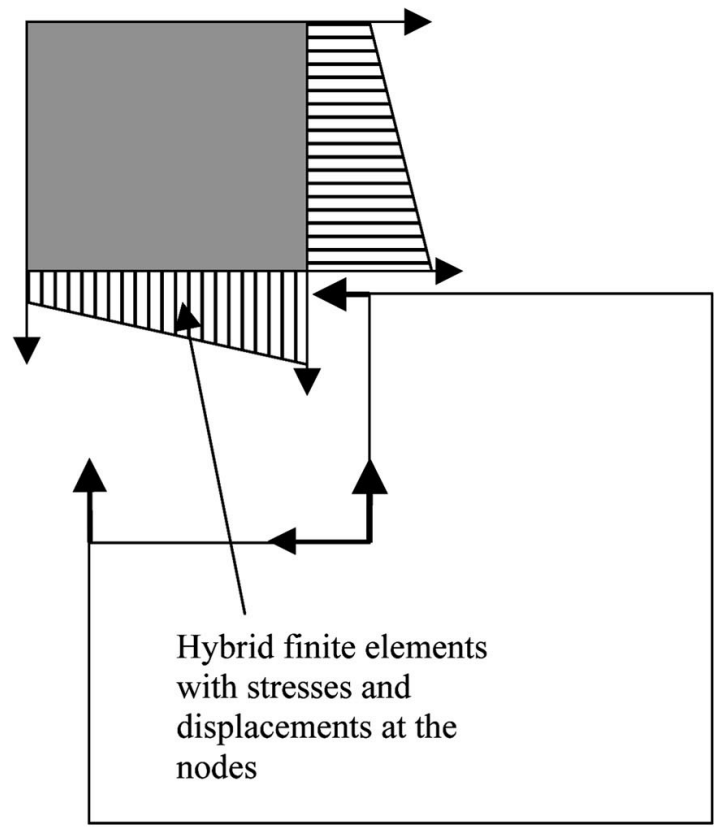

c. Excavation forces from nodal stresses and displacement of hybrid finite elements

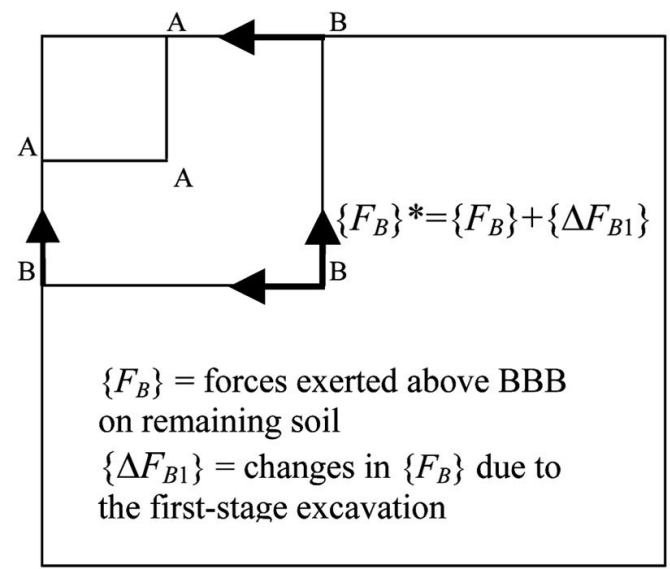

b. Excavation forces accumulated from excavation stages

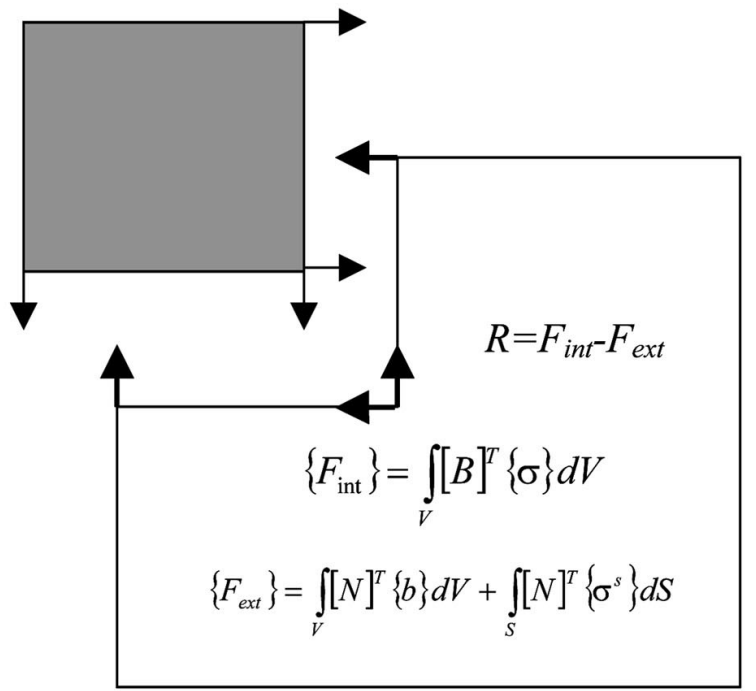

d. Excavation forces calculated from force residuals between internal and external forces

Figure 3.2. Excavation forces 


\subsection{Methods Based on Force Residuals}

The method of calculating excavation forces from the differences between the internal element forces and external loads appears to be one of the most widely used and perhaps most successful procedure for modeling excavation. For this reason, a detailed review of this procedure is given in this section. The method is based on the minimization of the residual forces $\{R\}$ calculated from the differences between the internal forces $\left\{F_{\text {int }}\right\}$ and the external forces $\left\{F_{\text {ext }}\right\}$ calculated at the nodes in a finite element discretization of a stress problem.

$$
\{R\}=\left\{F_{\text {int }}\right\}-\left\{F_{\text {ext }}\right\}=0
$$

In a finite element discretization, $\left\{F_{\text {int }}\right\}$ and $\left\{F_{\text {ext }}\right\}$ are calculated from the element stresses $\{\sigma\}$, body loads from self-weights $\{b\}=\left\{\begin{array}{ll}0 & \gamma\end{array}\right\}^{T}$ where $\gamma$ is the unit weight (force/length ${ }^{3}$ ), and surface stresses or tractions $\left\{\sigma^{S}\right\}$ at the boundaries:

$$
\begin{aligned}
& \left\{F_{\text {int }}\right\}=\int_{V}[B]^{T}\{\sigma\} d V \\
& \left\{F_{\text {ext }}\right\}=\int_{V}[N]^{T}\{b\} d V+\int_{S}[N]^{T}\left\{\sigma^{s}\right\} d S
\end{aligned}
$$

where $V$ and $S$ are, respectively, the volume and surface area of the element, $[N]$ is the global shape function matrix, and $[B]$ is the global strain-displacement transformation matrix.

For 2-D stress conditions, $[B]$ is equal to

$$
[B]=\left[\begin{array}{cc}
\frac{\partial N_{i}}{\partial x} & 0 \\
0 & \frac{\partial N_{i}}{\partial y} \\
\frac{\partial N_{i}}{\partial y} & \frac{\partial N_{i}}{\partial x}
\end{array}\right]
$$

where $i$ is the node number of the element.

So, in 2-D plane stress/plane strain problems, the internal forces are equal to

$$
\begin{aligned}
& \left(F_{x i}\right)_{\mathrm{int}}=\int_{V}\left(\sigma_{x} \frac{\partial N_{i}}{\partial x}+\sigma_{x y} \frac{\partial N_{i}}{\partial y}\right) d x d y \\
& \left(F_{y i}\right)_{\mathrm{int}}=\int_{V}\left(\sigma_{x y} \frac{\partial N_{i}}{\partial x}+\sigma_{y} \frac{\partial N_{i}}{\partial y}\right) d x d y
\end{aligned}
$$


Calculations of the internal and external forces at element level are illustrated in the case of the isoparametric four-noded quadrilateral element as shown in Appendix A.

The internal and external loads are summed for all elements connected to a node from the global internal and external force vectors $\left\{F_{\text {int }}\right\}$ and $\left\{F_{\text {ext }}\right\}$.

During excavation, both of these force vectors will change, and the differences between the two force vectors correspond to the excavation loads at the excavation boundaries. The changes in the internal forces are due to the removal of the element stresses of the excavated elements. For the deleted elements, the internal stresses $\{\sigma\}$ in Equation 3.2 are set to zero; thus, deleted elements no longer contribute to the internal forces.

The changes in the external forces are due to the removal of the nodal forces for the nodes within the excavation and to the reduction of the nodal forces in the nodes along the excavation boundaries. For the deleted elements, the body loads $\{b\}$ and the surface tractions on the boundary of the deleted elements $\left\{\sigma^{s}\right\}$ in Equation 3.3 are set to zero; thus, deleted elements no longer contribute to the external forces.

The difference $\left\{F_{\text {ext }}\right\}-\left\{F_{\text {int }}\right\}$ will cause deformations $\{\Delta u\}$, which are computed from the global force-displacement relation:

$$
[K]\{\Delta u\}=\left\{F_{\text {ext }}\right\}-\left\{F_{\text {int }}\right\}
$$

where $[K]=\int_{V}[B]^{T}[D][B] d V$ is the global stiffness matrix $([D]$ is referred to as either the constitutive or stress-strain matrix). The deformations $\{\Delta u\}$ are the deformations induced by the excavation.

One approach to apply the method of force residuals is illustrated in a flowchart in Figure 3.3.

Consistent nodal point forces due to the self-weight of each element are computed in Equation 3.3 using the following $\{b\}$-matrix:

$$
\{b\}=\left\{\begin{array}{l}
0 \\
\gamma
\end{array}\right\}
$$

where $\gamma$ is the unit weight of the soil. If the element is rectangular, the volume integral of $[N]^{T}\left\{\begin{array}{ll}0 & \gamma\end{array}\right\}^{T}$ in Equation 3.3 predicts $y$-direction loads at each node, each equal to one quarter of the total forces (i.e., the total weight) on the element. This is regardless of the orientation of the element with respect to the y-axis (Cook, Malkus, and Plesha 2002, p 114). 


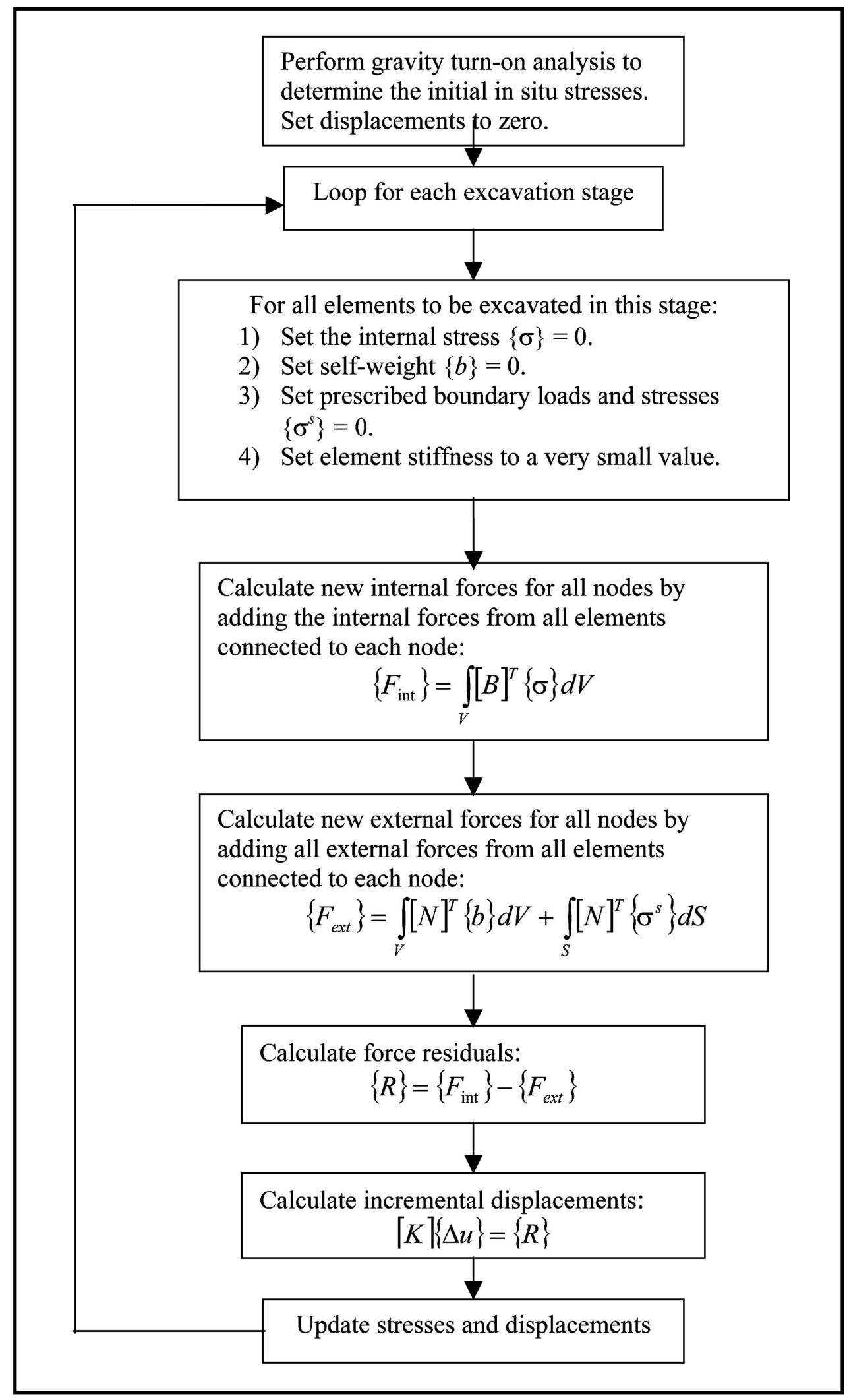

Figure 3.3. Flowchart for excavation modeling using the method of force residuals 


\subsection{Example Calculation}

The problem analyzed using the Clough and Duncan procedure in Section 2.2 will be reanalyzed to illustrate the use of the procedure described above. For convenience, the finite element mesh (Figure 2.9) is reproduced below as Figure 3.4.

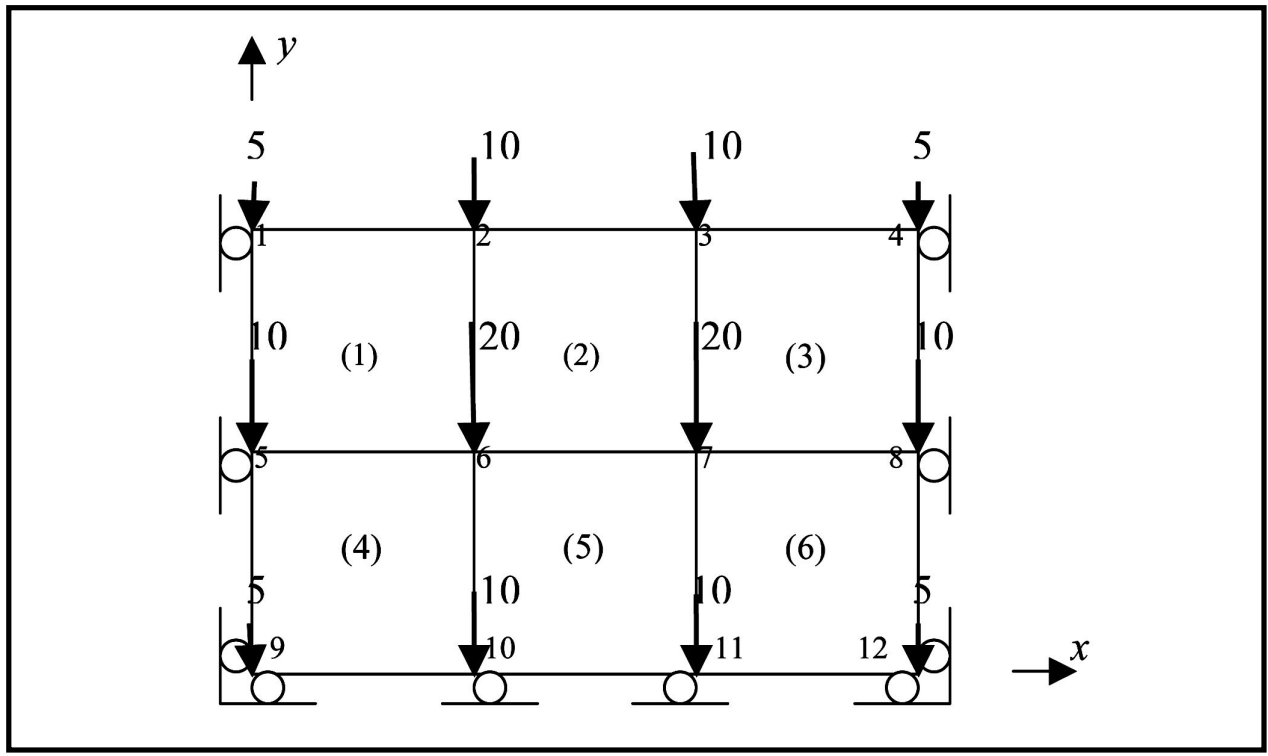

Figure 3.4. Nodal loads from self-weight (forces shown are in kilonewtons)

\section{Steps 1 and 2: Gravity turn-on analysis and results of analysis}

These steps are the same as those used in the Clough and Duncan procedure. At the end of this step, the nodal load vectors due to element self-weights are as shown in Figure 3.4.

\section{Step 2: Calculation of equivalent internal element forces from internal stresses}

These are the nodal forces that are equivalent to the internal stresses. The authors of this report will refer to them as the internal element forces. This step corresponds to the calculation of the equivalent element nodal forces $\left(F_{x i}\right)_{\text {int }}$ and $\left(F_{y i}\right)_{\text {int }}$ for each element using Equation 3.5 corresponding to the stresses $\sigma_{x}, \sigma_{y}$, and $\sigma_{x y}$ in the element. Recall that the element stresses due to the self-weight loads in Elements 1, 2, and 3 are $\sigma_{y}=10 \mathrm{kPa}$ and $\sigma_{x}=5 \mathrm{kPa}$, and the corresponding stresses for Elements 4, 5, and 6 are $\sigma_{y}=30 \mathrm{kPa}$ and $\sigma_{x}=15 \mathrm{kPa}$. For all elements, $\sigma_{x y}=0$. The calculations of element nodal forces are carried out for all the element nodes $i$ ( $=1$ to 4 for the four-noded constant stress element). 
In the case of constant stress elements this operation is trivial, as the element forces are simply based on force equilibrium. A constant stress distribution will yield an equal distribution of nodal forces among the nodes. This is shown in Figure 3.5 below in the calculation of the horizontal nodal forces at the two nodes on the right side of Element 2 . The horizontal nodal forces are simply what are needed to balance the horizontal stress $\sigma_{x}=5 \mathrm{kPa}$ in the elements based on the free-body diagram shown.

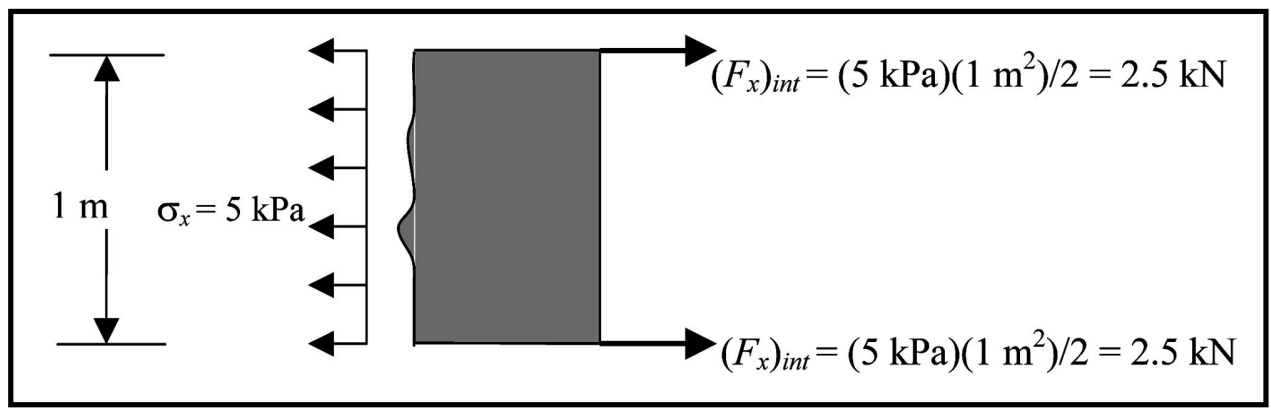

Figure 3.5. Calculation of reversed internal element nodal forces based on force equilibrium

The calculation of the internal element forces using Equations 3.2 and 3.5 is also illustrated in the Appendix A. For a general loading condition, the fournoded isoparametric element discussed in Appendix A does not in general have a constant strain nor constant stresses throughout the element. It can be shown that for the loading condition (i.e., gravity turn-on) applied to the Figure 3.4 (homogenous, elastic) regular mesh, the four-noded isoparametric element has constant stress throughout each element. For the isoparametric element, Equation A.22 results in the equivalent nodal point forces given in Figure 3.5. Appendix A discusses the different methodologies for computing the equivalent internal forces from the stress field within the element. The horizontal forces in all the nodes of the element are shown to be equal to $2.5 \mathrm{kN}$, as is obtained in Figure 3.5 and also from Equation A.22 with a uniform stress field. The complete element forces corresponding to the element stresses of $\sigma_{y}=10 \mathrm{kPa}$ and $\sigma_{x}=5 \mathrm{kPa}$ in Elements 1, 2, and 3, and $\sigma_{y}=30 \mathrm{kPa}$ and $\sigma_{x}=15 \mathrm{kPa}$ in Elements 4, 5, and 6 are shown in Figure 3.6.

\section{Step 3: Calculation of internal nodal forces from equivalent internal element forces}

In this step, the internal nodal forces from all the element stresses are obtained. This is done by summing the internal element forces from all the elements connected to each node after the excavation. The results from this step are shown in Figure 3.7. Note that only the forces along the excavation boundaries need to be calculated, as shown in Figure 3.7. It can be demonstrated that the summation of internal and external forces in the nodes that do not coincide with the excavation boundaries will be zero, and these nodes will be in equilibrium. The element internal forces are shown for both the excavated element (Element 2) and the remaining soil. The internal forces for Element 2 are the 


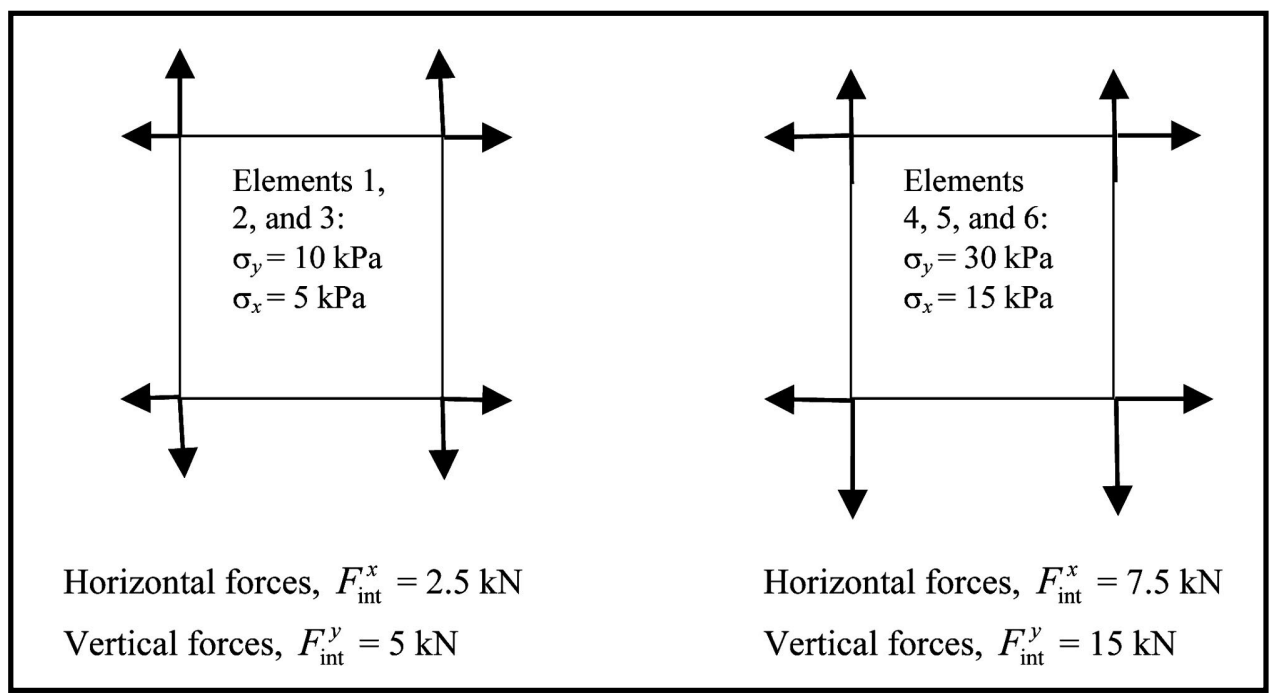

Figure 3.6. Reversed internal nodal forces from element stresses

same as those in Figure 3.6. For the remaining soil, the nodal forces are calculated from element force contributions from all elements connected to a node. For example, consider the upward vertical force of $25 \mathrm{kN}$ for node 6 in Figure $3.7 \mathrm{~b}$. The elements connected to node 6 after the excavation are 1, 4, and 5 . The upward vertical force of $25 \mathrm{kN}$ for node 6 is obtained from summation of the downward $5 \mathrm{kN}$ from Element 1, the upward force of $15 \mathrm{kN}$ for Element 4, and another upward force of $15 \mathrm{kN}$ for Element 5. Similar operations are carried out for all the nodes for both horizontal and vertical forces.

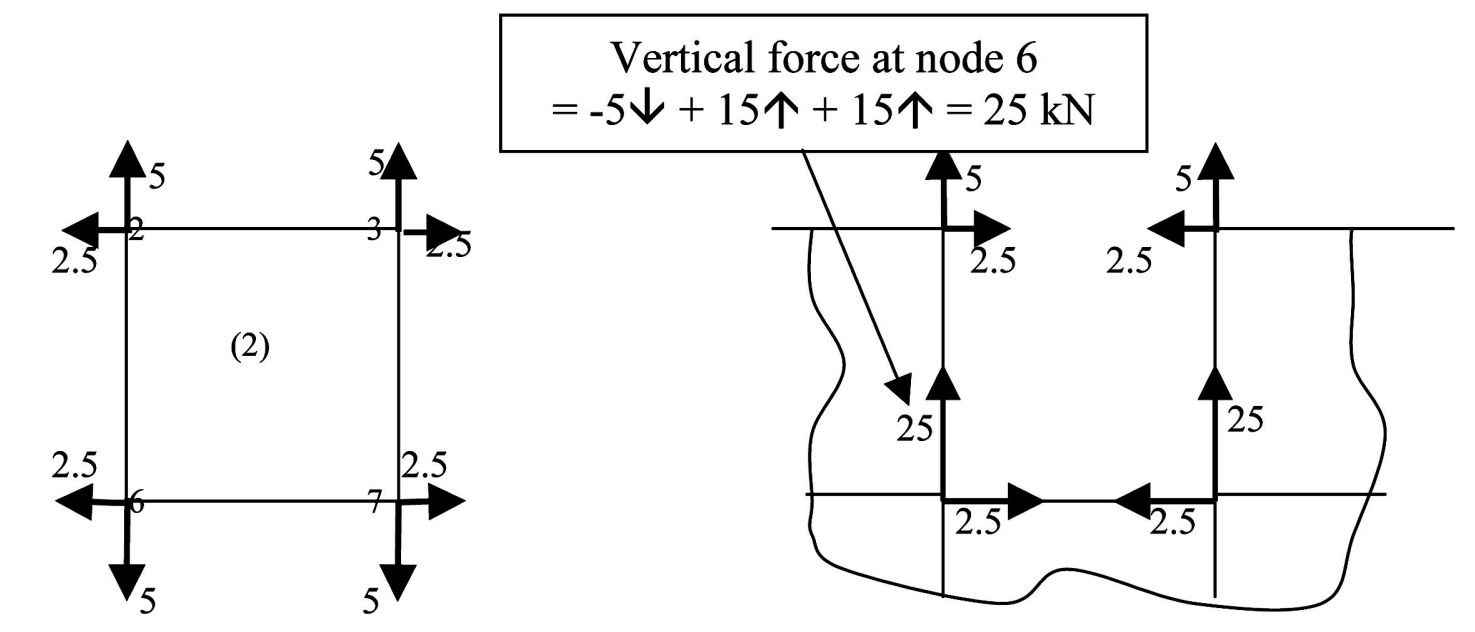

\section{a. Forces on the excavated element}

b. Forces acting on the remaining soil

Figure 3.7. Reversed total internal element forces along the excavation boundaries (forces are in kilonewtons) 


\section{Step 4: Calculation of external loads}

The external nodal loads due to the self-weight on the excavated element and the remaining soil after the excavation are calculated similarly to the loads in Figure 3.4. The new external nodal loads after excavation are shown in Figure 3.8. For the excavated Element 2, the external loads are simply equal to one quarter of the weight of the element $(20 \mathrm{kN} / 4=5 \mathrm{kN})$ equally distributed among the four nodes. For the remaining soil, the main difference from Figure 3.4 is that Element 2 no longer contributes to the external loads. Thus, the external loads at nodes 2, 3, 6, and 7 will have to be modified to account for the deletion of Element 2. The external loads in the other nodes not in the excavation boundary will be unchanged. For example, the nodal force in node 2, which was $10 \mathrm{kN}$ in Figure 3.4, is now only $5 \mathrm{kN}$. This force comes from one quarter of the weight of Element 1, the only element left connected to node 2 after the excavation.
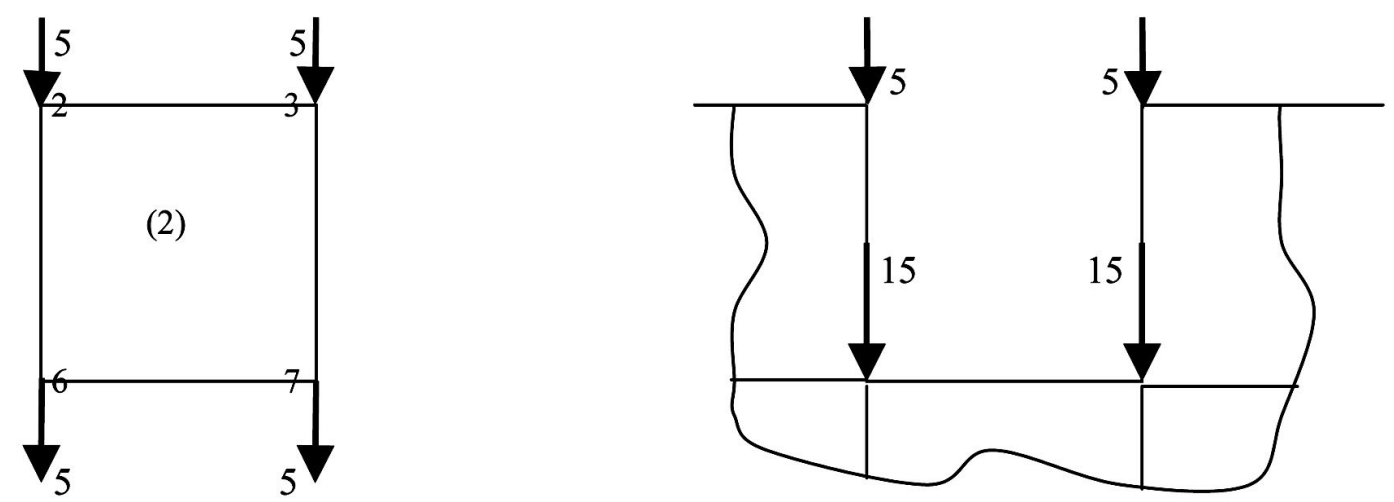

a. Loads on the excavated element

b. Loads acting on the remaining soil

Figure 3.8. Total external nodal loads along the excavation boundaries (forces are in kilonewtons)

\section{Step 5: Calculate unbalanced excavation forces}

After the gravity turn-on analysis, the internal forces and external forces are equal and the system is in equilibrium. However, the excavation of Element 2 will create unbalanced forces from the differences in the new external and internal forces. Adding the reversed internal forces (Figure 3.7) to the corresponding external loads from the self-weights (Figure 3.8) gives the net unbalanced excavation forces along the excavation boundaries (Figure 3.9). These are the forces that will cause displacements due to excavation.

Note the correspondence between the excavation forces on the excavated element and the remaining soil. The forces are of equal magnitudes but are opposite in sign. This means that excavation forces can be calculated using either the excavated element(s) or the remaining soil, and the results will be the same. 


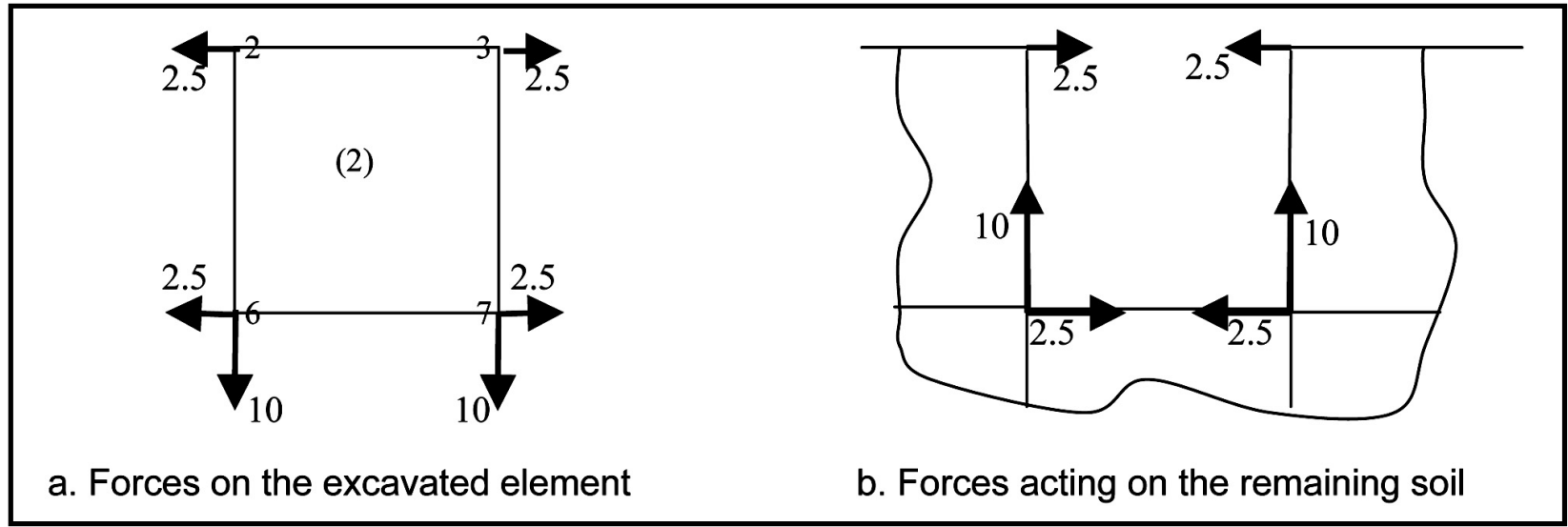

Figure 3.9. Excavation forces along the excavation boundaries (forces are in kilonewtons)

Note also the differences between the horizontal excavation forces shown in Figure $3.9 \mathrm{~b}$ and those obtained from the Clough and Duncan procedure in Figure 2.10. The results of the procedure based on minimization of residual forces are discussed further in Section 4.2. 


\section{Assessment of Numerical Models for Excavation}

This chapter provides a detailed comparison of the numerical procedures for simulating excavation presented in Chapter 3 . The different numerical procedures are evaluated in terms of uniqueness of the solution, satisfaction of force equilibrium, and convergence of the solution. Comparisons are also made in terms of practical issues, such as ease of implementation in SOILSTRUCT-ALPHA.

\subsection{Comparisons of Models}

Four types of numerical models for simulating excavation were identified from the review performed in Chapter 3, and the main features of these numerical models were summarized in Table 3.1. Based on this review, the advantages and disadvantages of the four methods were also identified. A brief summary of the major advantages and disadvantages of the methods is given in Table 4.1.

\begin{tabular}{|c|c|}
\hline \multicolumn{2}{|c|}{$\begin{array}{l}\text { Table } 4.1 \\
\text { Advantages and Disadvantages of Different Types of Numerical } \\
\text { Procedures for Simulating Excavation Processes }\end{array}$} \\
\hline $\begin{array}{l}\text { Numerical } \\
\text { Procedure }\end{array}$ & Advantages/Disadvantages \\
\hline $\begin{array}{l}\text { Excavation forces } \\
\text { from stresses along } \\
\text { the excavation } \\
\text { boundary }\end{array}$ & $\begin{array}{l}\text { Attempts to account for stress concentrations at sharp excavation corners } \\
\text { and between elements of different sizes. } \\
\text { Does not guarantee force equilibrium between internal element forces and } \\
\text { external loads. } \\
\text { Results are dependent on the excavation sequence, and do not guarantee } \\
\text { a unique solution for elastic problems. }\end{array}$ \\
\hline $\begin{array}{l}\text { Accumulation of } \\
\text { excavation forces }\end{array}$ & $\begin{array}{l}\text { Solution is independent of the number of excavation stages for elastic } \\
\text { problems. } \\
\text { Difficult to program, particularly for complicated excavation sequences and } \\
\text { geometries. } \\
\text { Requires large computer memory to store loads from previous excavation } \\
\text { sequences. }\end{array}$ \\
\hline $\begin{array}{l}\text { Hybrid finite element } \\
\text { procedure }\end{array}$ & $\begin{array}{l}\text { Solution is independent of the number of excavation stages for elastic } \\
\text { problems. } \\
\text { Uses nonstandard element formulations. } \\
\text { Difficult to program and requires more computer resources. }\end{array}$ \\
\hline $\begin{array}{l}\text { Excavation forces } \\
\text { from force residuals }\end{array}$ & $\begin{array}{l}\text { Consistent formulation, guaranteeing force equilibrium between internal } \\
\text { element forces and external loads. } \\
\text { Results are independent of the excavation sequence for elastic materials. } \\
\text { Uses standard finite element calculations (e.g., use of the }[B] \text {-matrix and } \\
\text { Gaussian quadrature to calculate internal elements forces). } \\
\text { Can be extended to nonlinear problems in a consistent manner. }\end{array}$ \\
\hline
\end{tabular}


As mentioned in Chapter 3, although the Clough and Duncan (1969) approach was one of the earliest procedures to be widely used to analyze excavation problems, Christian and Wong (1973) later recognized potential problems with this approach. One difficulty of using the Clough and Duncan procedure is that the results of the modeling are strongly dependent on the number of steps used to simulate the excavation. The method they suggested to minimize the dependency of results on the number of excavation steps was to model the excavation in as few steps as possible. However, the suggested method goes against the philosophy in finite element analysis of achieving a converging solution as the problem domain is refined (both in size and the load increment). It also poses a difficulty for nonlinear problems where the solution calls for the application of small load increments at a time.

Christian and Wong (1973) believed that the discrepancies in the results were due to the inability of finite elements to model high stress concentrations at the toe of the excavation. However, even with an improved method to extrapolate stresses along the excavation boundaries using a fifth-order polynomial (in comparison to the bilinear interpolation used in the Clough and Duncan procedure), the results were still dependent on the number of excavation steps used. In fact, the difficulties associated with the Clough and Duncan procedure can be attributed to the attempt at arriving at an accurate representation of the stress concentrations caused by excavation. It was argued, quite reasonably, that an accurate representation of the stresses along the excavation boundaries is essential in obtaining an accurate solution of the excavation process. Unfortunately, their method can produce boundary stresses that are not in equilibrium with the element stresses and self-weights of the excavated elements.

Although three other methods of excavation modeling were identified, two of these methods have fallen out of use in recent years. The method of Chandrasekaran and King (1974) is based on the accumulation of loads from previous stages of excavation and requires the excavated region to be divided into different stages. The loads at the nodes corresponding to the boundaries dividing the excavation stages must be recalculated and stored at every stage of the excavation. This method is cumbersome, difficult to program (particularly for complicated excavation sequences and geometries), and uses a lot of computer memory.

Another method that has not found wide application is that developed by Desai and Sargand (1984). Again, this method is an outcome of the belief that stresses along the excavation boundary must be accurately represented to model excavation accurately. To accomplish this, Desai and Sargand used a hybrid finite element formulation where stresses, in addition to the usual displacements, are treated as nodal unknowns. The result of this formulation, however, is an increase in complication of the finite element solution. Hybrid finite element formulations are more difficult to program and require more computational resources due to the increased number of nodal unknowns. Moreover, it is not clear how the Desai and Sargand procedure can be extended to account for body loads from element self-weights.

Of the four methods reviewed, it appears that the most rigorous and analytically robust method is the one based on balancing residual forces from the differences between the internal and external loads in a loaded body. This method is 
now the most widely used and accepted procedure for excavation modeling (e.g., Ghaboussi and Pecknold 1984; Borja, Lee, and Seed 1989; Langer and Stockmann 1985; Morrison and Duncan 1996). The objective of this method is first and foremost to balance any unbalanced loads created by the excavation. The method is based on the recognition that, prior to excavation, a body of soil is in a state of equilibrium with the internal stresses (stresses in the elements) just balancing the external loads (from body weights and external surface tractions). Excavation disturbs this equilibrium when stressed elements are taken out (changing the internal loads) and the loads from the self-weights are reduced by the excavation (changing the external loads). By ensuring that force equilibrium is satisfied at every stage of calculation, the method based on minimization of residual forces guarantees a unique solution for any number of excavation stages for an elastic material. This was proven formally by Ghaboussi and Pecknold (1984).

Aside from rigorously satisfying force equilibrium, the method based on force residuals has other distinct advantages over the other methods. One major advantage is that the method requires quantities that can be directly obtained from standard finite element calculations. This is particularly true for the calculation of the forces from internal stresses based on Equation 3.2. Calculation of element stresses is routinely done in all finite element codes. Also, the $[B]-$ matrix is already available from the calculation of the stiffness matrix, and it can be stored for later use or recalculated when needed in the evaluation of the internal nodal forces. Similarly for the recalculation of the external loads, the new external loads may either be prescribed manually or calculated from Equation 3.3. The numerical integration required in Equations 3.2 and 3.5 can be done using routines for generating element matrices. In fact, most of the calculations are standard and can be done at the element level, and later assembled following standard finite element assembly procedures.

Another major advantage is that the method based on balancing of force residuals lends itself naturally to nonlinear problems, as shown by Ghaboussi and Pecknold (1984) and Borja, Lee, and Seed (1989). In the case of nonlinear problems, the force residuals are due to the loads from differences in stresses between the correct and the current solution (the so-called initial stresses in nonlinear analysis). In fact, in the formulations of Ghaboussi and Pecknold (1984) and Borja, Lee, and Seed (1989), changes in the problem geometry from excavation and addition of soil mass (e.g., from embankments) are simply treated as part of the nonlinear problem. In this manner, excavation modeling can take advantage of available methods to solve nonlinear problems.

\subsection{Performance of Numerical Procedures for Excavation Modeling}

Based on the above comparisons, it is apparent that the most viable and realistic alternative to the procedure based on interpolation of stresses along the excavation boundary, in particular the Clough and Duncan procedure used in SOILSTRUCT-ALPHA, is the one based on the minimization of force residuals. The other methods based on accumulation of excavation loads and the use of 
hybrid finite element formulation have not gained much acceptance, and are computationally more difficult to implement and use. As mentioned, the method based on achieving force equilibrium between internal and external forces is currently the most accepted and widely used method for modeling excavation. In the following sections, further comparisons are made between the procedure based on interpolation of boundary stresses and the method based on force residuals. As the Clough and Duncan procedure is used to interpolate the stresses along the excavation boundary in SOILSTRUCT, the comparisons here will be made using the Clough and Duncan procedure. The comparisons and performance analyses are made to show whether and how the two methods meet three fundamental requirements: (a) the solution must be unique for path-independent linear problems, (b) force equilibrium must be satisfied at every stage of the calculation, and (c) the solution must be convergent with refinement of the finite element discretization.

\subsubsection{Uniqueness of solution for homogenous elastic regime}

As discussed in Chapter 3, the uniqueness of solution for excavation in homogenous elastic media has been demonstrated by Clough and Duncan (1969) for one-dimensional (1-D) excavation and fill placement, and more formally by Ishihara (1970) for general 2- and 3-D excavation. The simple problem shown in Figure 4.1a involving excavation in an elastic soil will be used to illustrate whether the methods based on force residuals and the Clough and Duncan procedure yield unique solutions for elastic materials independent of the number of excavation steps. The problem consists of 16 four-noded isoparametric quadrilateral finite elements with the same elastic properties for all elements. The soil has a unit weight of 120 pcf, a Young's modulus of $E=1 \cdot 10^{6} \mathrm{psf}$ and Poisson's ratio of $v=0.3$. Each element is 10 by $10 \mathrm{ft}(3$ by $3 \mathrm{~m})$ in size. The objective is to simulate the displacements of the soil after Elements 1, 2, 5, and 6 are deleted from the problem domain. Roller boundaries are used on the sides and the base of the model to prevent displacements normal to the boundaries but allow displacements parallel to the boundaries. The first step in the modeling is the gravity turn-on analysis to determine the initial stresses from the element self-weights. This is followed by the deletion of the elements in the excavated region.

Uniqueness of solution will be investigated first in the case of the method of force residuals. Figure $4.1 \mathrm{~b}$ shows the deformed mesh (with displacements exaggerated 10×) after the excavation is made in one stage (i.e., Elements 1, 2, 5, and 6 were taken out at the same time). The most prominent effect of the excavation is the heaving at the base of the excavation, with the maximum upward movement of the base equal to $0.401 \mathrm{ft}(0.12 \mathrm{~m})$. There are only minor lateral movements along the vertical edge of excavation.

Figures $4.2 \mathrm{a}$ and $\mathrm{b}$ show the results for the case of a two-step excavation. The nodal forces shown in these two figures are discussed below. In the first stage of the excavation, only the first layer (consisting of Elements 1 and 5) was deleted. The deformed mesh after this first stage of excavation is shown in Figure 4.2a. In the second stage, Elements 2 and 6 (corresponding to the second row) are deleted. The deformed mesh after the second stage excavation is shown in 


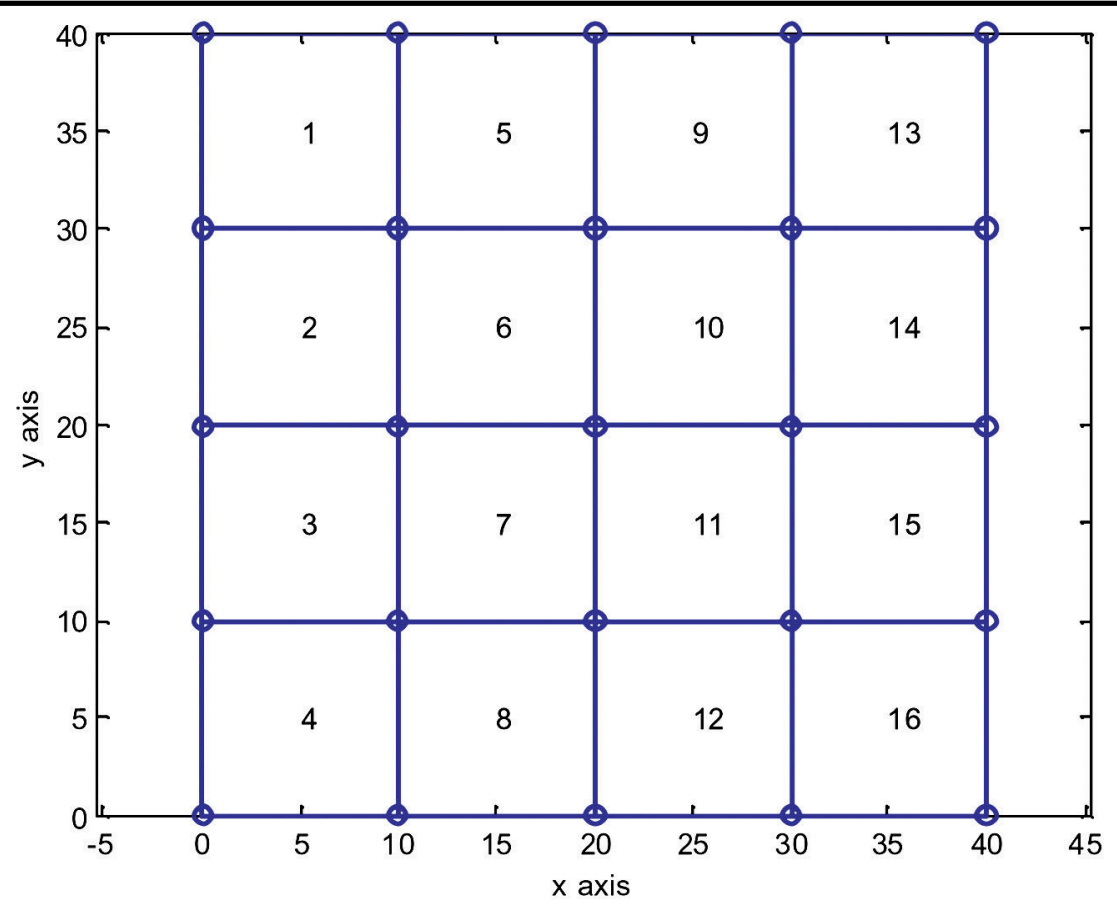

a. Finite element mesh (dimensions in feet)

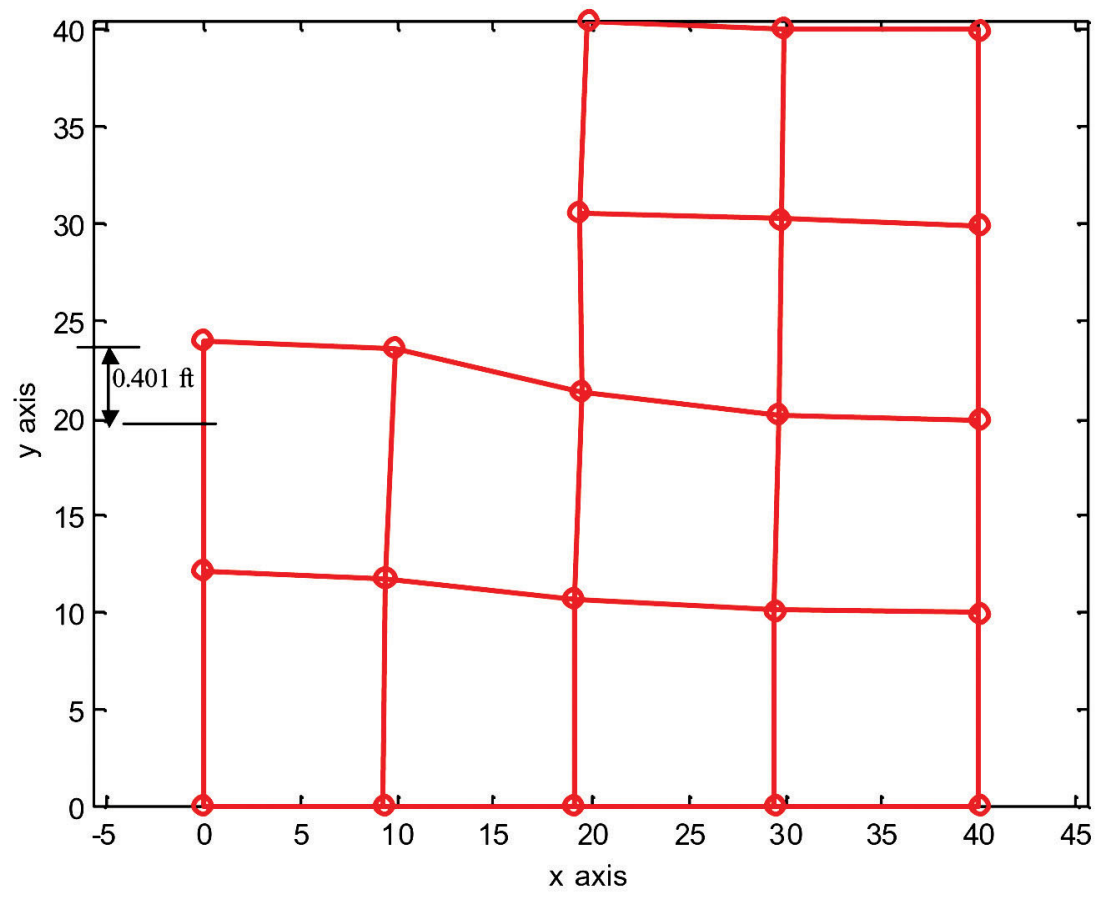

b. Deformed mesh after a single-stage excavation (deformations magnified 10x)

Figure 4.1. Method of force residuals using four-nodal isoparametric quadrilateral elements-single-stage excavation 


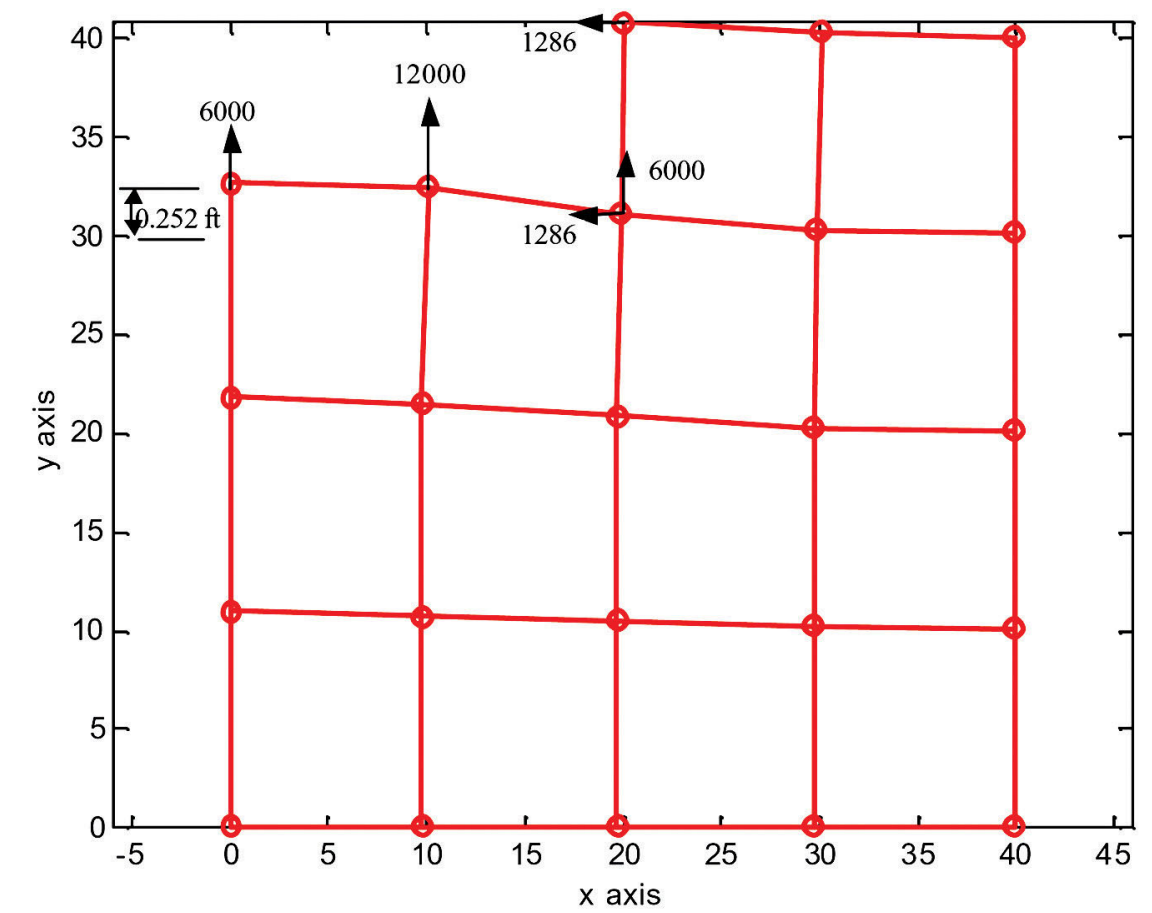

a. Deformed mesh after the first stage of a two-stage excavation

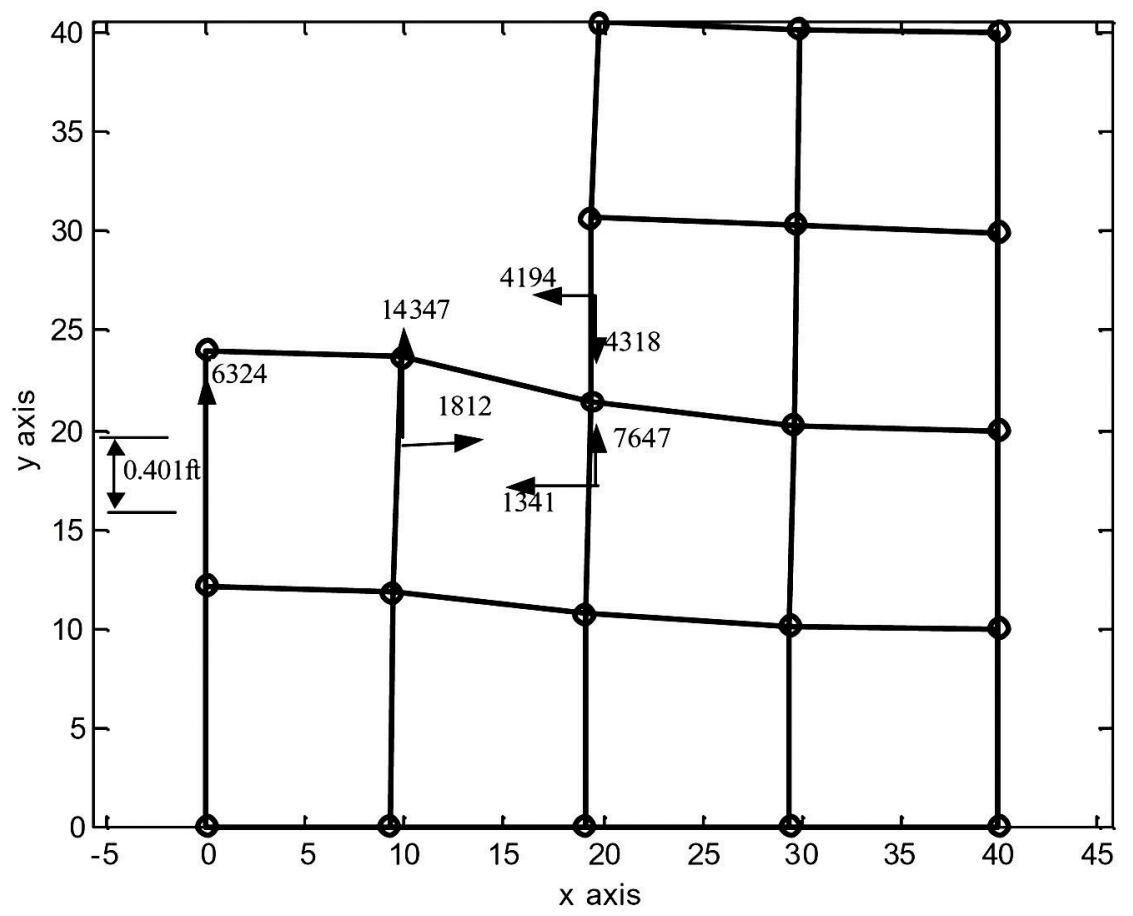

b. Deformed mesh after the second stage of a two-stage excavation

Figure 4.2. Method of force residuals using four-nodal isoparametric quadrilateral elements-two-stage excavation (deformations magnified 10x; nodal forces given in pounds) 
Figure $4.2 \mathrm{~b}$. The maximum heave at the base of the excavation is also $0.401 \mathrm{ft}$. Comparison of Figures $4.1 \mathrm{~b}$ and $4.2 \mathrm{~b}$ shows that the two figures are identical, demonstrating that the results of one- and two-stage excavation are identical for this case.

To illustrate further the uniqueness of excavation solutions for elastic materials using the method of force residuals, the same problem shown in Figure 4.1a is reanalyzed using higher order eight-noded isoparametric quadrilateral elements (Figure 4.3a). Due to the higher order of the element used, the mesh shown in Figure 4.3a has twice as many nodes as in Figure 4.1a. The same properties and dimensions are used as those in Figure 4.1. The results of the one- and two-stage excavation are shown in the deformed meshes with exaggerated deformations in Figure $4.3 \mathrm{~b}$ and 4.4, respectively. Again, identical results are obtained from the single- and the two-stage excavations. The maximum heave at the base of the excavation is $0.399 \mathrm{ft}$ for both Figures $4.3 \mathrm{~b}$ and $4.4 \mathrm{~b}$, which is only slightly smaller than the maximum heave of $0.401 \mathrm{ft}$ from the analysis using four-noded elements.

The same problem shown in Figure 4.4 is now analyzed using the method based on the Clough and Duncan interpolation of stresses along the excavation boundary. The result of the one-stage simulation is shown in a deformed mesh in Figure 4.5a. The maximum heave at the base of the excavation is equal to $0.406 \mathrm{ft}$, which is only slightly higher than the corresponding value of $0.401 \mathrm{ft}$ for the method of force residuals. A comparison of this result with that obtained from the method of force residuals is shown in Figure 4.5b. As can be seen, there is very little difference in the results from the two methods, showing that the onestage Clough and Duncan procedure can yield comparable results to the method of force residuals, at least for the simple problem analyzed.

The results of the two-stage excavation using the Clough and Duncan procedure are shown in Figure 4.6. The deformed mesh at the end of the first stage excavation is shown in Figure 4.6a, and for the second stage in Figure 4.6b. (The nodal forces shown in Figures 4.6a and 4.6b are discussed below.) The maximum heave at the base of the excavation is about $0.419 \mathrm{ft}$, which is slightly larger than that for the single-stage excavation. A comparison of the deformed mesh at the end of the complete excavation from the single- and two-stage excavation using the Clough and Duncan procedure is shown in Figure 4.7. As can be seen, the results are different with the two-stage excavation, showing more heave at the base of the excavation and at the top of the vertical edge of the excavation than the one-stage excavation. This result is counter to the requirement that the results be independent of the number of excavation stages for linear elastic materials.

It is expected that differences between multistage excavation and single-stage excavation will increase with increasing number of excavation stages in the Clough and Duncan procedure. This is due to the accumulative nature of the error in the magnitude and distribution of excavation forces in their procedure (Desai and Sargand 1984). One approach to reduce inaccuracies in the Clough and Duncan procedure is to perform as few excavation steps as possible, and preferably use only a single stage of excavation. The results given above show that, at least for simple geometries, the single-stage excavation approach can yield similar results to those obtained from the method of force residuals. Christian and 


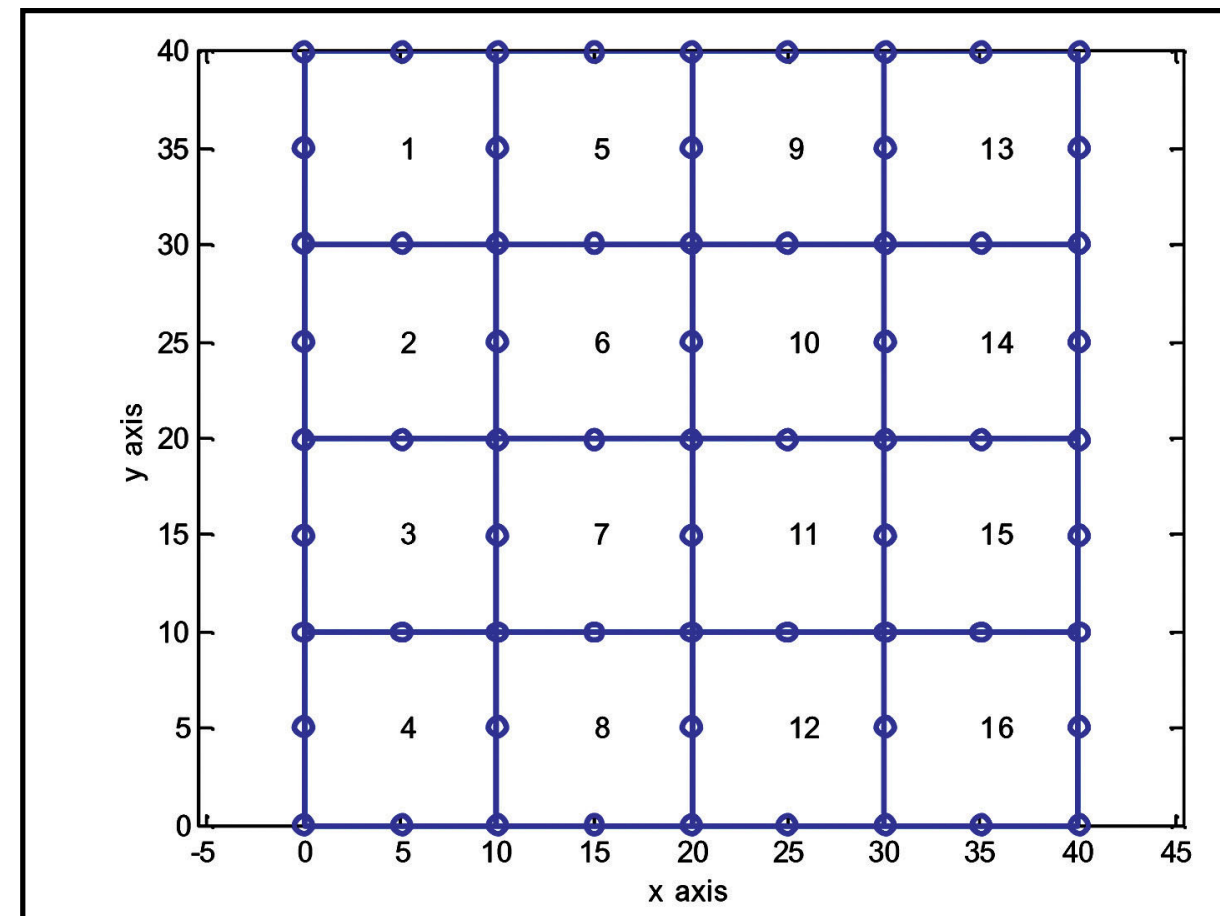

a. Finite element mesh (dimensions in feet)

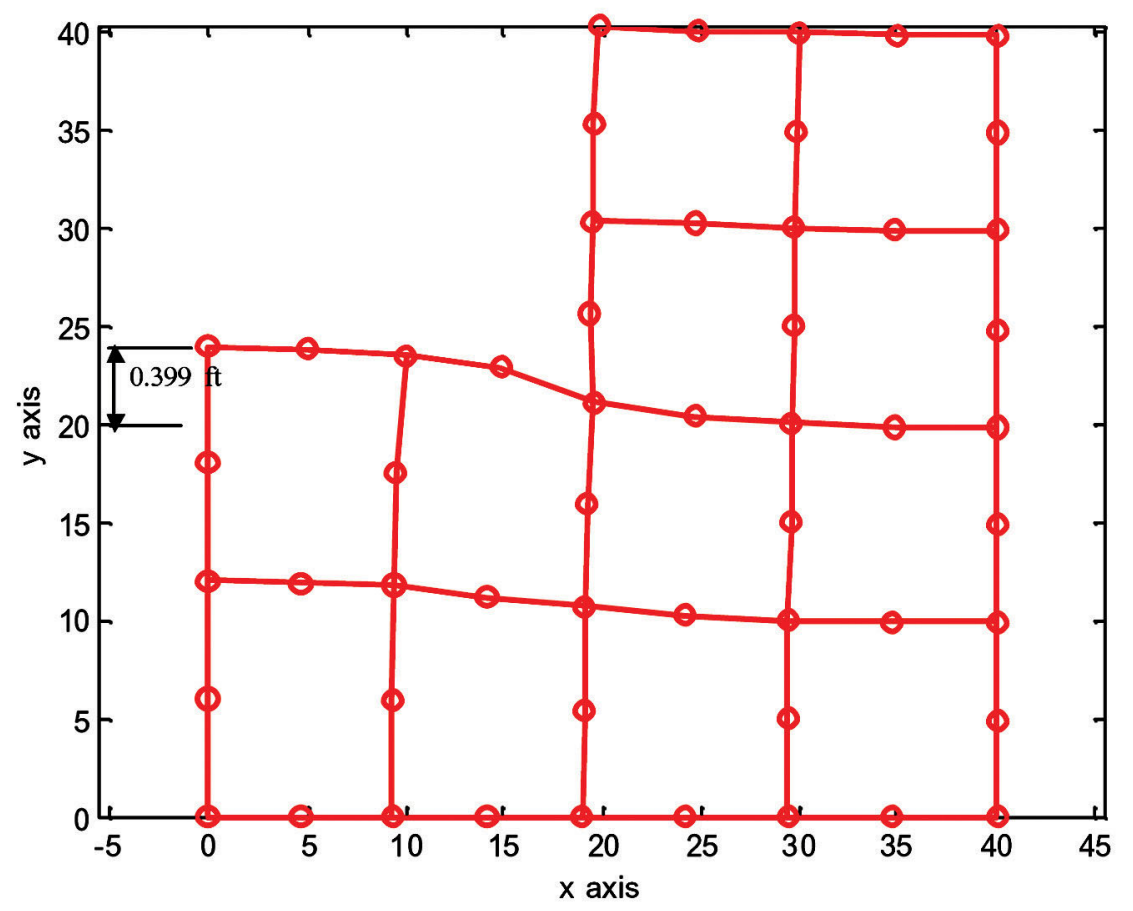

b. Deformed mesh after a single-stage excavation (deformations magnified 10x)

Figure 4.3. Method of force residuals using eight-nodal isoparametric quadrilateral elements-single-stage excavation 


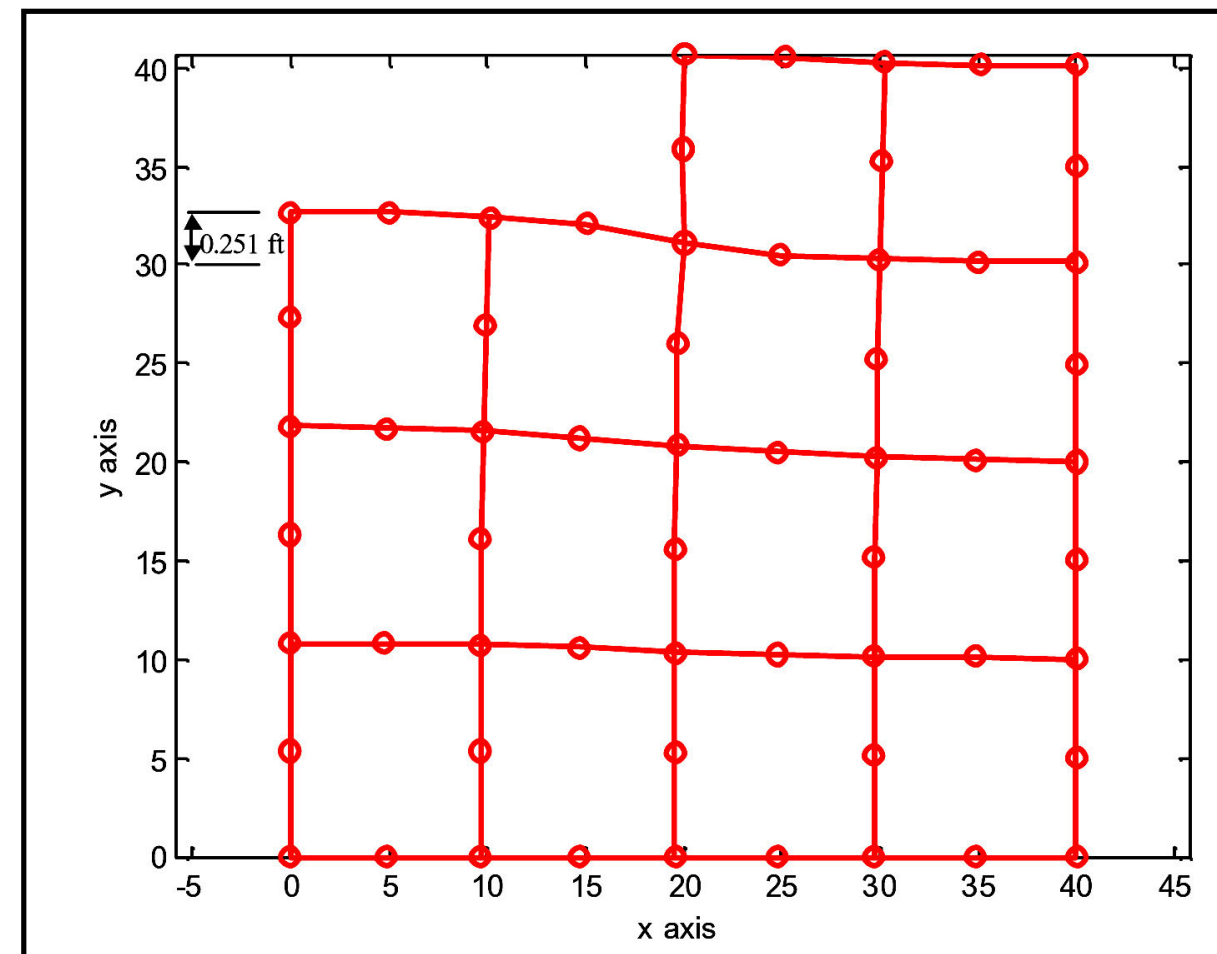

a. Deformed mesh after the first stage of a two-stage excavation

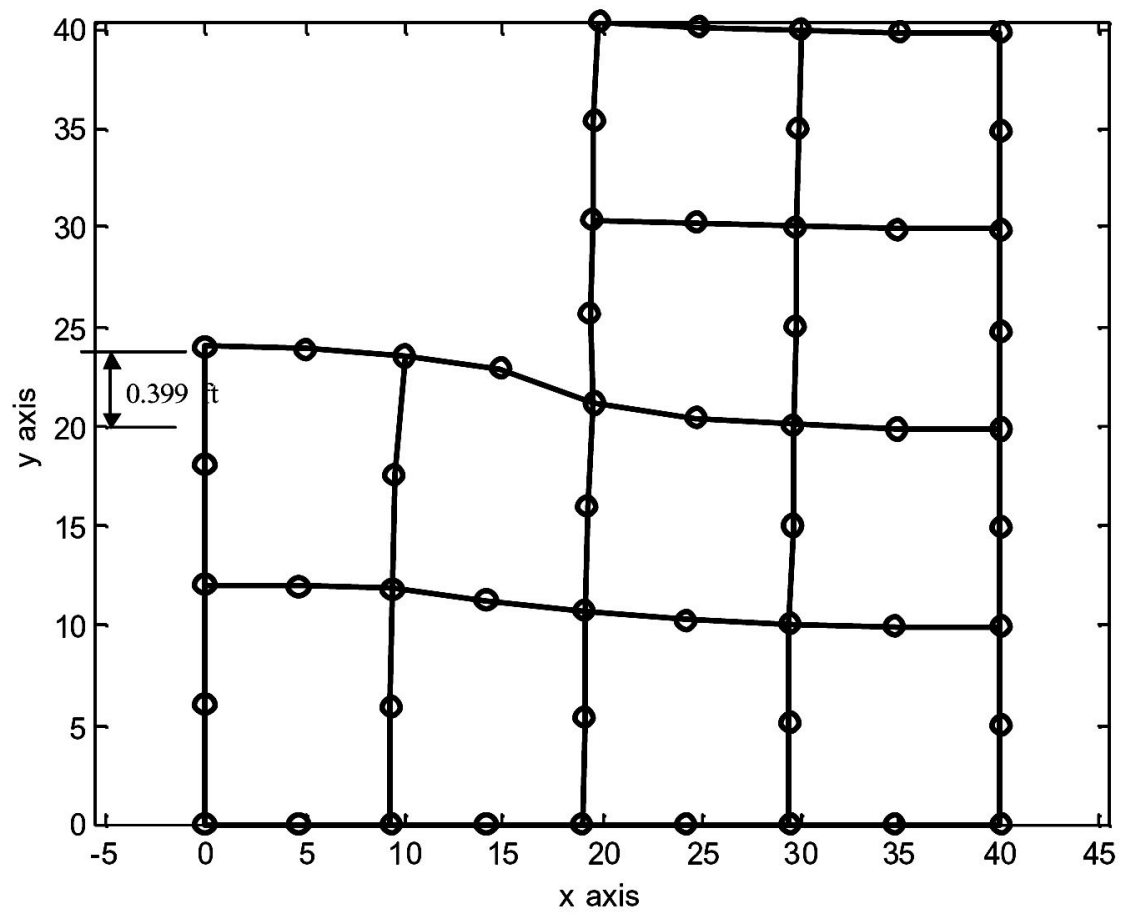

b. Deformed mesh after the second stage of a two-stage excavation

Figure 4.4. Method of force residuals using eight-nodal isoparametric quadrilateral elements-two-stage excavation (deformations magnified 10x) 


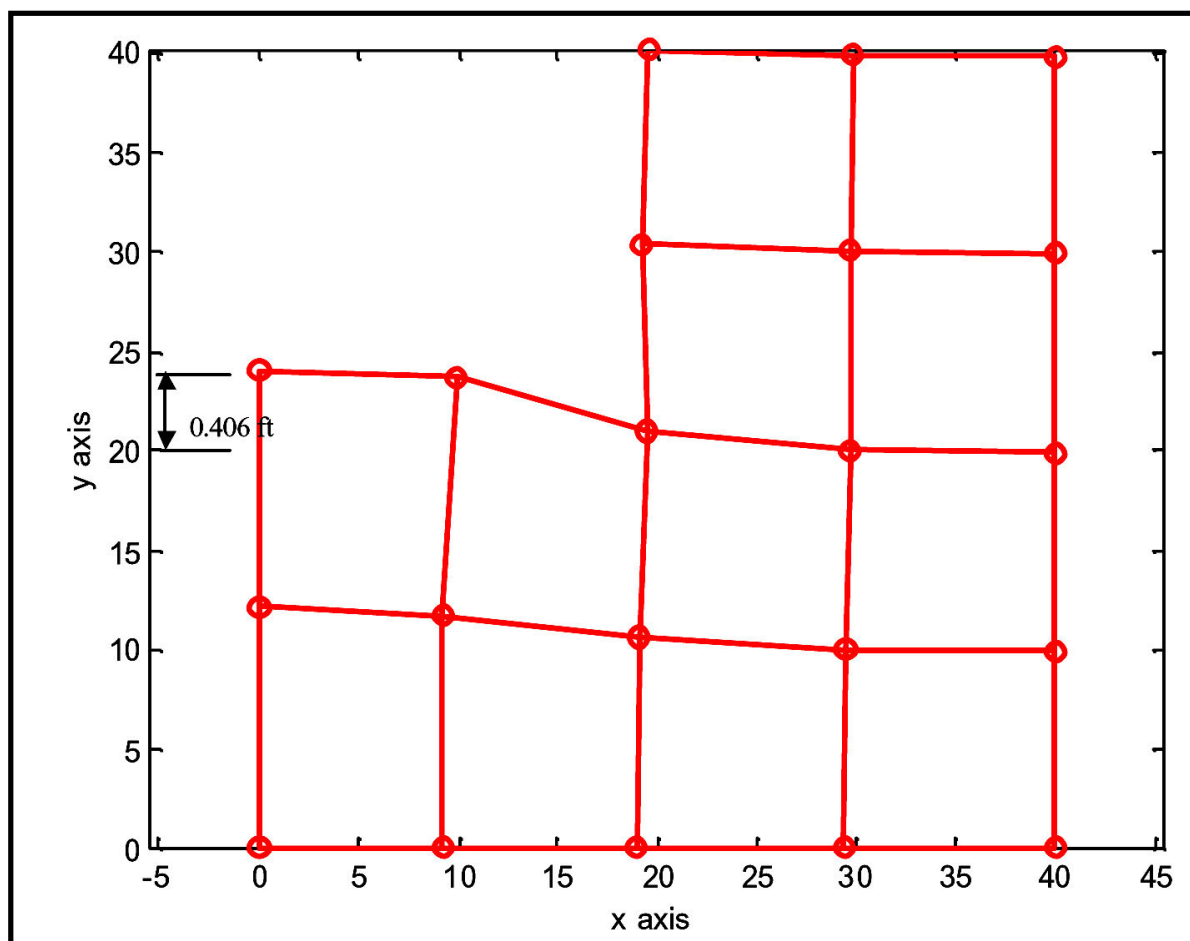

a. Deformed mesh after single-stage excavation (Clough and Duncan procedure)

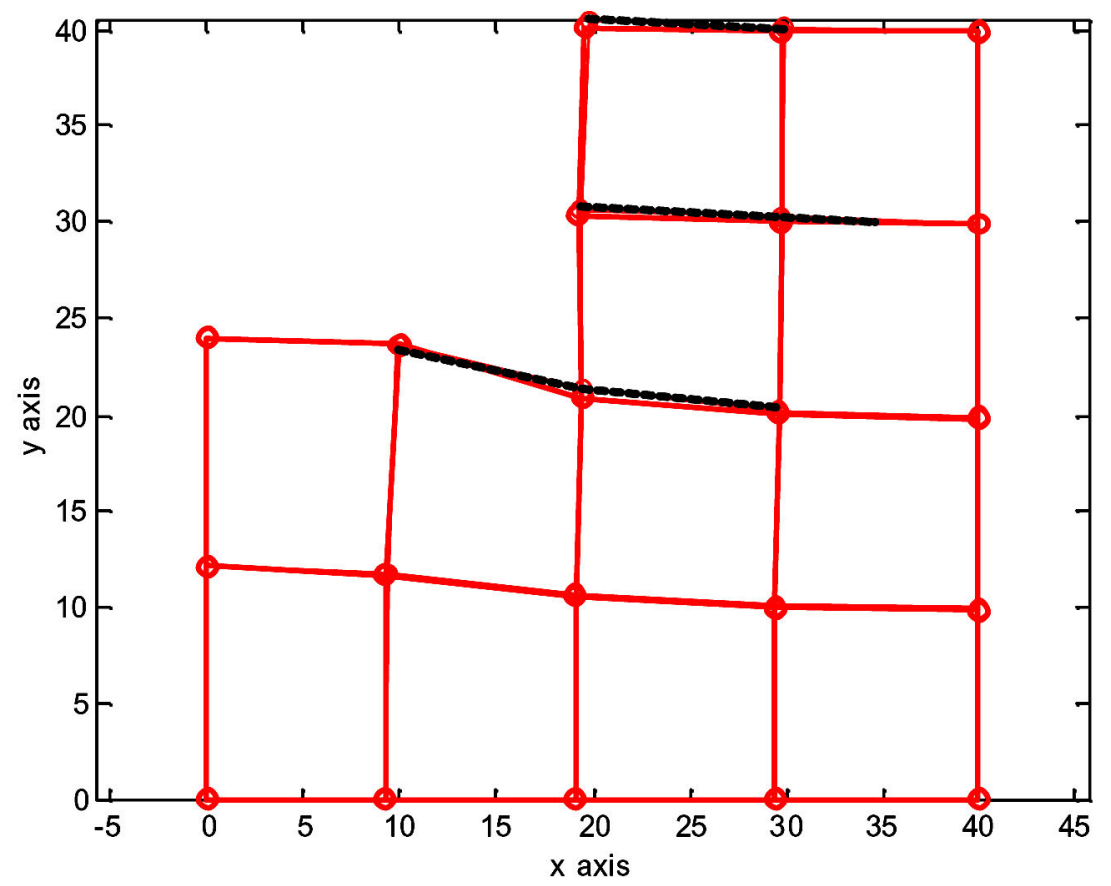

b. Clough and Duncan procedure (dotted lines) and Method of Force Residuals (solid lines)

Figure 4.5. Comparison the results of a single-stage excavation using the Clough and Duncan procedure and the Method of Force Residuals 


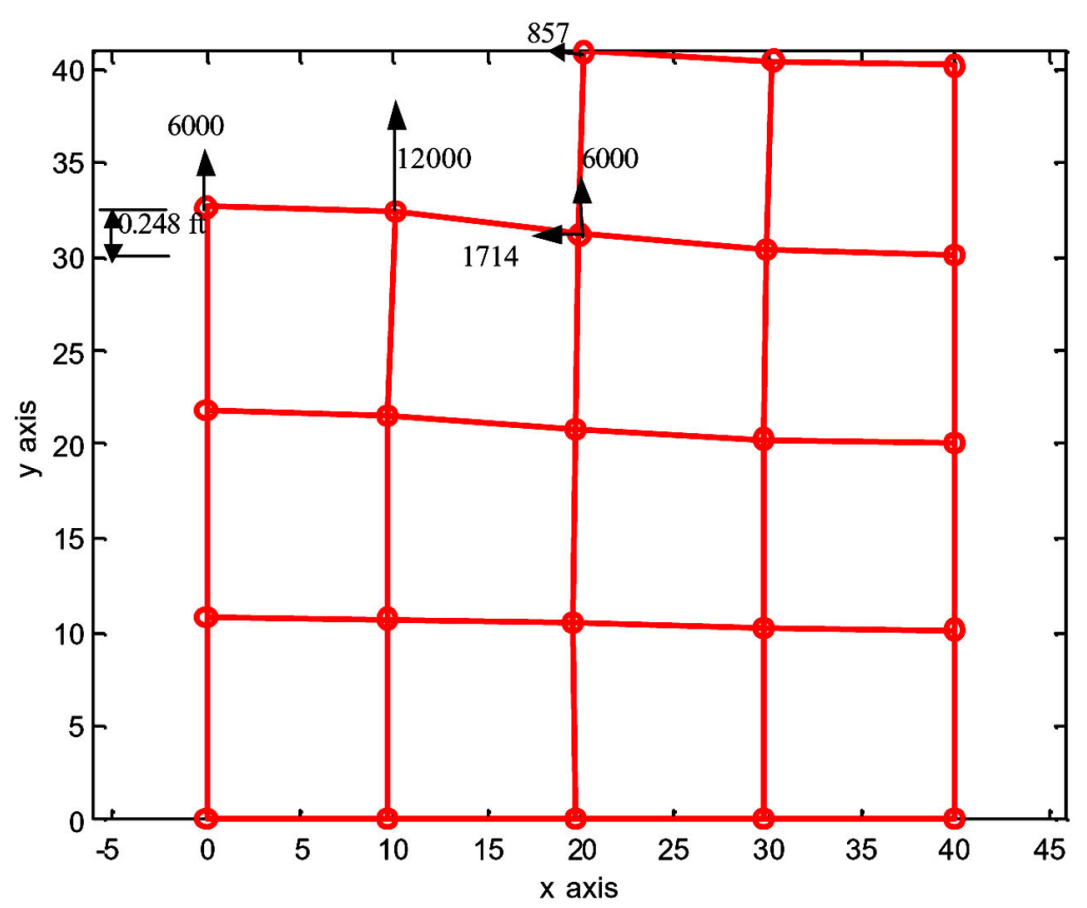

a. Deformed mesh after the first stage of a two-stage excavation

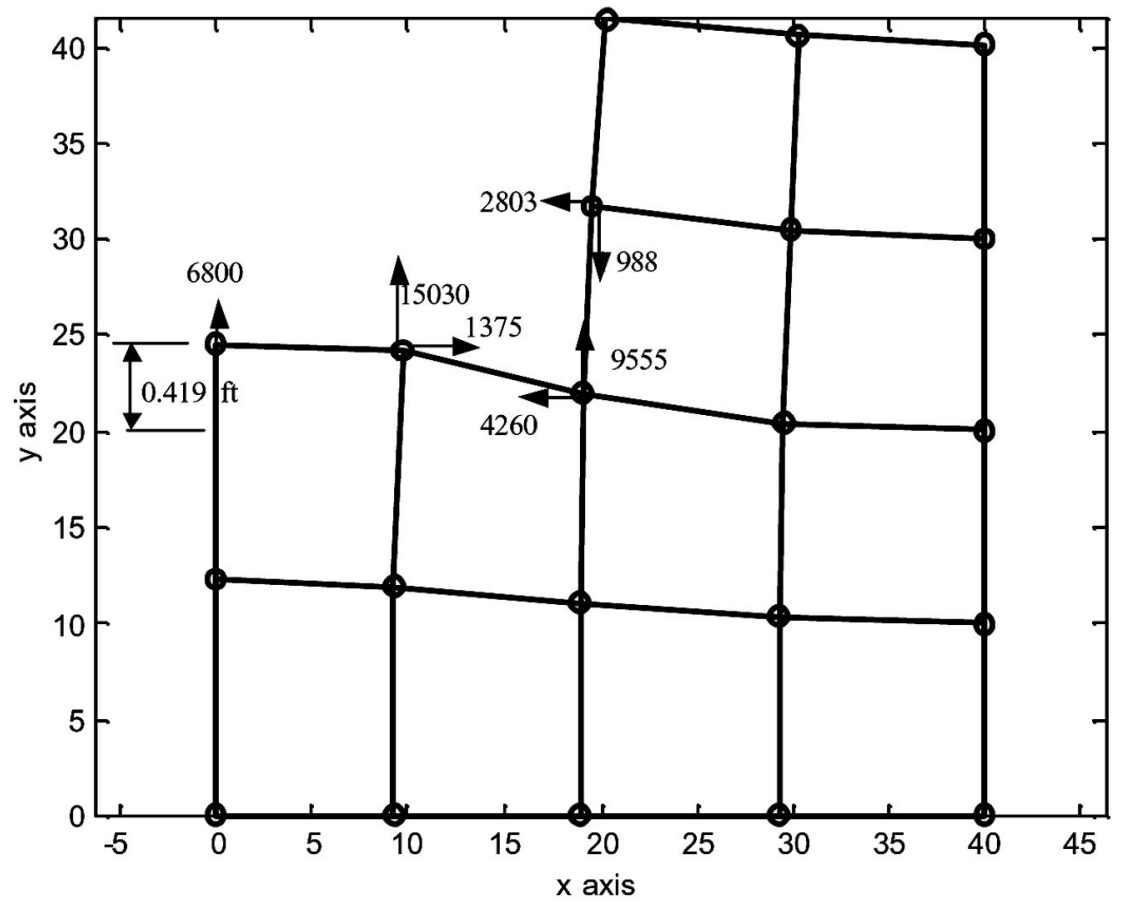

b. Deformed mesh after the second stage of a two-stage excavation

Figure 4.6. Clough and Duncan procedure-two-stage excavation (deformations magnified 10x) (nodal forces shown are in pounds) 


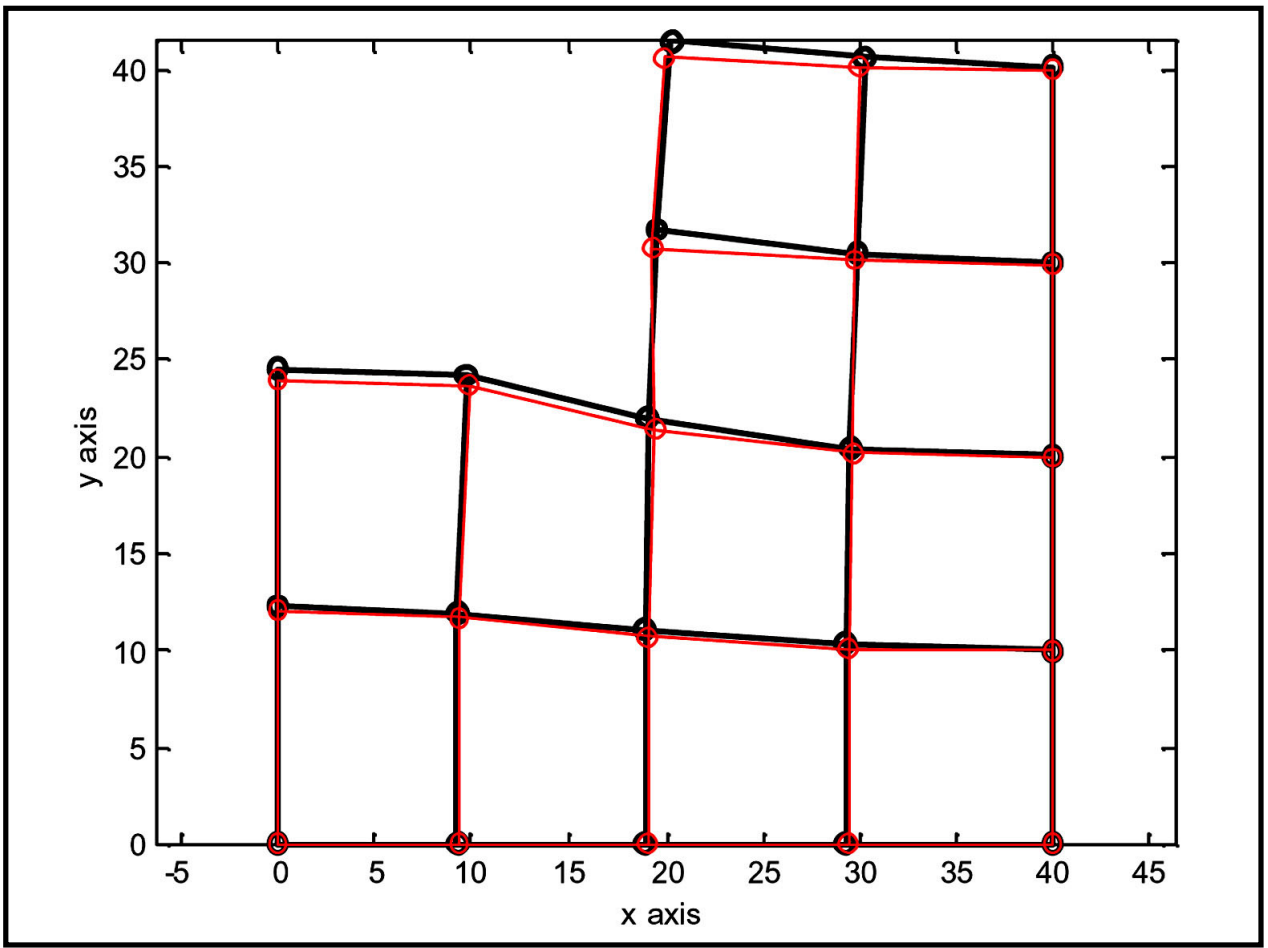

Figure 4.7. Comparison of the results of a single-stage (thin lines) and a twostage (thick lines) excavation using the Clough and Duncan procedure (deformations magnified 10x)

Wong (1973) also provided numerical results to support the use of few excavation stages. It is should be noted, however, that this recommendation runs counter to the requirement of using small load increments for problems with significant material nonlinearity. Also, the nature of the construction (e.g., excavations using tieback construction) can set a limit on the minimum number of excavation stages that can be simulated.

The results of the different simulations are summarized in Table 4.2 in terms of the maximum heave at the base of the excavation. The method of force residuals gave displacements of $0.401 \mathrm{ft}$ for both the one- and the two-stage excavation using four-noded elements. The corresponding results using the eight-noded elements are only slightly less at $0.399 \mathrm{ft}$, showing very minimal dependency of the results from the level of discretization. The results of the Clough and Duncan procedure gave a maximum heave of $0.406 \mathrm{ft}$ for the single-stage excavation and $0.419 \mathrm{ft}$ for the two-stage excavation.

\section{Table 4.2}

\section{Calculated Maximum Heave at End of Excavation}

\begin{tabular}{||l|l|l||}
\hline \hline Model & One-Stage Excavation & Two-Stage Excavation \\
\hline \hline $\begin{array}{l}\text { Method of force residuals } \\
\quad \text { 4-noded elements } \\
\text { 8-noded elements }\end{array}$ & $0.401 \mathrm{ft}$ & $0.401 \mathrm{ft}$ \\
\hline $\begin{array}{l}\text { Clough and Duncan procedure } \\
\text { 4-noded elements }\end{array}$ & $0.399 \mathrm{ft}$ & $0.399 \mathrm{ft}$ \\
\hline \hline
\end{tabular}

Note: To convert feet to meters, multiply by 0.3048 . 
The larger heave at the base of the excavation and of the original ground surface at the top of the vertical excavation boundary for the two-stage excavation compared to the single-stage excavation (Figure 4.7) is attributed to the larger vertical excavation forces in Figure 4.6b. This will be discussed further in Section 4.2.2 in connection with force equilibrium. The results shown in Figure 4.7 illustrate that the Clough and Duncan procedure does not yield a unique result independent of the number of excavation stages, as expected for linear elastic materials.

The element internal forces were calculated using stresses evaluated at four Gaussian quadrature points. These are the internal forces used in the force residual method shown in Figures 4.1-4.4. Note also that there are horizontal forces at the lateral vertical boundaries due to the gravity turn-on. However, these forces are not active since the nodes along the lateral boundaries are fixed along the horizontal direction. These forces are, therefore, not shown in Figures 4.2 and 4.6.

\subsubsection{Force and moment equilibrium}

The lack of moment equilibrium in the Clough and Duncan procedure for constant stress elements can be shown by recalling the example problem that was analyzed in Section 2.2. At the end of the calculation, the stresses along the excavation boundaries and the equivalent nodal forces (but opposite in sign) from these stresses are as shown in Figure 4.8 below. It can be seen that equilibrium of forces is satisfied along the vertical direction, as shown in Figure 4.9, since the nodal force of $2(10) \mathrm{kN}$ equals half the weight of the element $(10 \mathrm{kN})$ plus the effect of vertical stress at the element center of $(10 \mathrm{kPa})\left(1 \mathrm{~m}^{2}\right)=10 \mathrm{kN}$.

In the horizontal direction, the horizontal forces required to satisfy force and moment equilibrium at the top and bottom nodes are $2.5 \mathrm{kN}$ for a constant stress element. However, the nodal forces are equal to $1.67 \mathrm{kN}$ at the top nodes and $3.33 \mathrm{kN}$ at the bottom nodes (in Figure 4.8b) according to the Clough and Duncan procedure. Horizontal force equilibrium is achieved only on the average, as the average horizontal nodal force is equal to $(1.67+3.33) / 2=2.5 \mathrm{kN}$. However, moment equilibrium will not be satisfied for a constant stress element.

In comparison, the excavation nodal forces obtained by minimizing the residual forces, which are reproduced in Figure 4.10, satisfy force and moment equilibrium both in the horizontal and vertical directions.

More convincing evidence of the lack of force equilibrium in the Clough and Duncan procedure can be obtained from the results of the finite element analysis carried out in Section 4.2.1, particularly by comparing the excavation nodal forces shown in Figures 4.2 and 4.6. As can be seen in Figures 4.2a and 4.6a, the vertical excavation forces from the method of force residuals and the Clough and Duncan procedure are the same for the first stage of excavation. Also, the summation of the vertical excavation forces equals $24,000 \mathrm{lb}$ for both procedures, which is the same as the weight of the two excavated elements. Thus, force equilibrium is satisfied for both procedures for the first-stage excavation. 


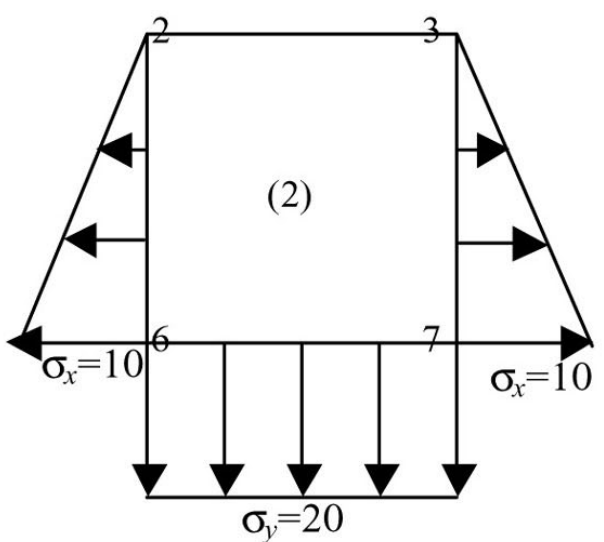

(a)

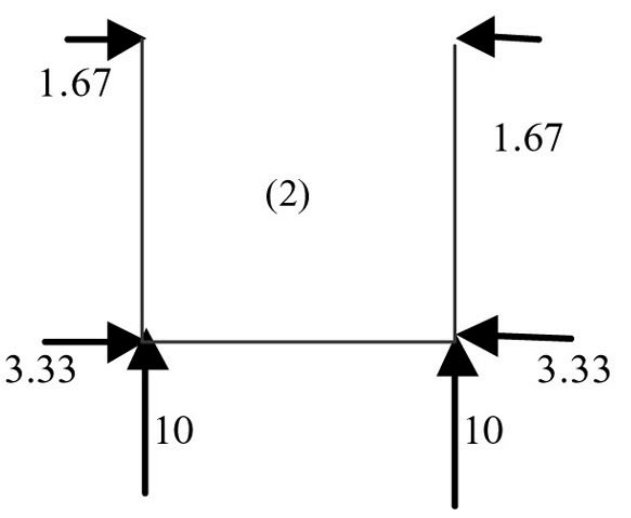

(b)

Figure 4.8. Interpolated stresses at element edges (a) and equivalent nodal forces (b) along the excavation boundaries from Element 2, calculated from the Clough and Duncan procedure (stresses are in kilopascals, forces are in kilonewtons)

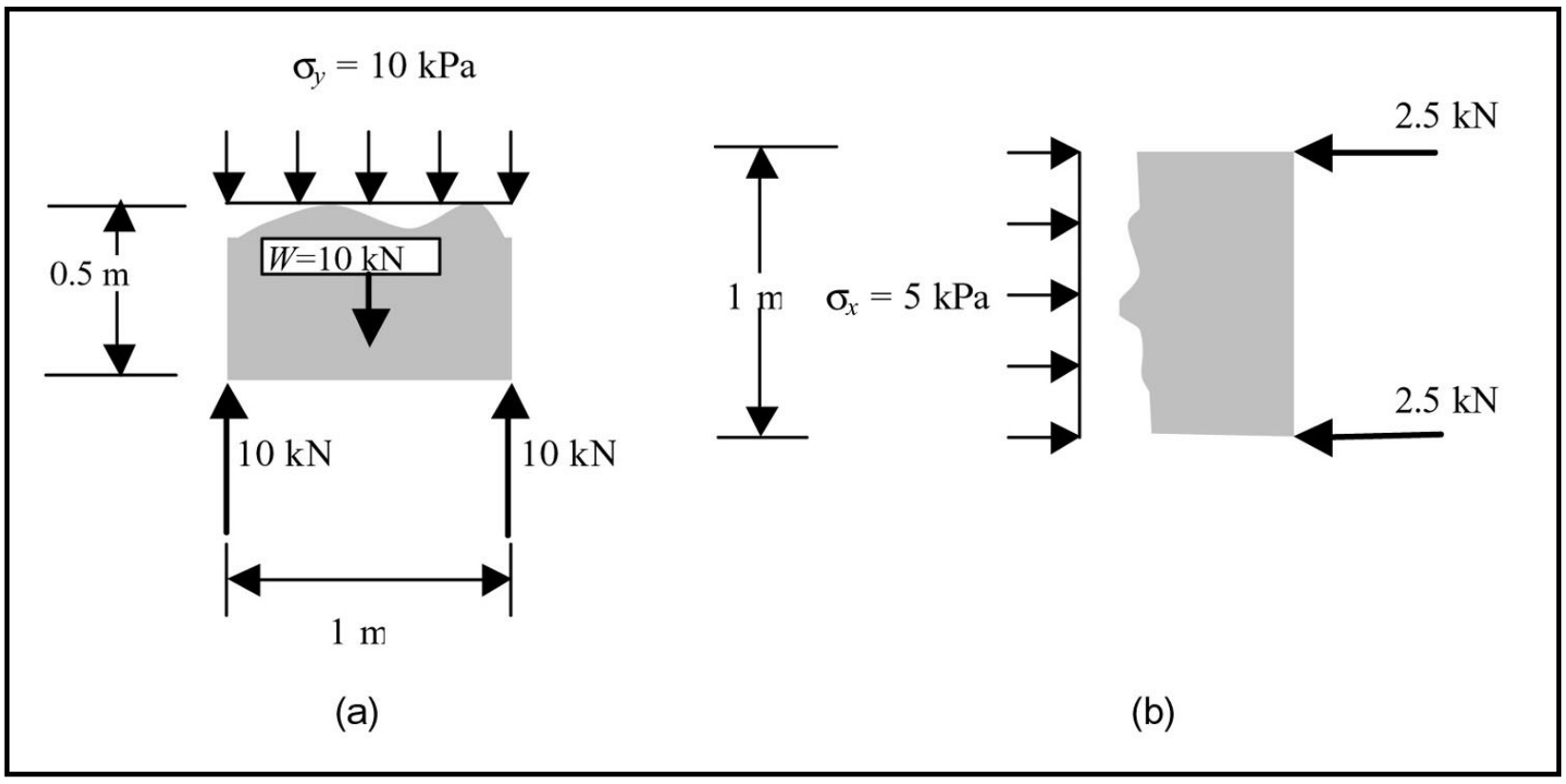

Figure 4.9. Nodal forces required to satisfy equilibrium of forces in the (a) vertical and (b) horizontal directions 
The lack of force equilibrium for the Clough and Duncan procedure becomes apparent for the second stage of excavation. This can be seen by comparing the vertical excavation forces in Figures $4.2 \mathrm{~b}$ and $4.6 \mathrm{~b}$. The summation of the vertical excavation forces gives $24,000 \mathrm{lb}(=6,324+14,347$ $+7,647-4,318)$ for the method of force residuals. This value is again equal to the total weight of the two excavated elements in the second stage of excavation.

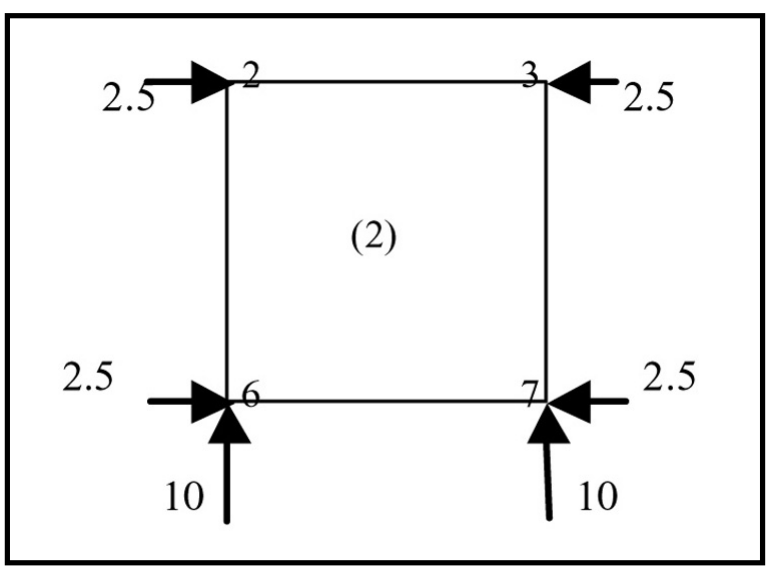

Figure 4.10. Equivalent nodal forces based on minimization of force residuals (forces are in kilonewtons)

In comparison, the summation of the vertical forces from the Clough and Duncan procedure is equal to $30,397 \mathrm{lb}(=6,800+15,030+9,555-988)$. This is much larger than the total weight of the two excavated elements of $24,000 \mathrm{lb}$ and, therefore, force equilibrium is not satisfied for the second stage of excavation.

\subsubsection{Convergence of solution}

As pointed out by Ghaboussi and Pecknold (1984), a clear distinction should be made between solution accuracy and step-size independence. While it is true that more accurate results should be obtained by the use of higher order elements or finer discretizations, this has little to do with the problem of cumulative step errors. If the numerical solution process is carried out correctly, the solution will always be independent of the number of steps, no matter how crude the finite element mesh used to model the stress distribution. Of course, a finer discretization will yield a more accurate result using the method of force residuals. However, as pointed out by Brown and Booker (1986) the method of force residuals does not require a large degree of mesh refinement or the use of high-order finite elements to obtain accurate results for an elastic material. This was shown above where the finite element model using four-noded elements yielded results almost identical to the finite element model using eight-noded finite elements (and doubling the number of nodes).

\subsection{Implementation Issues in SOILSTRUCT- ALPHA}

Based on the comparisons made in Section 4.1 and the results of the finite

element analysis carried out in Section 4.2, it is recommended that the method of force residuals be implemented as another option for excavation modeling in SOILSTRUCT-ALPHA. There are several alternatives for implementing the method of force residuals in SOILSTRUCT-ALPHA. In the different alternatives, the overriding issue is the type of element that is available or can be 
implemented in SOILSTRUCT-ALPHA. Currently, the only continuum element available in this code is the so-called QM5 quadrilateral element. The properties of this element are discussed further below.

The alternatives for implementing the method of force residuals in SOILSTRUCT-ALPHA are

a. Using the existing QM5 finite element routine with constant element stresses.

$b$. Using the existing QM5 finite element routine but with element stresses calculated at the Gaussian quadrature points.

c. Using a four-noded isoparametric finite element.

d. Using higher order (e.g., eight-noded) finite elements.

The simplest option is, of course, to retain the existing Clough and Duncan procedure in SOILSTRUCT-ALPHA, and use as few excavation steps as possible based on the recommendation by Christian and Wong (1973). As shown above, a single-stage excavation may yield results comparable to those obtained from the method of force residuals, at least for linear elastic problems. Because this approach is not feasible for many problems of practical interest, it is recommended that the method of force residuals be implemented in SOILSTRUCTALPHA. The following sections discuss issues related to this implementation.

\subsubsection{Implementation using QM5 or other element types}

Using the existing QM5 element appears to be the most straightforward way of implementing the method of residuals in SOILSTRUCT-ALPHA. It is desirable to retain the use of QM5 element since this would involve the least amount of modifications to SOILSTRUCT-ALPHA, and there is already a large experience base with the use of this element. In the following, a brief description of QM5 is given first to clarify the feasibility of implementing the method of force residuals in SOILSTRUCT-ALPHA.

QM5 is one of the family of higher order quadrilateral elements developed by Doherty, Wilson, and Taylor (1969) for stress analysis of axisymmetric solids. The axisymmetric formulation was reduced to a plane strain formulation when QM5 was implemented in SOILSTRUCT. The main feature of the five-noded quadrilateral element QM5 is that it has better bending characteristics over other elements with the same number of nodes. This is accomplished by using a displacement function of the following form:

$$
\begin{gathered}
u=a_{o}+a_{1} s+a_{2} t+a_{3} s t+a_{4}\left(1-s^{2}\right)\left(1-t^{2}\right) \\
v=b_{o}+b_{1} s+b_{2} t+b_{3} s t+b_{4}\left(1-s^{2}\right)\left(1-t^{2}\right)
\end{gathered}
$$


where $u$ and $v$ are the horizontal and vertical displacements, $a_{o} \ldots a_{4}$ and $b_{o} \ldots b_{4}$ are interpolation constants that can be determined from the values of $u$ and $v$ at the five nodes (the fifth node is located at the element centroid), and $s$ and $t$ are the local element coordinates. (See Appendix A for an explanation of local coordinates.) The first four terms in the two polynomials in Equation 4.1 are the same as those used in standard four-noded isoparametric elements. Note that the equation is an incomplete polynomial.

The fifth terms involving $a_{4}$ and $b_{4}$ are added to improve the bending performance of the standard four-noded quadrilateral element. However, compatibility requires that only the first four bilinear terms in Equation 4.1 can be used for the four corner nodes. This forces the element to have linear displacements along the element sides. To retain the improved bending performance of the element, a constant shear strain is imposed on the element. The shear strain is calculated at the center or the fifth node of the element using the displacement function given in Equation 4.1. Once the shear strain has been calculated, the central node is deleted from the finite element formulation using a method of static condensation. In the assembly of the stiffness matrix, only the four corner nodes are included, and the central node does not participate in the displacement calculations.

Due to the assumed constant shear strain in the element, only one set of stresses is currently calculated in QM5, and these are calculated at the element center. This is equivalent to assuming that QM5 is a constant stress element. It is possible to calculate at least four different stresses at four Gaussian stress points in QM5; however, this will require the displacements at the central node to be calculated. Two methods were tried to recover the displacements at the central node from the four corner nodes: averaging the four corner displacements, and using a technique to decondensate the internal degrees of freedom (Desai and Abel 1972).

The first method, while very simple and straightforward, yielded very high forces at the central node that are an order of magnitude larger than the forces at the corners.

The second method was found to be very cumbersome, involving re-solution of the systems of equations in order to recover the internal degrees-of-freedom from the four corner nodes. Such a procedure was nonetheless tried, and the resulting finite element formulation was used in the same problem analyzed (shown in Figure 4.2). To achieve complete integration of the fourth-order displacement function (Equation 4.1), a 3 by 3 Gaussian quadrature was used to integrate the stiffness matrix, and the element stresses are determined at the nine quadrature points. The result of a two-stage excavation using the QM5 with recovered internal displacements is shown in Figure 4.11. As can be seen, the overall pattern of displacement looks reasonable, but individual elements gave very unusual displacement modes. The displacement mode of each element is due to the imposed constant shear strain within the element and the compatibility condition that elements must show linear displacements along the edges. The results of the analysis indicate that it is difficult to obtain a reasonable displacement response from the QM5 element if the internal displacements are recovered 


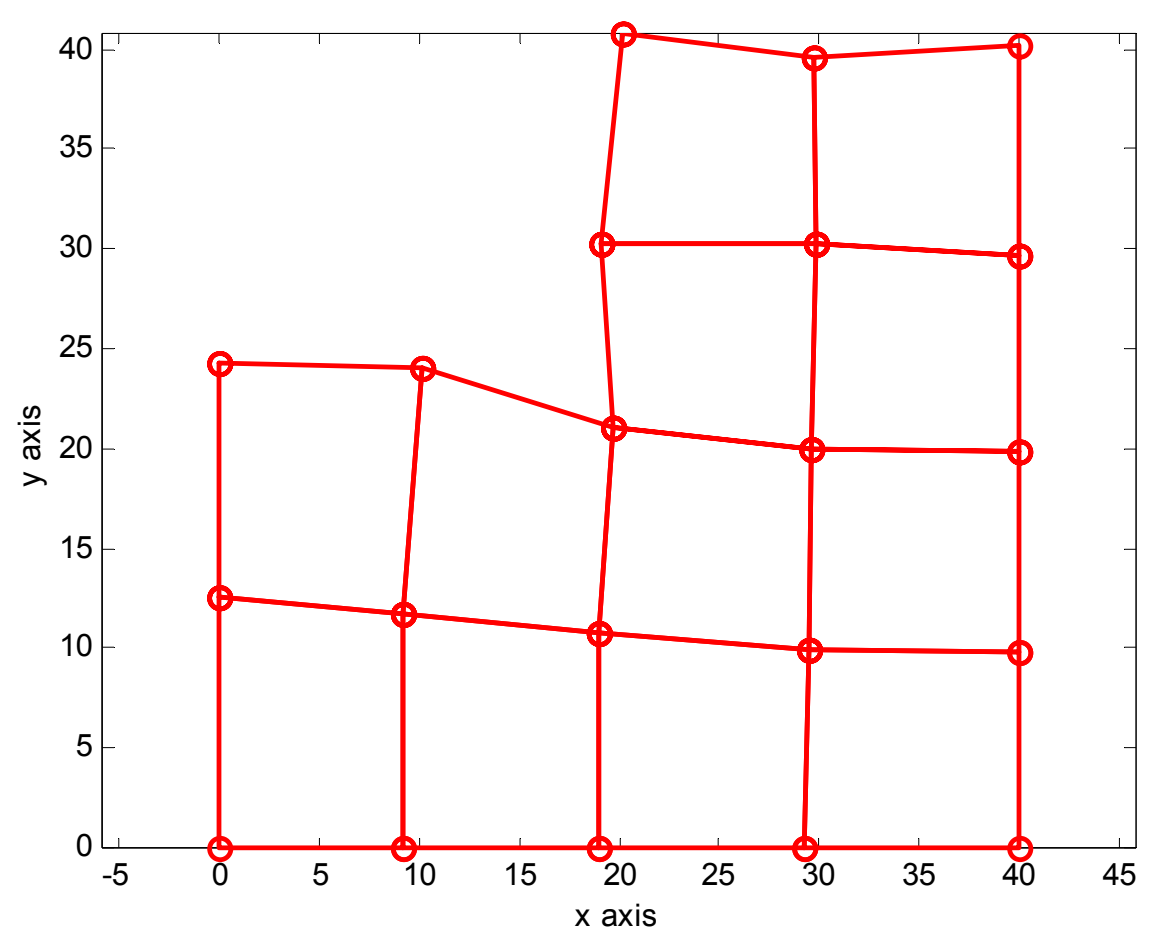

Figure 4.11. Deformed mesh after excavation using the QM5 element with recovered internal displacements

to calculate stresses at the Gaussian points while at the same time keeping the constant shear strain condition.

Regardless of how the internal element stresses are determined, only one set of element nodal forces can be calculated for an element. This means that, although stresses can be calculated at four or nine Gaussian points, these stresses will have to be weighted and summed to get a single set of nodal forces. However, calculating stresses at the Gaussian points will give a better representation of the stresses within the elements, and thus highly stressed regions in the element are better represented than by assuming a constant stress distribution. A better representation of element stresses will eventually yield a more realistic distribution of element forces. Finally, it should be noted that the central node should give zero residual forces at the end of the gravity turn-on and excavation analyses since a central node is not connected to any other node. Thus, there is no added value in keeping the internal degree-of-freedom in the calculation of excavation forces.

Based on the above observations and considerations of other element types, a summary of the finite element options for simulating excavation in SOILSTRUCT-ALPHA is given in Table 4.3. 


\begin{tabular}{|c|c|}
\hline \multicolumn{2}{|c|}{$\begin{array}{l}\text { Table } 4.3 \\
\text { Summary of Advantages and Disadvantages of Finite Element } \\
\text { Routines That Could Be Used in Implementing the Method of Force } \\
\text { Residuals in SOILSTRUCT-ALPHA } \\
\end{array}$} \\
\hline Method & Advantages/Disadvantages \\
\hline $\begin{array}{l}\text { Using QM5 with only } \\
\text { one set of element } \\
\text { stresses. }\end{array}$ & $\begin{array}{l}\text { This is the simplest and most straightforward approach of introducing the } \\
\text { method of force residuals in SOILSTRUCT-ALPHA. } \\
\text { Most of the required routines are already available in the code. } \\
\text { It is anticipated that even with a constant-stress QM5 element, there will } \\
\text { be improvement over the Clough and Duncan procedure. }\end{array}$ \\
\hline $\begin{array}{l}\text { Using QM5 but extract } \\
\text { four stresses at the four } \\
\text { Gaussian points. }\end{array}$ & $\begin{array}{l}\text { This will require very complicated programming to recover the internal } \\
\text { degree-of-freedom (DOF) that was taken out during the static } \\
\text { condensation. } \\
\text { The extra calculations will significantly slow down the code. } \\
\text { The added sophistication is shown not to give substantial improvement } \\
\text { from the current constant stress QM5. In fact, the QM5 element with } \\
\text { recovered internal displacements is shown to exhibit rather unusual } \\
\text { displacement response. }\end{array}$ \\
\hline $\begin{array}{l}\text { Introduce a new four- } \\
\text { noded element. }\end{array}$ & $\begin{array}{l}\text { This is preferred over the second option, as it will require less } \\
\text { programming, and the code will be more robust than one where internal } \\
\text { DOFs are recovered from QM5. This is particularly true if elements with } \\
\text { four nodes are used as in the reduced QM5 element. } \\
\text { An isoparametric four-noded quadrilateral (Q4), which will yield four } \\
\text { stresses at the Gaussian points, can replace or be used side-by-side with } \\
\text { the QM5 that has the same number of DOFs. } \\
\text { The Q4 does not have the advantage of the improved bending } \\
\text { performance of the QM5. The Q4 can be modified to produce an } \\
\text { improved bending performance, again by imposing a constant strain } \\
\text { condition in the element, as was done in the element QM4 developed by } \\
\text { Doherty, Wilson, and Taylor (1969). As in the QM5, the penalty is that only } \\
\text { one set of stresses can be calculated in the QM4. }\end{array}$ \\
\hline $\begin{array}{l}\text { Introduce a higher order } \\
\text { element. }\end{array}$ & $\begin{array}{l}\text { Higher order elements will yield better performance including bending that } \\
\text { lower order elements. } \\
\text { This will require the most modification, particularly in the data structure of } \\
\text { the code to allow for midside nodes. Modifications would be necessary in } \\
\text { almost all parts of the code, including the interface element routine and } \\
\text { the calculation of initial stresses }\end{array}$ \\
\hline
\end{tabular}

\subsubsection{Interface elements}

Another issue that needs to be considered in implementing a new excavation routine in SOILSTRUCT-ALPHA is the influence of interface elements. These elements are introduced between the soil and a retaining structure to permit relative deformation between the soil and the structure. There has been an active development of models for interface behavior in SOILSTRUCT-ALPHA (Gómez, Filz, and Ebeling 2000a, 2000b). Currently, however, the interface element has no influence on the excavation routine in SOILSTRUCT-ALPHA. During excavation, the interface elements are assumed to be "locked" and are given large normal and shear stiffness values during the excavation simulation.

Interface elements are 1-D elements or elements without thickness introduced between the structure and the soil. Interface elements allow adjacent continuum soil and structure elements to move independently of each other. In the case of the problem shown in Figures 1.3 and 2.1, interface elements would be used between the two sides of the slurry wall and the soil (see Figure 4.12). The behavior of these interface elements is governed by normal and shear stiffnesses, with the former controlling the opening and closure and the latter 


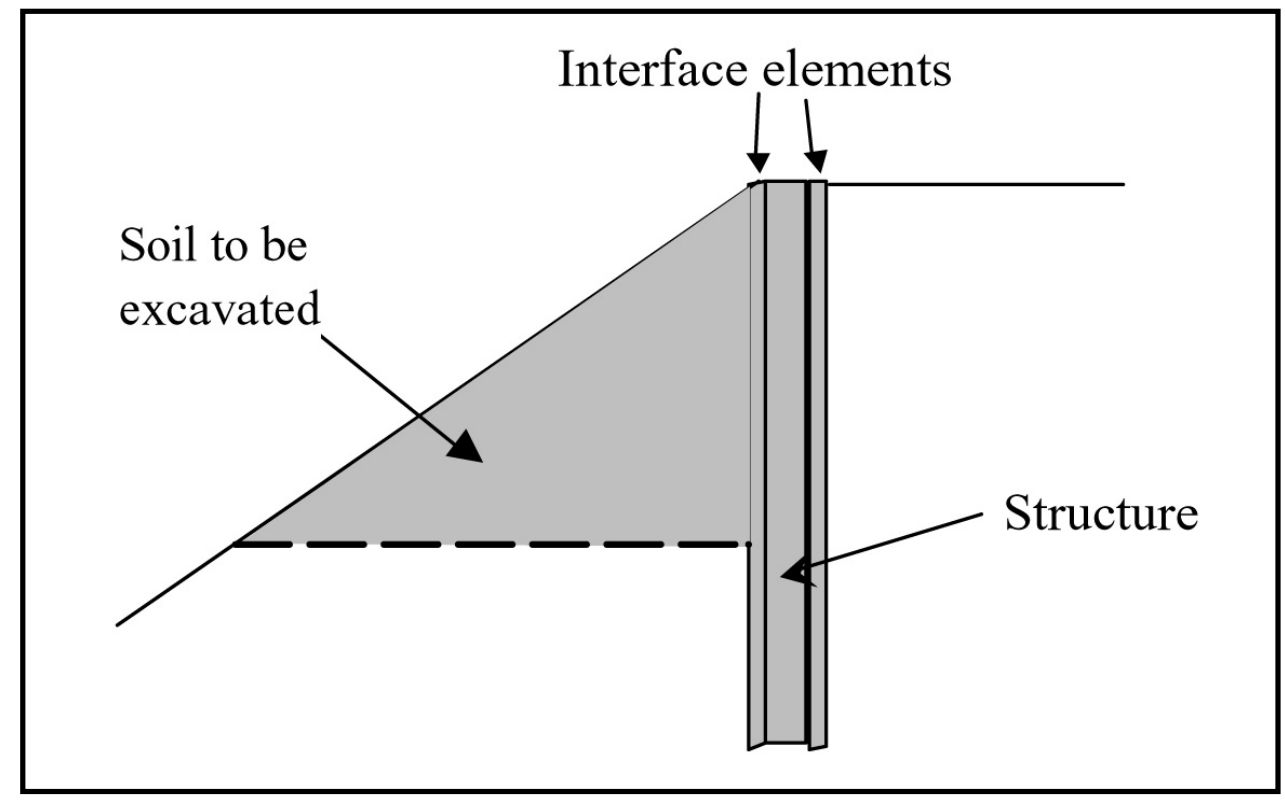

Figure 4.12. Use of interface elements to model interaction between soil and structure

controlling the shear displacement along the interface. In SOILSTRUCTALPHA, the interface element has four nodes, with each of two nodes in a pair having the same coordinates.

Interface behavior can have important influence on the excavation forces that are built up in the structure due to the backfilling of the soil around the structure, or due to the driving shear stresses in the case of structures driven into the soils. In the case of backfilling, an important effect is the generation of downdrag or vertical shear force exerted by the backfill on the structure, as referred to in Section 1.2. As noted above, downdrag effects have been reported in earlier studies by Ebeling, Duncan, and Clough (1990); Ebeling et al. (1993); Ebeling and Mosher (1996); Ebeling and Wahl (1977); and Ebeling, Peters, and Mosher (1997). The main purpose of interface elements is to be able to permit slippage between the soil and the structure during construction and also during subsequent loading of the structure.

To include interface elements in the excavation simulation using the method of force residuals, it is necessary to calculate the internal forces in the interface elements. In case of continuum elements, the internal forces are calculated from the built-up stresses $\{\sigma\}$ in the element using the equation

$$
\left\{F_{\text {int }}\right\}=\int_{V}[B]^{T}\{\sigma\} d V
$$

A more direct approach can also be used to calculate the internal force that is applicable to both continuum and interface elements. Again, for continuum elements, the stress increments $\{\sigma\}$ are related to the strain increments $\{\varepsilon\}$ by the constitutive matrix $[D]$ : 


$$
\{\sigma\}=[D]\{\varepsilon\}
$$

while the strain increments $\{\varepsilon\}$ are related to the incremental element nodal displacements $\left\{u^{e}\right\}$ by the strain-displacement matrix:

$$
\{\varepsilon\}=[B]\left\{u^{e}\right\}
$$

Substitution in Equation 4.2 gives the internal nodal loads:

$$
\left\{F_{\text {int }}\right\}=\int_{V}\{B\}^{T}[D]\{B\}\left\{u^{e}\right\} d V
$$

Here, the quantity $\int_{V}\{B\}^{T}[D]\{B\} d V$ is actually equal to the element stiffness matrix $\left[k^{e}\right]$ and, therefore, Equation 4.4 can also be written as

$$
\left\{F_{\text {int }}\right\}=\left[k^{e}\right]\left\{u^{e}\right\}, \quad\left[k^{e}\right]=\int_{V}\{B\}^{T}[D]\{B\} d V
$$

Equation 4.6 provides another way of calculating equivalent internal nodal forces from element stresses. In the case of interface elements, the internal forces can be calculated from the relative nodal displacements along the element and the normal and shear stiffnesses of the interface:

$$
\left\{F_{\text {int }}\right\}=\left[k^{e}\right]\left\{u^{e}\right\}
$$

Note that Equation 4.7 is applicable to all kinds of elements, and thus, the internal forces can be computed in a consistent manner and included in the internal stresses from the continuum elements. The internal forces in the interface are then included in the calculation of the residual forces due to excavation. Deletion of interface elements causes no change in the external body loads as interface elements have no self-weights. In this manner, no special programming is needed to handle interface elements in the excavation simulation using the method of force residuals. In the case of nonlinear material response, Equation 4.7 must be evaluated incrementally using the nonlinear stiffness matrix $\left[k^{e}\right]$ consistent with the variation of stresses and strain.

To illustrate the importance of interface response and to show the use of the method of force residuals to account for interface elements in excavations, the problem shown in Figure 4.13 below is used. This is a similar problem to that analyzed in Section 4.3.1 except that interface elements are placed along the vertical excavation boundary, extending from the top to the bottom of the model. In practice, such elements will be installed between soil elements and a structural element (e.g., a slurry wall). However, in this simple problem, the interface elements are placed artificially between soil elements. Again, the objective is to simulate the deformation of the soil after Elements 1, 5, 2, and 6 are deleted. 
The interface element used is the four-noded isoparametric interface element developed by Beer (1985) and Carol and Alonso (1983). This interface element is similar in formulation to the interface element developed by Goodman, Taylor, and Brekke (1968) with the numerical integration proposed by Morrison and Duncan (1995). For simplicity, the relative displacements at the two sides of the element are related to the normal and shear forces $F_{n}$ and $F_{s}$ along the element by linear elastic normal and shear stiffnesses $K_{n}$ and $K_{s}$ :

$$
\left\{\begin{array}{l}
F_{n} \\
F_{s}
\end{array}\right\}=\left[\begin{array}{cc}
K_{n} & 0 \\
0 & K_{s}
\end{array}\right]\left\{\begin{array}{l}
\left(u_{t o p}-u_{b o t}\right) \\
\left(v_{t o p}-v_{b o t}\right)
\end{array}\right\}
$$

where $\left(u_{t o p}-u_{b o t}\right)$ and $\left(v_{t o p}-v_{b o t}\right)$ are the relative displacements normal and parallel to the interface.

The response of the soil after the single-stage excavation is shown in Figures 4.14-4.16. In all the simulations, the same normal stiffness of $K_{n}=1 \cdot 10^{6} \mathrm{lb} / \mathrm{ft}$ is used, while three different values of the shear stiffness $K_{s}$ (equal to $1 \cdot 10^{6}, 1 \cdot 10^{3}, 1 \cdot 10^{2} \mathrm{lb} / \mathrm{ft}$ ) were used. The values of the maximum vertical displacements or heave at the base of the excavation from the simulations with the different shear stiffness values are also summarized in Table 4.4 below. The simulation using $K_{s}=1 \cdot 10^{6} \mathrm{lb} / \mathrm{ft}$ gave almost the same response as the case without interface elements, except for the slight interpenetration or overlap of the soil elements attached to the interface below the excavation. Note that the overlap of the finite elements shown in Figure 4.14 can be reduced by using a higher value of the contact normal stiffness $K_{n}$.

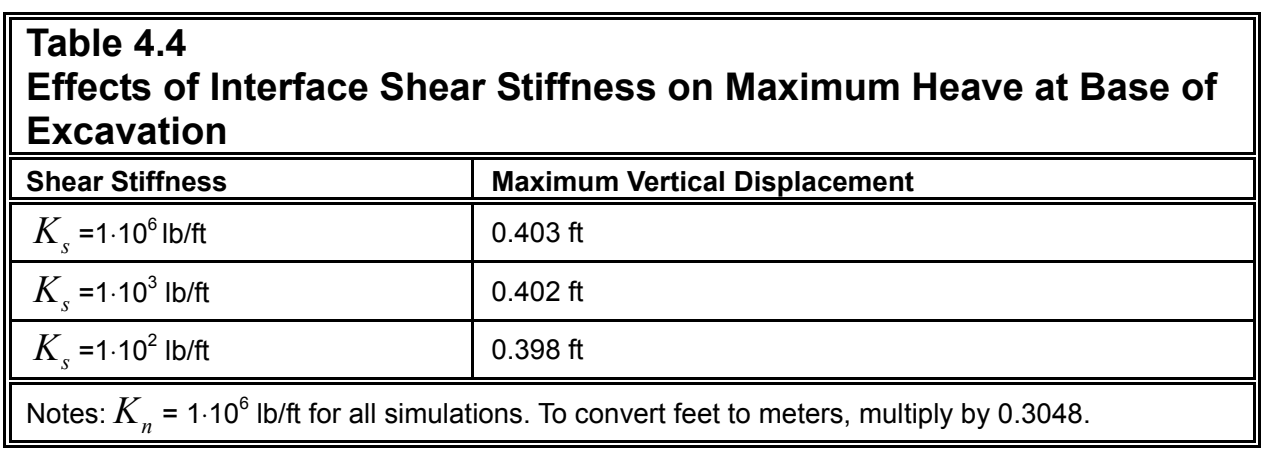

As shown in Table 4.4, there is very little effect of the interface shear stiffness on the maximum heave at the base of the excavation. The main effect of the shear stiffness is on the pattern of deformation below the excavation. The heave of the remaining soil below the excavation becomes more uniform as the interface shear stiffness is reduced. For the lowest value of $K_{s}=1 \cdot 10^{2} \mathrm{lb} / \mathrm{ft}$ used, the soil below the excavation deformed in a piston-like manner with an almost complete vertical slip along the interface. 
The results shown in Figures 4.13-4.16 show the significance of including interface elements in the excavation simulation. The results also demonstrate that interface elements can be included in a consistent manner using the method of force residuals with internal forces determined from Equation 4.7.

\subsubsection{Nonlinear material properties and the ALPHA method}

Soil and interface behavior are modeled using nonlinear models in SOILSTRUCT-ALPHA. For instance, soils are modeled using the Duncan and Chang (1970) hyperbolic model. Currently, the so-called ALPHA method (Ebeling, Duncan, and Clough 1990; Regalado, Duncan, and Clough 1992) is used in the code for analyzing the nonlinear response of soil structures. It is, therefore, important to investigate how the method of force residuals can be implemented in SOILSTRUCT-ALPHA taking into consideration the ALPHA method. Nonlinear analysis is carried out in a series of increments or steps in SOILSTRUCT-ALPHA. For each increment the deformation moduli of the different materials are adjusted according to the level of the current stress and deformation, and the analysis for each increment is carried out as if the materials behave linearly.

Consider the case of the structure shown in Figure 4.17. Let $P$ be the current load, let $\Delta P$ be the load increment, and assume that the current stresses at the most stressed element are below the failure surface in the Mohr-Coulomb diagram (Figure 4.17a). Due to the finite nature of the load increment $\Delta P$, some

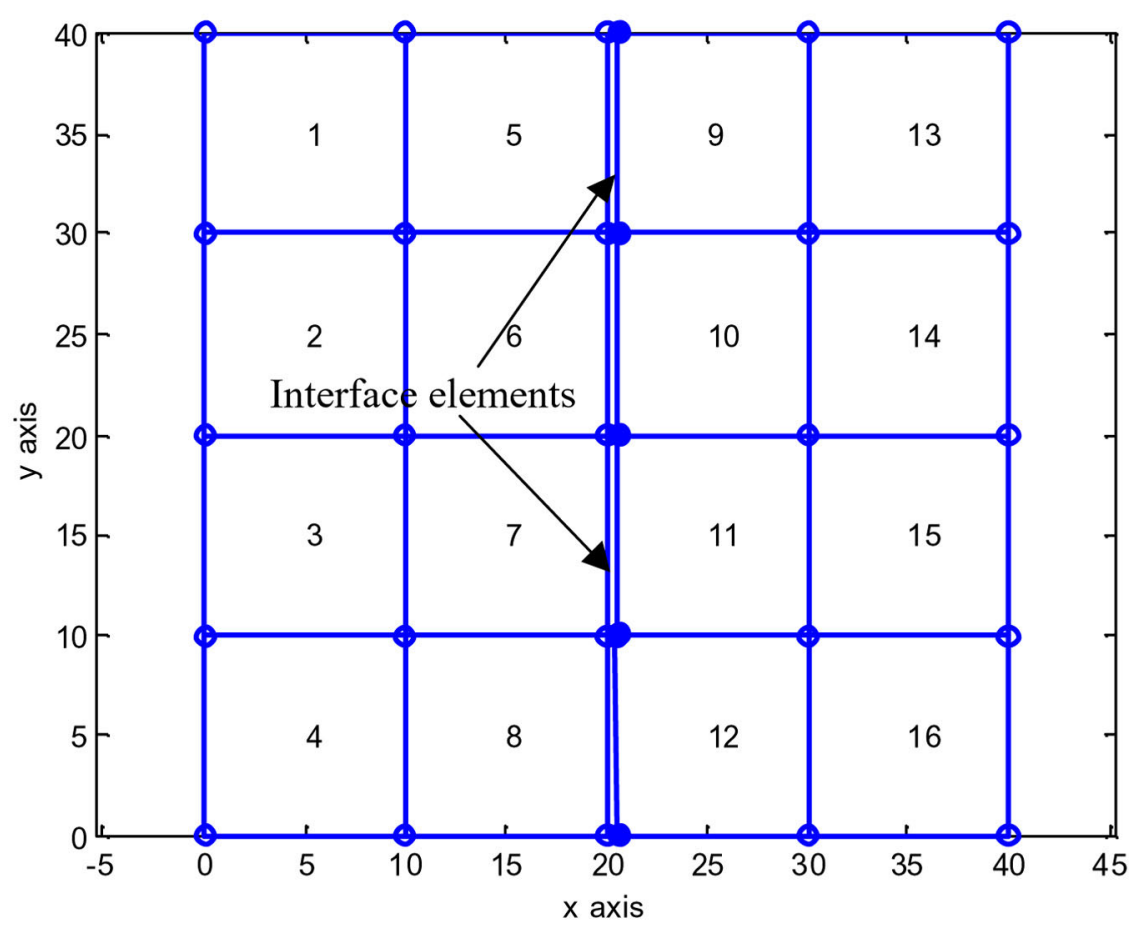

Figure 4.13. Simulation of excavation with interface elements 


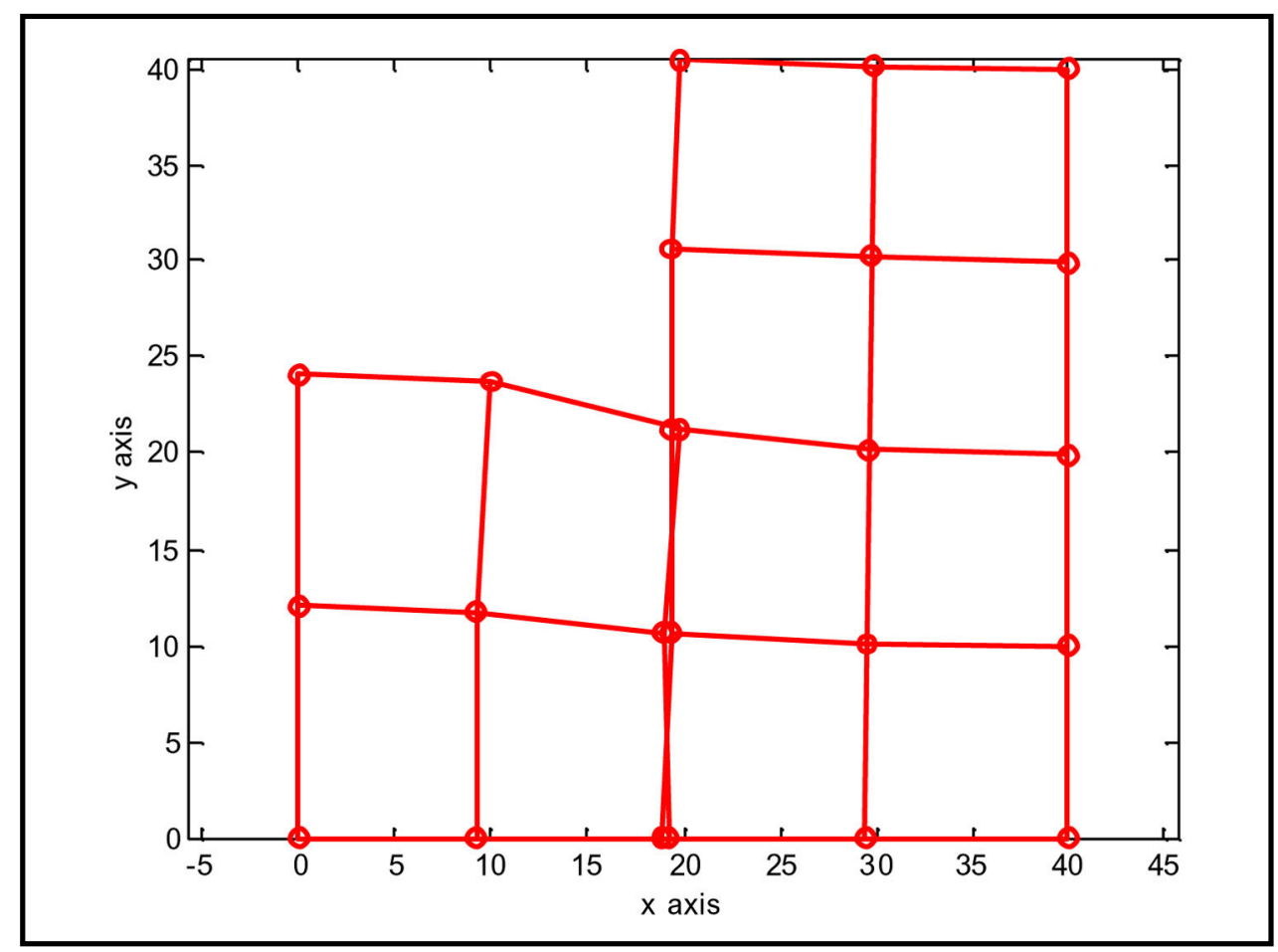

Figure 4.14. Deformed mesh after excavation with $K_{s}=1 \cdot 10^{6} \mathrm{Ib} / \mathrm{ft}$ (deformations magnified 10x)

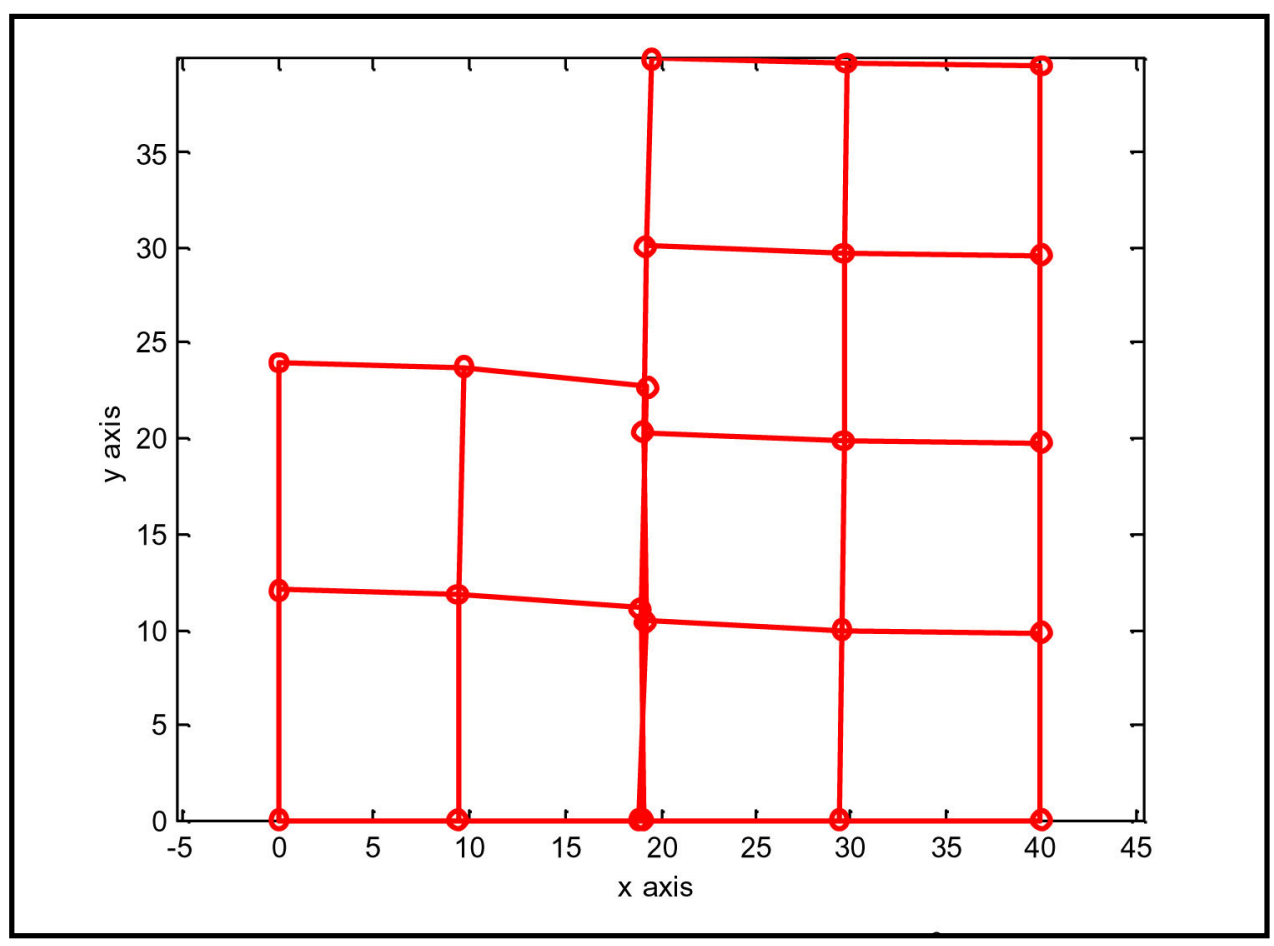

Figure 4.15. Deformed mesh after excavation with $K_{s}=1 \cdot 10^{3} \mathrm{lb} / \mathrm{ft}$ (deformations magnified 10x) 


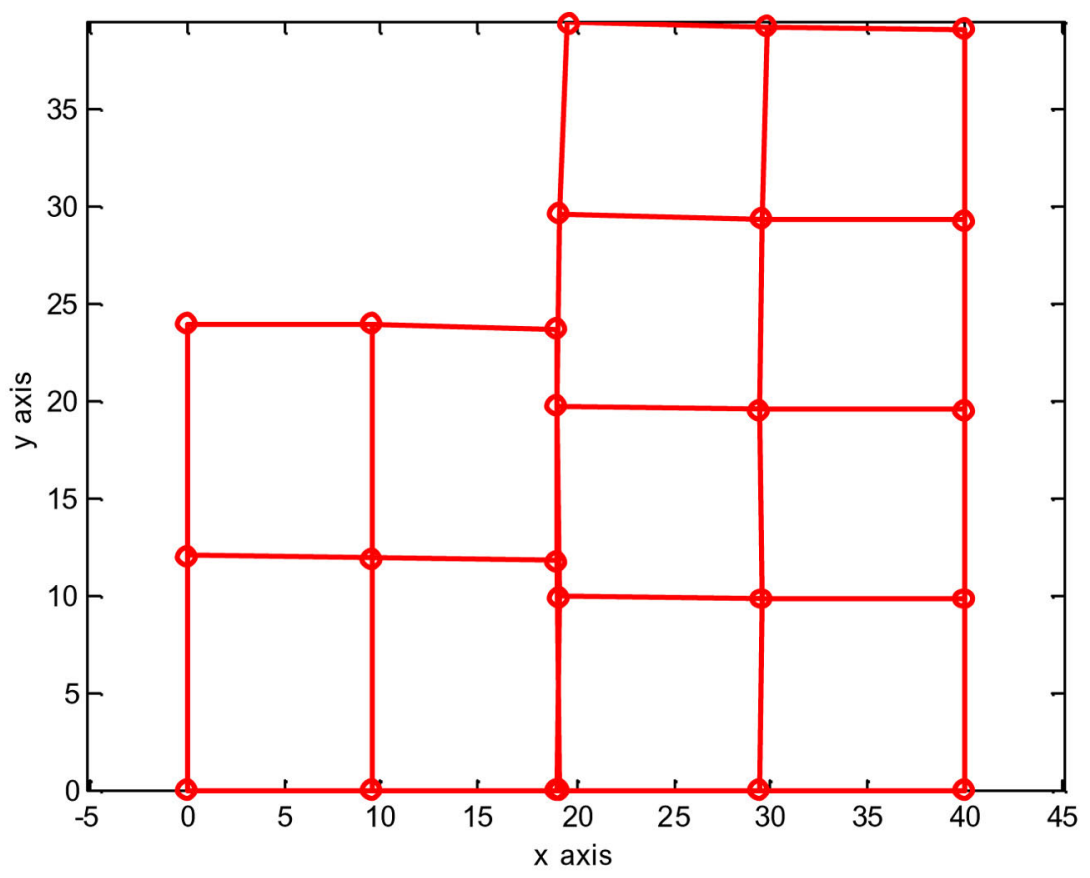

Figure 4.16. Deformed mesh after excavation with $K_{s}=1 \cdot 10^{2} \mathrm{lb} / \mathrm{ft}$ (deformations magnified 10x)

elements will experience stresses that overshoot the failure surface (Figure 4.17b). Ideally, the load should be applied in each increment such that it is large enough to bring the most severely stressed soil element(s) exactly to failure (i.e., no overshoot), as shown in Figure $4.17 \mathrm{c}$. The load $\Delta P$ should then be reduced by a factor in order to bring the most-stressed element just to a failure condition. This factor, called $\alpha$ (hence the term "ALPHA method"), is calculated from the stresses that are just tangential to the Mohr-Coulomb surface (Figure $4.17 \mathrm{c}$ ). Using the $\alpha$-factor to reduce the load will ensure that failure takes place only in the worst stressed element and nowhere else in the modeled region. The ALPHA-factor is applied to both continuum and interface elements.

Due to its incremental nature, the method of force residuals can be equally and directly implemented using the ALPHA-method to integrate the nonlinear equations. As shown in Section 3.2, in the method of force residuals, the loads due to excavation are calculated from the difference in the internal and external forces:

$$
\begin{aligned}
& {[K]\{\Delta u\}=\{R\}} \\
& \{R\}=\left\{F_{\text {int }}\right\}-\left\{F_{\text {ext }}\right\}
\end{aligned}
$$




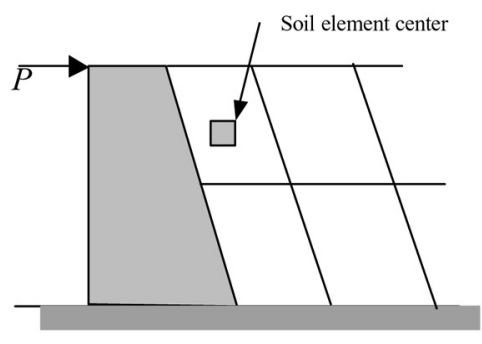

a. Initial state of stress

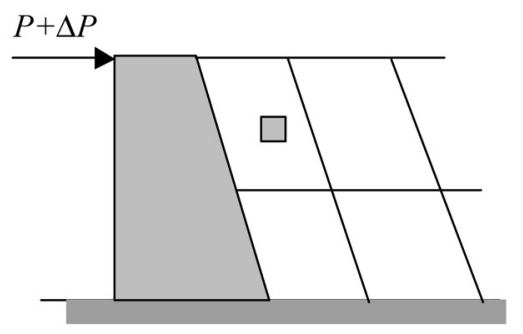

b. State of stress after application of load increment $\Delta P$
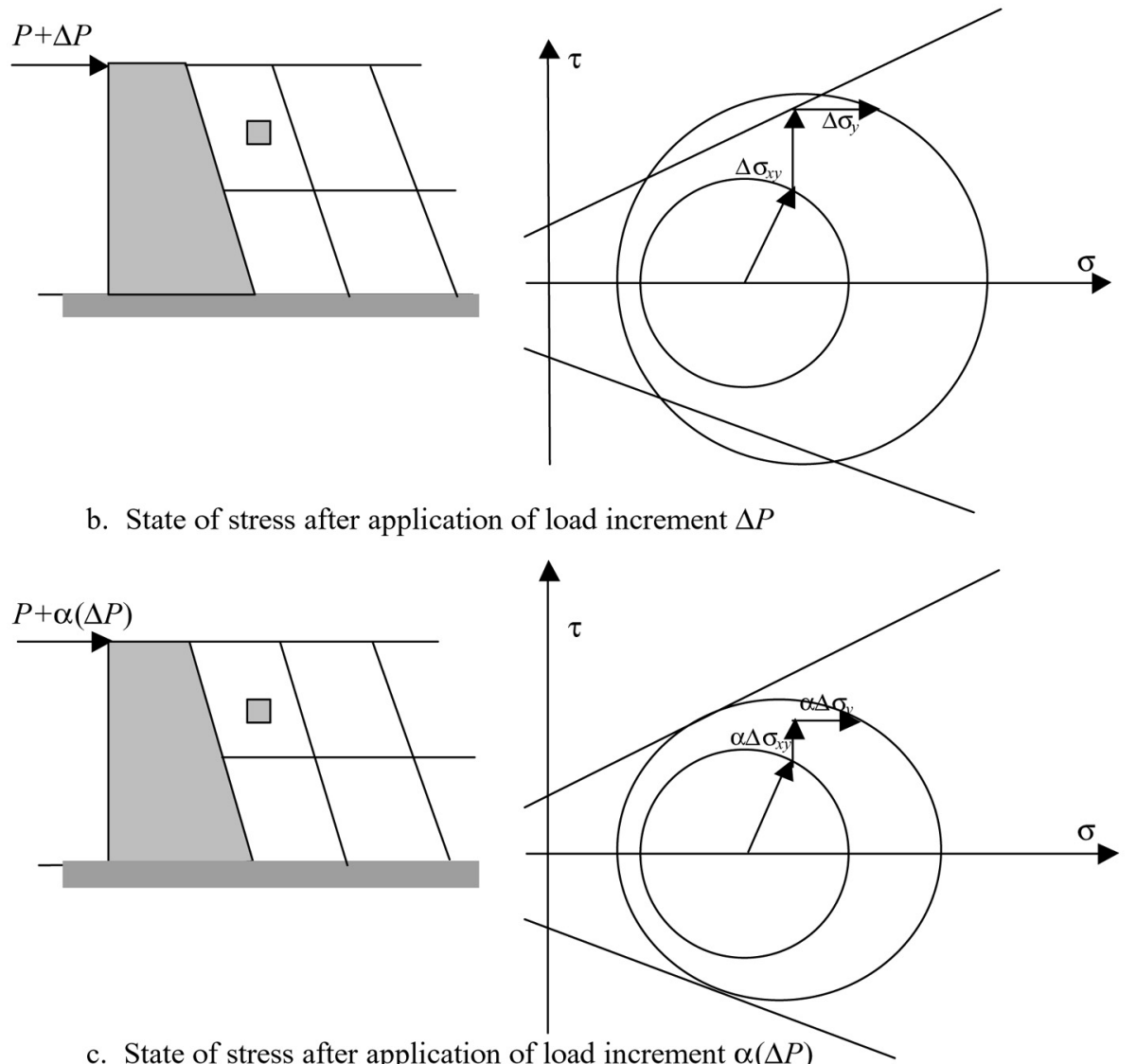

c. State of stress after application of load increment $\alpha(\Delta P)$

Figure 4.17. ALPHA-method in factoring out load increments to avoid overshoot

Therefore, using the ALPHA-method, the $\alpha$-factor can be directly applied to the residual force vector $\{R\}$. An advantage is that the force residuals may either be applied using a single stage excavation or using multiple stages of excavation. In a single-stage excavation, the residual forces along the excavation boundary are calculated all at once but are applied incrementally using the $\alpha$-factor. An alternative is to perform the excavation in stages taking a few elements at a time (via a layer-by-layer excavation for instance), and apply the ALPHA-method for each excavation stage. The latter method is preferred, as the excavation response of 
the soil will now be dependent on the number of excavation stages used and the size of each excavation stage.

\subsubsection{Programming issues}

There are some programming issues that need to be addressed in the implementation of the method of force residuals in SOILSTRUCT-ALPHA. As mentioned above, implementing the method of residuals using the existing QM5 element with constant stresses would entail the least amount of modification of SOILSTRUCT-ALPHA. The modifications and related programming issues discussed below are based on using the QM5 with constant stresses.

The Clough and Duncan excavation procedure is currently implemented in the subroutine EXCAV. This subroutine is called once every loading increment by the MAIN program. For each element to be excavated, EXCAV locates the centers of the four interpolation elements and performs the interpolation on the stresses at the centers of these elements. The interpolation constants are then used to determine the stresses at the nodes of the elements, which are then passed to the subroutine EQNDFO, which converts the nodal stresses to equivalent nodal forces along the excavation boundary.

Instead of rewriting EXCAV, it is proposed to develop a new subroutine EXCAV2 to implement the method force residuals in SOILSTRUCT-ALPA. EXCAV can be retained, and EXCAV2 may be used as an alternative to EXCAV so that users will be allowed to choose either excavation procedure. Another solution is to develop a new version of SOILSTRUCT-ALPHA where EXCAV2 completely replaces EXCAV and is the only procedure available.

The main calculations to be done in EXCAV2 are these: (a) modifying the element properties of the excavated elements, (b) calculating the internal forces, (c) modifying the load vector to account for deleted elements, and (d) calculating the residual force vector. The calculation of the internal element forces will be performed after the incremental displacements have been solved for a previous loading increment and the global displacements and element stresses have been updated. The calculations of the residual forces should be made only on the nodes along the excavation boundary. The residual forces are incremental, and the calculated displacements and stresses are also incremental and must be added to the cumulative displacement and stress vectors. Special precautions must be made to incorporate the effects of seepage, temperature, and added elements from fill placement lifts in the residual force calculations. The flow charts for two recommended procedures to incorporate the method of residuals in SOILSTRUCT-ALPHA are given in Figures 4.18 and 4.19.

4.3.4.1 Calculation of equivalent internal nodal forces. There are two options in calculating the internal element force vector: (a) using the $[B]$-matrix, the element stresses $\{\sigma\}$, and Equation 3.2 (as illustrated in Figure 4.18) and

(b) using the element matrices $\left[k_{e}\right]$, the element displacements $\left\{u_{e}\right\}$, and 


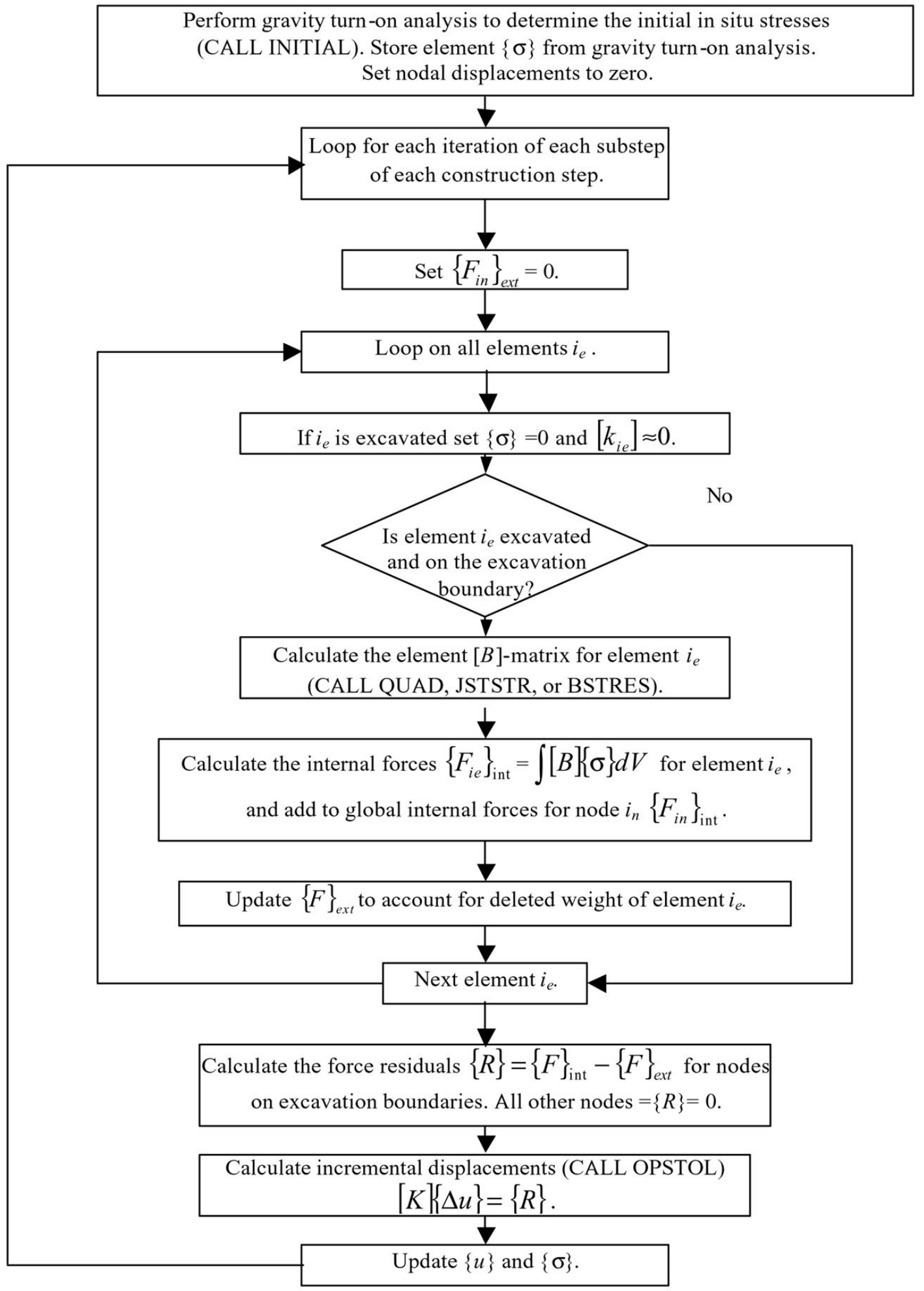

Figure 4.18. Flowchart for implementing the method of force residuals in SOILSTRUCTALPHA using element stresses for calculating internal element forces 


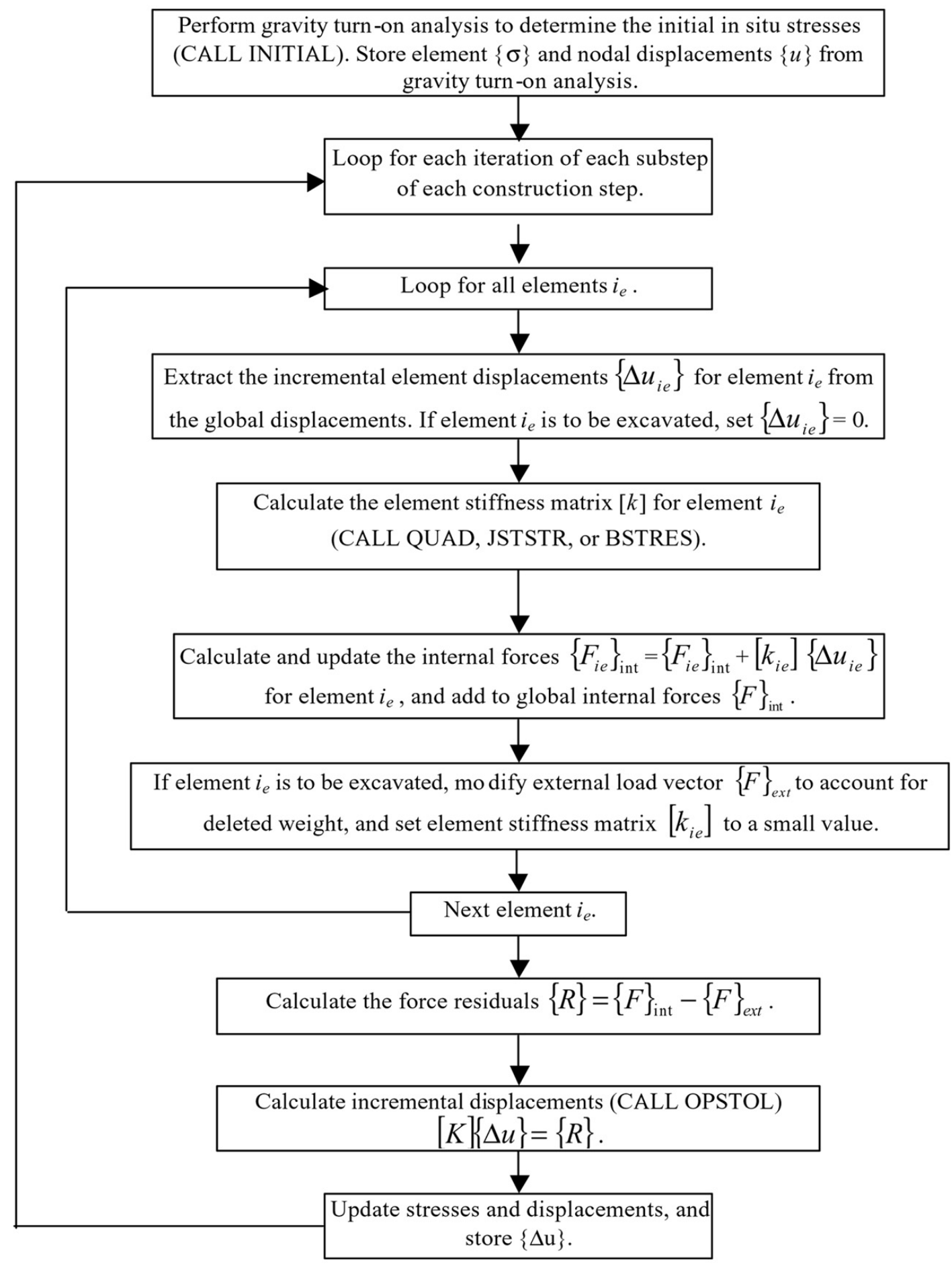

Figure 4.19. Flowchart for implementing the method of force residuals in SOILSTRUCTALPHA using incremental element displacements in calculating internal element forces 
Equation 4.7 (as illustrated in Figure 4.19). The element stiffness matrices are calculated in the subroutines QUAD, JTSTF, and BAREL for the continuum, interface, and structural elements, respectively. These subroutines pass the stiffness matrices to the subroutine STRSTF, which assembles the global stiffness matrix at the start of every new load increment. Although QUAD, JTSTF, and BAREL generate the $\left[k_{e}\right]$-matrices, the element $[B]$-matrices are not generated explicitly (QUAD assembles the elements of the $[B]$-matrix, but these are not stored in any matrix and are currently not passed to other subroutines). Element stresses are generated in STRESS, JSTRES, and BSTRES for the continuum, interface, and structural elements, respectively. Note that $\left[k_{e}\right]$ is the tangent element stiffness matrix for incremental analyses.

Using the first option would, therefore, require that the $[B]$-matrices be generated (for JTSTF and BAREL), stored in a matrix, and passed via the COMMON block. In the second option, the internal forces must be stored in an array and updated incrementally using the incremental displacements from each increment of loading (and taking into consideration the nonlinear response of the soil and the interface elements). The accumulated internal forces should include the internal forces from displacements generated in the gravity turn-on analysis.

The advantage of calculating the internal element forces by using the element stresses and Equation 3.2 is that the element stresses are already updated and stored globally by SOILSTRUCT-ALPHA. The disadvantage of the approach is that the element $[B]$ matrices must be generated; however, these are needed only for the excavated elements.

The advantage of calculating the internal element forces by accumulating and storing the element internal forces from Equation 4.7 using the element tangent stiffness matrix $\left[k_{e}\right]$ is that a new matrix corresponding to $[B]$ is not created and passed via the COMMON statement. The disadvantage of this approach is that the internal element load vector must be stored for each element in the entire mesh and updated continuously.

4.3.4.2 Calculation of external element forces. To calculate the external forces, a new subroutine must be written that modifies the current external load vector to account for the deletion of the weight of the excavated elements. Changes in the external loads due to deletion of the weight of structural elements can and should also be accounted for. This requires that the load vector must be stored separately and not be overwritten by the displacement vector as is commonly done in many finite element programs. The load vector must also continuously track the changes made to the external loads calculated from the in situ stresses created in the INITIAL subroutine. These changes, which are mainly from the weights of added elements simulating embankment lift, are calculated in the subroutine BUILD. Changes from external loads on the boundaries of the excavated elements should also be accounted for in the load vector. 


\section{Summary and Conclusions}

The Corps uses SOILSTRUCT-ALPHA to perform soil-structure interaction analyses of multi-anchored or tieback retaining walls. Permanent multi-anchored walls have been used as guide walls and approach walls on navigation projects, and as retaining walls on highway and railroad protection and relocation projects. A critical aspect for SSI analyses of such structures is the modeling of the excavation process. The case of the Bonneville temporary tieback wall was used to illustrate the importance of SSI analyses, and particularly the need for a robust and efficient procedure to simulate excavation processes. The excavation algorithm in SOILSTRUCT was developed in the late 1960s by Clough and Duncan (1969), and it has not been updated since that time, even though improved methods have been developed by Ghaboussi and Pecknold (1984), Borja et al. (1989), and others.

The objectives of the study described in this report are to

a. Complete a comprehensive literature review of numerical modeling of excavation.

$b$. Determine the suitability of existing excavation algorithms for their use in SOILSTRUCT.

c. Provide the information necessary to implement an improved excavation algorithm in SOILSTRUCT.

The Clough and Duncan excavation algorithm was reviewed extensively. An example problem was analyzed to illustrate the main steps in this algorithm, particularly the extrapolation of stresses from nearby elements to the excavation boundary and integration of the extrapolated stresses to produce excavation forces at element nodes. In addition to the Clough and Duncan procedure, other algorithms were also reviewed, including 1) the method of force residuals, 2) the method based on accumulation of excavation forces along the excavation boundaries, and 3) the method based on hybrid finite elements. Of these procedures, the method of force residuals is the most widely used procedure for modeling excavation. The example problem analyzed using the Clough and Duncan procedure was reanalyzed to illustrate the main steps involved in the method of force residuals.

The different excavation algorithms were rigorously analyzed and compared in terms of their numerical performance. It was shown that the Clough and Duncan excavation procedure yields results that are dependent on the number of excavation stages used in the simulations for linear elastic materials. For such 
materials, it has been shown formally by Ishihara (1970) that the results of the excavation should be independent of the number of steps and the sequence used to simulate the excavation. The lack of uniqueness in the results of the Clough and Duncan excavation algorithms stems from the fact that the excavation forces applied along the excavation boundary are not always consistent with the stresses in the excavated elements. Force equilibrium is not necessarily satisfied, and the resulting deformations can be either larger or smaller than they should be. The lack of force equilibrium can result in a distribution of excavation unloading force in which either too much or too little force is applied to the underlying soil and, correspondingly, either too little or too much force is applied to the structure.

One strategy to minimize the errors from the Clough and Duncan procedure is to use as few excavation stages as possible in the simulation. However, this strategy is not appropriate for problems with significant nonlinearity or for excavation problems in which struts or tiebacks are placed as excavation proceeds.

Both the method based on the accumulation of forces and the method based on hybrid finite elements satisfy force equilibrium and uniqueness of solution for excavation in elastic media. However, both methods are complicated and difficult to implement in a finite element program, and the requirements of force equilibrium and uniqueness of solution are satisfied only at the expense of additional computational effort.

Of the four general methods reviewed, the most appropriate method for implementation in SOILSTRUCT-ALPHA is the method of force residuals. This procedure is based on the balancing of the residual forces from the differences between the external loads and the equivalent internal loads in a loaded body. The method was shown to satisfy uniqueness of solution and force equilibrium in example calculations. It was also noted that the method of force residuals is now the most widely used and accepted procedure for excavation modeling. Other advantages of the method of force residuals are that it uses standard finite element calculations and can be easily extended to nonlinear problems in a consistent manner. Based on these considerations, it was recommended to update the excavation algorithm in SOILSTRUCT-ALPHA by using the method of force residuals.

A detailed discussion of the issues related to implementation of the method of force residuals in SOILSTRUCT-ALPHA was provided. These issues include 1) the type of finite element(s) to be used, 2) the implementation of interface elements, 3) the use of the APHA method for nonlinear problems, and 4) issues related to the computer programming of the method of force residuals in SOILSTRUCT-ALPHA.

The following specific recommendations were given concerning implementation of the method of force residuals in SOILSTRUCT-ALPHA:

a. With regard to the finite element formulation, it is recommended to keep the current QM5 finite element with constant stresses in the code. This has the advantage of retaining the improved bending performance of the 
QM5. It is also suggested to implement a new four-noded isoparametric Q4 finite element, which permits the calculation of element stresses at four Gaussian quadrature points. An isoparametric element will give better resolution of stresses and excavation forces at sharp excavation boundaries than the QM5. Future extension to SOILSTRUCT-ALPHA should also consider higher order elements such as the eight-noded isoparametric Q8 finite element.

$b$. It was shown that interface elements can be accounted for in similar manner as continuum elements in the method of force residuals. Example problems were used to show the significance of interface behavior in excavation modeling.

c. It was shown that the ALPHA method for nonlinear materials can be used in conjunction with the method of force residuals. It is recommended that excavation be performed in stages, taking out a few elements at a time (via a layer-by-layer excavation for instance) and applying the ALPHA-method for each excavation stage. This method is preferred because both geometric and material nonlinearity can be better accommodated.

d. Two algorithms for implementing the method of force residuals in SOILSTRUCT-ALPHA are described. Flowcharts are given for these two algorithms. 


\section{References}

Beer, G. (1985). "An isoparametric joint/interface element for finite element analysis," International Journal of Numerical. Methods in Engineering, 21, 585-600.

Borja, R. I., Lee, S. R., and Seed, R. B. (1989), "Numerical simulation of excavation in elastoplastic soils," International Journal of Numerical and Analytical Methods in Geomechanics 13, 231-49.

Brown, C. B., and King, I. P. (1966). "Automatic embankment analysis; Equilibrium and instability conditions," Geotechnique 16(3), 209-19.

Brown, P. T., and Booker, J. R. (1986). "Finite element analysis of excavations," Research Report No. 532, School of Civil and Mining Engineering, The University of Sydney, Australia.

Carol, I., and Alonso, E. E. (1983). "A new joint element for the analysis of fractured rocks," Proceedings, fifth international congress of rock mechanics, Melbourne, Australia. F, 147-51.

Chandrasekaran, V. S., and King, G. J. W. (1974). "Simulation of excavation using finite elements," Journal of Geotechnical Engineering 100, 1086-89.

Chang, C. V. (1969). "Finite element analysis of soil movements caused by deep excavation and dewatering," Ph.D. thesis, University of California, Berkeley.

Chow, Y. K. (1985). "Discussion of 'Hybrid FE procedure for soil-structure interaction," Journal of Geotechnical Engineering 111(6), 1057-58.

Christian, J. T., and Wong, I. H. (1973). "Errors in simulating excavation in elastic media by finite elements," Soils and Foundations 12(1), 1-10.

Clough, G. W., and Duncan, J. M. (1969). "Finite element analyses of Port Allen and Old River Locks," Contract Report S-69-6, U.S. Army Engineer Waterways Experiment Station, Vicksburg, MS.

Clough, G. W., and Duncan, J. M. (1971). "Finite element analysis of retaining wall behavior," Journal of the Soil Mechanics and Foundations Division 97(SM12), 1657-73. 
Clough, G. W., and Mana, A. I. (1976). "Lessons learned in finite element analysis of temporary excavations," Proceedings, second international conference, numerical methods in geomechanics. American Society of Civil Engineers, Blacksburg, VA.

Cook, R. D., Malkus, D. S., and Plesha, M. E. (2002). Concepts and applications of finite element analysis. 4th ed., John-Wiley and Sons, New York.

Desai, C. S., and Abel, J. F. (1972). Introduction to the finite element method. Van Nostrand Reinhold, New York.

Desai, C. S., and Sargand, S. (1984). "Hybrid FE procedure for soil-structure interaction," Journal of Geotechnical Engineering 110, 473-86.

Doherty, W. P., Wilson, E. L., and Taylor, R. L. (1969), "Stress analysis of axisymmetric solids utilizing higher-order quadrilateral finite elements," Report 69-3, Structural Engineering Laboratory, University of California, Berkeley.

Duncan, J. M., and Chang, C. Y. (1970). "Nonlinear analysis of stress and strain in soils," Journal of Soil Mechanics and Foundations Division 96(SM5), $1629-53$

Duncan, J. M., and Clough, G. W. (1971). "Finite element analyses of Port Allen Lock," Journal of Soil Mechanics and Foundations Division 97(SM8), 105368.

Dunlop, P., Duncan, J. M., and Seed, H. B. (1968). "Finite element analyses of slopes in soil," Report TE 68-3, Office of Research Services, University of California.

Ebeling, R. M., and Mosher, R. L. (1996). "Red River U-frame Lock No. 1 backfill-structure-foundation interaction," Journal of Geotechnical Engineering 122(3), 216-25.

Ebeling, R. M., and Wahl, R. E. (1997). "Soil-structure-foundation interaction analysis of new roller-compacted concrete North Lock Wall at McAlpine Locks," Technical Report ITL-97-5, U.S. Army Engineer Waterways Experiment Station, Vicksburg, MS.

Ebeling, R. M., Clough, G. W., Duncan, J. M., and Brandon, T. L. (1992). "Methods of evaluating the stability and safety of gravity earth retaining structures founded on rock," Technical Report REMR-CS-29, U.S. Army Engineer Waterways Experiment Station, Vicksburg, MS.

Ebeling, R. M., Duncan, J. M., and Clough, G. W. (1990). "Methods of evaluating the stability and safety of gravity earth retaining structures founded on rock-Phase 2 study," Technical Report ITL-90-7, U.S. Army Engineer Waterways Experiment Station, Vicksburg, MS. 
Ebeling, R. M., Mosher, R. L., Abraham, K., and Peters, J. F. (1993). "Soilstructure interaction study of the Red River Locks and Dam No. 1 subjected to sediment loading," Technical Report ITL-93-3, U.S. Army Engineer Waterways Experiment Station, Vicksburg, MS.

Ebeling, R. M., Pace, M. E., and Morrison, E. E. (1997). "Evaluating the stability of existing massive concrete gravity structures founded on rock," Technical Report REMR-CS-54, U.S. Army Engineer Waterways Experiment Station, Vicksburg, MS.

Ebeling, R. M., Peters, J. F., and Clough, G. W. (1992). "User's guide for the incremental construction soil-structure interaction program SOILSTRUCT," Technical Report ITL-90-6, U.S. Army Engineer Waterways Experiment Station, Vicksburg, MS.

Ebeling, R. M., Peters, J. F., and Mosher, R. L. (1997). "The role of non-linear deformation analyses in the design of a reinforced soil berm at Red-River Uframe Lock No. 1," International Journal of Numerical and Analytical Methods in Geomechanics 21,753-87.

Filz, G. M. (1992). "An analytic and experimental study of earth loads on rigid retaining walls," Ph.D. dissertation, Virginia Tech, Blacksburg.

Filz, G. M., and Duncan, J. M. (1997), "Vertical shear loads on nonmoving walls; I, Theory," Journal of Geotechnical Engineering 123(9), 856-62.

Filz, G. M., Duncan, J. M., and Ebeling, R. M. (1997), "Vertical shear loads on nonmoving walls; II, Applications," Journal of Geotechnical Engineering 123(9), 863-73.

Ghaboussi, J., and Pecknold, D. A. (1984). "Incremental finite element analysis of geometrically altered structures," International Journal of Numerical Methods in Engineering 20, 2051-64.

Gómez, J. E., Filz, G. M., and Ebeling, R. M. (2000a). "Development of an improved numerical model for concrete-to-soil interfaces in soil-structure interaction analyses," Technical Report ITL-99-1, U.S. Army Engineer Research and Development Center, Vicksburg, MS.

Gómez, J. E., Filz, G. M., and Ebeling, R. M. (2000b). “Extended load/unload/reload hyperbolic model for interfaces; Parameter values and model performance for the contact between concrete and coarse sand," Technical Report ERDC/ITL TR-00-7, U.S. Army Engineer Research and Development Center, Vicksburg, MS.

Goodman, L. E., Taylor, R. L., and Brekke, T. L. (1968), "A model for the mechanics of jointed rock," Journal of the Soil Mechanics and Foundations Division 94(SM3), 637-68.

Ishihara, K. (1970). "Relations between process of cutting and uniqueness of solutions," Soils and Foundations 10(3), 50-65. 
Langer, F. T., and Stockmann, K. (1995). "Stability analysis of tunnels using the program ADINA," Computers and Structures, 21(1/2), 341-51.

Maurseth, J., and Sedey, J. S. (1992). "Slurry constructed diaphragm guard wall, Bonneville Navigation Lock," Corps of Engineers Structural Engineering Conference, July 8-12, St. Louis County, FL. 1, 251-60.

Morrison, C. S., and Duncan, J. M. (1996). "The development of a modular finite element program for analysis of soil-structure interaction," Contract Report prepared for U.S. Army Engineer Waterways Experiment Station, Vicksburg, MS, and Nikken Sekkei, Ltd.

Mosher, R. L., and Knowles, V. R. (1990). "Finite element study of tieback wall for Bonneville Navigation Lock," Technical Report, ITL-90-4, U.S. Army Engineer Waterways Experiment Station, Vicksburg, MS.

Munger, D. F., Jones, P. T., and Johnson, J. (1990). "Temporary tie-back wall, Bonneville Navigation Lock," ASCE Specialty Conference on Design and Performance of Earth Retaining Structures. ASCE Special Publication 25, 778-83. American Society of Civil Engineers, Reston, VA.

NAVFAC. (1982). "Foundations and earth structures," Design Manual 7.2, Department of the Navy, Naval Facilities Engineering Command, Alexandria, VA.

Regalado, L. R., Duncan, J. M., and Clough, G. W. (1992). "Finite element analyses of gravity earth retaining structures founded on soil," Contract Report prepared for the U.S. Army Engineer Waterways Experiment Station, Vicksburg, MS.

Strom, R. W., and Ebeling, R. M. (2001). "State of the practice in the design of tall, stiff, and flexible tieback retaining walls," Technical Report ERDC/ITL TR-01-1, U.S. Army Engineer Research and Development Center, Vicksburg, MS. 


\section{Appendix A Internal and External Nodal Forces Using Isoparametric Elements}

To clarify the nature of the equivalent external nodal forces from surface tractions $\left\{F_{\text {ext }}\right\}$ (shown in Figure 2.3 and given in Equation 3.3) and the equivalent internal element forces $\left\{F_{\text {int }}\right\}$ from the element internal stresses (given in Equation 3.4), isoparametric elements will be used. Isoparametric elements use the same shape functions to describe the geometry (or shape) of the element and the unknowns that are being solved. Further details of the isoparametric formulation can be found in finite element textbooks (e.g., Cook, Malkus and Plesha 1989).

\section{A.1 External Nodal Forces from Surface Tractions}

Consider the line element or the edge of a two-dimensional (2-D) element shown in Figure A.1, which has linear displacements $u$ and under the surface tractions $\sigma^{s}$. To represent the displacements $u$ along the line or edge of an element, a linear function of the coordinate $x$ can be assumed:

$$
u(x)=a_{1}+a_{2} x
$$

The values of the interpolation constants $a_{1}$ and $a_{2}$ can be obtained from the known values of $u$ at the element endpoints at $x=x_{1}$ and $x=x_{2}$ :

$$
\begin{aligned}
& u_{1}=a_{1}+a_{2} x_{1} \\
& u_{2}=a_{1}+a_{2} x_{2}
\end{aligned}
$$

Solving these two equations simultaneously gives the values of the two unknowns, $a_{1}$ and $a_{2}$ : 


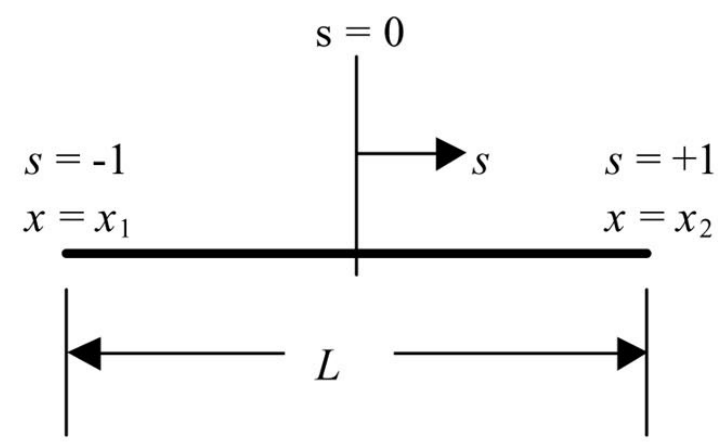

a

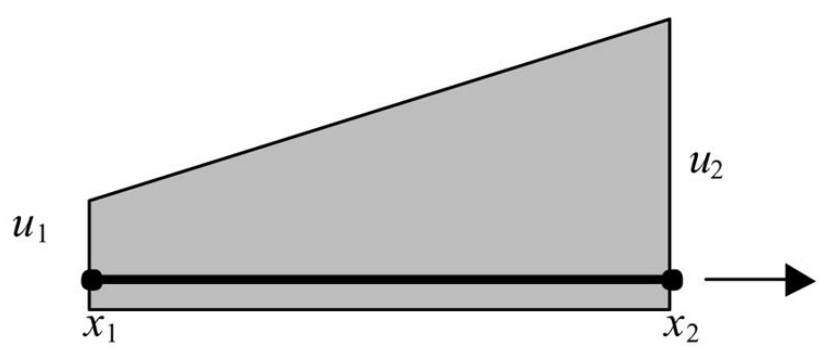

$\mathrm{b}$

Figure A.1. One-dimensional isoparametric element showing (a) local coordinates and (b) linear function approximation

$$
\begin{gathered}
a_{1}=u_{1}-\frac{u_{2}-u_{1}}{x_{2}-x_{1}} x_{1} \\
a_{2}=\frac{u_{2}-u_{1}}{x_{2}-x_{1}}
\end{gathered}
$$

Substituting Equation A.3 in Equation A.1 yields

$$
\begin{aligned}
& u(x)=N_{1}(x) u_{1}+N_{2}(x) u_{2}=[N(x)]\{u\} \\
& {[N(x)]=\left[N_{1}(x) \quad N_{2}(x)\right],\{u\}=\left\{\begin{array}{l}
u_{1} \\
u_{2}
\end{array}\right\}} \\
& N_{1}(x)=1-\frac{x-x_{1}}{x_{2}-x_{1}}, N_{2}(x)=\frac{x-x_{1}}{x_{2}-x_{1}}
\end{aligned}
$$

where the $N_{i}$ values are called element shape functions. The shape functions $N_{i}$ can be also expressed in terms of the local coordinate $(s)$ :

$$
\begin{gathered}
u(s)=[N(s)]\{u\} \\
N_{1}(s)=\frac{1-s}{2}, N_{2}(s)=\frac{1+s}{2} \\
s=2\left(\frac{x-x_{1}}{x_{2}-x_{1}}\right)-1
\end{gathered}
$$

The local coordinate $s$ takes a value between -1 at $x=x_{1}$ and +1 at $x=x_{2}$, and $s=0$ at the midpoint between $x_{1}$ and $x_{2}$ (Figure A.1). 
Equation 3.3, which gives the equivalent nodal forces $\left\{F_{\text {ext }}\right\}$ from the surface traction $\sigma^{s}$, is actually calculated from the work $W_{T}$ done by the surface traction $\sigma$ in producing the surface deformations $u$ :

$$
W_{T}=\int_{x_{1}}^{x_{2}} F_{e x t}(x) u(x) d x=\int_{-1}^{+1} F_{e x t}(s) u(s) d s
$$

Using the linear distribution of displacement $u$ in Equation A.4a,

$$
W_{T}=\int_{-1}^{+1} F_{e x t}(s)\left[\begin{array}{cc}
\frac{1-s}{2} & \frac{1+s}{2}
\end{array}\right]\left\{\begin{array}{l}
u_{1} \\
u_{2}
\end{array}\right\} d s
$$

In the case of the constant distribution of traction force $\sigma^{s}$ along the line element, as shown in Figure 2.3a,

$$
\begin{aligned}
& F_{\text {ext }}(s)=\sigma_{o} \\
& W_{T}=\int_{-1}^{+1} \sigma_{o}\left[\begin{array}{ll}
\frac{1-s}{2} & \frac{1+s}{2}
\end{array}\right]\left\{\begin{array}{l}
u_{1} \\
u_{2}
\end{array}\right\} d s
\end{aligned}
$$

Performing the integration,

$$
W_{T}=\int_{-1}^{+1} \frac{\sigma_{o} L}{2}\left[\begin{array}{ll}
1 & 1
\end{array}\right]\left\{\begin{array}{l}
u_{1} \\
u_{2}
\end{array}\right\} d s
$$

results in the external force vectors shown in Figure 2.3a

$$
\left\{F_{\text {ext }}\right\}=\frac{\sigma_{o} L}{2}\left[\begin{array}{ll}
1 & 1
\end{array}\right]
$$

where $L=x_{2}-x_{1}$ is the length of the element.

In the case where the traction force $\sigma^{s}$ varies linearly along the side of the element, as shown in Figure 2.3b, the same displacement function $[N(s)]$ can be used to express the variation of the surface traction $\sigma^{s}$, as

$$
F_{e x t}(s)=\left[\begin{array}{ll}
N_{1}(s) & N_{2}(s)
\end{array}\right]\left\{\begin{array}{l}
\sigma_{I} \\
\sigma_{j}
\end{array}\right\}
$$

where $\sigma_{I}$ and $\sigma_{J}$ are the magnitudes of the surface tractions at nodes $I$ and $J$. Substituting in Equation A.7: 


$$
W_{T}=\int_{-1}^{+1}\left[\left(\frac{1-s}{2}\right) \sigma_{I} \quad\left(\frac{1+s}{2}\right) \sigma_{j}\right]\left\{\begin{array}{l}
\left(\frac{1-s}{2}\right) u_{1} \\
\left(\frac{1+s}{2}\right) u_{2}
\end{array}\right\} d s
$$

Performing the integration yields the external load vector shown in Figure 2.3b.

$$
\left\{F_{\text {ext }}\right\}=\frac{L}{6}\left[\begin{array}{ll}
2 & 1 \\
1 & 2
\end{array}\right]\left\{\begin{array}{l}
\sigma_{I} \\
\sigma_{J}
\end{array}\right\}
$$

Similar procedures can be derived for the external forces from body loads as given in Equation 3.3.

\section{A.2 Equivalent Internal Nodal Forces from Element Stresses}

The meaning of the internal force vector $\left\{F_{\text {int }}\right\}$ given in Equations 3.2 and 3.5 will be illustrated in this section using the four-noded isoparametric quadrilateral element. This element is shown in Figure A.2 in the global $\{x, y\}$ coordinates. Using the isoparametric formulation, the element can be mapped to the local (or natural) $\{s, t\}$ coordinate system shown in Figure A.2.
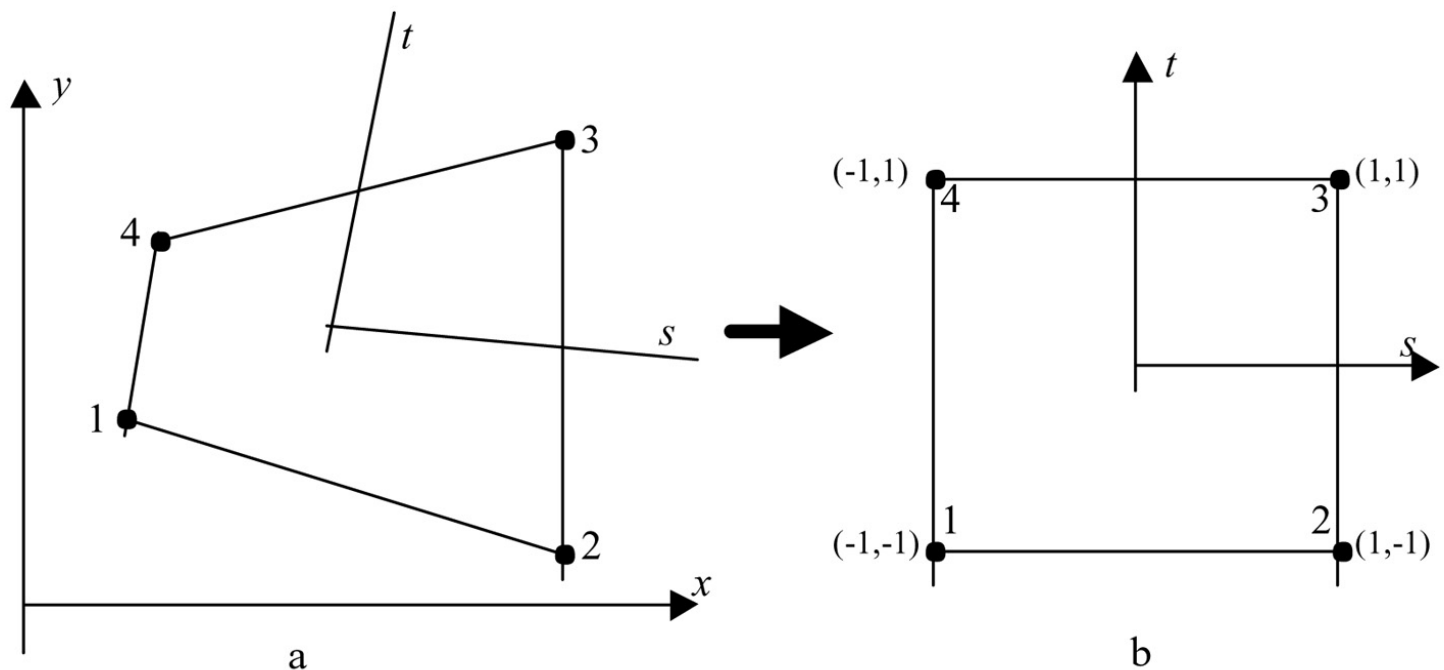

$\mathrm{b}$

Figure A.2. Quadrilateral finite element (a) in the global coordinate system and (b) in the local (natural) coordinate system 
Using shape functions, the horizontal and vertical displacements $u$ and $v$ are interpolated from the $x$ and $y$ displacements $\{u\}=\left\{\begin{array}{llll}u_{1} & u_{2} & u_{3} & u_{4}\end{array}\right\}$ and $\{v\}=\left\{\begin{array}{llll}v_{1} & v_{2} & v_{3} & v_{4}\end{array}\right\}$ at the four nodes of the elements

$$
\begin{aligned}
& u=N_{1} u_{1}+N_{2} u_{2}+N_{3} u_{3}+N_{4} u_{4} \\
& v=N_{1} v_{1}+N_{2} v_{2}+N_{3} v_{3}+N_{4} v_{4}
\end{aligned}
$$

In the isoparametric formulation, the same functions used to express the unknowns $u$ and $v$ are used to express the shape of the elements:

$$
\begin{aligned}
& x=N_{1} x_{1}+N_{2} x_{2}+N_{3} x_{3}+N_{4} x_{4} \\
& y=N_{1} y_{1}+N_{2} y_{2}+N_{3} y_{3}+N_{4} y_{4}
\end{aligned}
$$

where $\{x\}=\left\{\begin{array}{llll}x_{1} & x_{2} & x_{3} & x_{4}\end{array}\right\}$ and $\{y\}=\left\{\begin{array}{llll}y_{1} & y_{2} & y_{3} & y_{4}\end{array}\right\}$ are the coordinates of the four nodes.

Using a linear combination of the 1-D shape function, $N_{i}$, given in Equation A.5 for both the local axes $s$ and $t$, the four 2-D shape functions required in Equations A.15 and A.16 can be written as

$$
\begin{array}{ll}
N_{1}=\frac{(1-s)(1-t)}{4} & N_{2}=\frac{(1+s)(1-t)}{4} \\
N_{3}=\frac{(1+s)(1+t)}{4} & N_{4}=\frac{(1-s)(1+t)}{4}
\end{array}
$$

The $[B]$-matrix needed in Equation 3.3 to determine the internal nodal forces is defined as

$$
[B]=\left[\begin{array}{cc}
\frac{\partial N_{i}}{\partial x} & 0 \\
0 & \frac{\partial N_{i}}{\partial y} \\
\frac{\partial N_{i}}{\partial y} & \frac{\partial N_{i}}{\partial x}
\end{array}\right]
$$

The derivatives $\partial N_{i} / \partial x$ and $\partial N_{i} / \partial y$ in the above equation can be obtained from the derivative $\partial N_{i} / \partial s$ and $\partial N_{i} / \partial t$ via the following transformation: 


$$
\left\{\begin{array}{l}
\frac{\partial N_{i}}{\partial x} \\
\frac{\partial N_{i}}{\partial y}
\end{array}\right\}=[J]^{-1}\left\{\begin{array}{l}
\frac{\partial N_{i}}{\partial s} \\
\frac{\partial N_{i}}{\partial t}
\end{array}\right\}
$$

where $[J]$ is the Jacobian matrix:

$$
[J]=\left[\begin{array}{cccc}
\frac{\partial N_{1}}{\partial s} & \frac{\partial N_{2}}{\partial s} & \frac{\partial N_{3}}{\partial s} & \frac{\partial N_{4}}{\partial s} \\
\frac{\partial N_{1}}{\partial t} & \frac{\partial N_{2}}{\partial t} & \frac{\partial N_{3}}{\partial t} & \frac{\partial N_{4}}{\partial t}
\end{array}\right]\left[\begin{array}{ll}
x_{1} & y_{1} \\
x_{2} & y_{2} \\
x_{3} & y_{3} \\
x_{4} & y_{4}
\end{array}\right]
$$

From Equation A.17, the derivatives $\partial N_{i} / \partial s$ and $\partial N_{i} / \partial t$ can be obtained simply as

$$
\begin{array}{ll}
\frac{\partial N_{1}}{\partial s}=-\frac{(1-t)}{4} & \frac{\partial N_{1}}{\partial t}=\frac{(1-s)}{4} \\
\frac{\partial N_{2}}{\partial s}=\frac{(1-t)}{4} & \frac{\partial N_{2}}{\partial t}=-\frac{(1+s)}{4} \\
\frac{\partial N_{3}}{\partial s}=\frac{(1+t)}{4} & \frac{\partial N_{3}}{\partial t}=-\frac{(1+s)}{4} \\
\frac{\partial N_{4}}{\partial s}=-\frac{(1+t)}{4} & \frac{\partial N_{4}}{\partial t}=\frac{(1+s)}{4}
\end{array}
$$

In the local $s$ and $t$ coordinate system, the equivalent internal force vector is expressed as

$$
\left\{F_{\text {int }}\right\}=\int_{V}[B]^{T}\{\sigma\} \quad d V=\int_{-1}^{+1} \int_{-1}^{+1}[B]^{T}\{\sigma\}|J| d s d t
$$

where $|J|$ is the determinant of the Jacobian matrix:

$$
\operatorname{det}|J|=\frac{\partial(x, y)}{\partial(s, t)}=\left|\begin{array}{ll}
\frac{\partial x}{\partial s} & \frac{\partial y}{\partial s} \\
\frac{\partial x}{\partial t} & \frac{\partial y}{\partial t}
\end{array}\right|
$$


The derivatives $\partial x / \partial s, \partial x / \partial t, \partial y / \partial s$ and $\partial y / \partial t$ can be obtained from Equation A.15 as

$$
\begin{array}{ll}
\frac{\partial x}{\partial s}=\sum_{i=1}^{4} \frac{\partial N_{i}}{\partial s} x_{i} & \frac{\partial x}{\partial t}=\sum_{i=1}^{4} \frac{\partial N_{i}}{\partial t} x_{i} \\
\frac{\partial y}{\partial s}=\sum_{i=1}^{4} \frac{\partial N_{i}}{\partial s} y_{i} & \frac{\partial y}{\partial t}=\sum_{i=1}^{4} \frac{\partial N_{i}}{\partial t} y_{i}
\end{array}
$$

For illustration, only the value of the horizontal force at node 1 will be calculated. From Equation A.23,

$$
\left(F_{x 1}\right)_{\text {int }}=\int_{-1}^{+1} \int_{-1}^{+1} B_{11} \sigma_{x}|J| d s d t
$$

Expanding the above equations, it can be shown that $B_{11}$ and $|J|$ take the following values:

$$
\begin{aligned}
& B_{11}==\frac{1}{8|J|}\left[\left(y_{4}-y_{2}\right)+s\left(y_{3}-y_{4}\right)+t\left(y_{2}-y_{3}\right)\right] \\
& |J|=\frac{1}{8}\left\{x_{i}\right\}^{T}[a]\left\{y_{i}\right\}
\end{aligned}
$$

where

$$
[a]=\left[\begin{array}{cccc}
0 & 1-t & t-s & s-1 \\
t-1 & 0 & s+1 & -(s+t) \\
s-t & -(1+s) & 0 & 1+t \\
1-s & s+t & -(1+t) & 0
\end{array}\right]
$$

For Element 2 in the example problem solved in Chapters 2 and 3, $\left\{x_{i}\right\}=\left\{\begin{array}{llll}1 & 2 & 2 & 1\end{array}\right\}$ and $\left\{y_{i}\right\}=\left\{\begin{array}{llll}1 & 1 & 2 & 2\end{array}\right\}$. Also, in the same example problem in Chapters 2 and 3, the stresses are constant in the four-noded isoparametric element. Thus, the shape functions can be evaluated anywhere in the element. For convenience, the local coordinates of the center of the element, $s=0$ and $t=0$ are used. These values give $|J|=1 / 4$ and

$$
B_{11}=\frac{1}{8\left(\frac{1}{4}\right)}[1+0(0)+0(-1)]=\frac{1}{2}
$$




$$
\left(F_{x 1}\right)_{\mathrm{int}}=\frac{1}{2} \int_{-1}^{+1} \int_{-1}^{+1} \frac{1}{4} \sigma_{x} d s d t=\frac{1}{2} \sigma_{x}
$$

Note that, in general, the equivalent internal force vector given in Equation A.22 is evaluated by numerical integration. The most common technique used is the Gaussian quadrature. In this technique, the function to be integrated is evaluated at some optimum locations (called quadrature points), the value of the function multiplied by a weighting factor, and summed for all quadrature points. In similar manner, the element stiffness $[k]$ given in Equation A.31 below is also integrated numerically.

$$
[k]=\int_{-1}^{+1} \int_{-1}^{+1}[B]^{T}[D][B]|J| d s d t
$$

For a four-noded isoparametric element, exact numerical integration is achieved with four quadrature points, while for an eight-noded element, eight quadrature points are required. Consequently, values of equivalent internal nodal forces $\left\{F_{\text {int }}\right\}$ and the element stiffness matrix $[k]$ depend upon the characteristics of the element shape functions being used and how the numerical integration is carried out in Equations A.22 and A.31. Thus, it is not sufficient to calculate excavation forces from equivalent internal forces alone. To ensure consistency in the method of force residuals, the following conditions should also be met:

a. The same shape function(s) used to formulate the $[B]$-matrix for the load vector in Equation A.22 should be used in the $[B]$-matrix for the stiffness matrix in Equation A.31.

$b$. The equivalent internal nodal forces should be evaluated using the stresses at the same Gaussian points used to evaluate the stiffness matrix.

Condition $b$ also implies that the same level of Gaussian quadrature (i.e., the same number of quadrature points) is used in evaluating the stiffness matrix and the equivalent internal load vector. 


\section{Appendix B Notation}

\begin{tabular}{|c|c|}
\hline$\{a\}$ & Interpolation coefficient matrix \\
\hline$a_{i}, b_{i}$ & Interpolation constants \\
\hline$\{b\}$ & Self-weight matrix $=\left\{\begin{array}{ll}0 & \gamma\end{array}\right\}^{T}$ \\
\hline$B]$ & Strain-displacement matrix \\
\hline$D]$ & Constitutive matrix \\
\hline$F_{i}$ & Nodal force at node $i$ \\
\hline$\left\{F_{e x t}\right\}$ & External load vector \\
\hline$\left\{F_{\text {int }}\right\}$ & Internal load vector \\
\hline$[k]$ & Element stiffness matrix \\
\hline$[K]$ & Global stiffness matrix \\
\hline$K_{n}, K_{s}$ & Interface normal and shear stiffnesses \\
\hline$K_{o}$ & Coefficient of earth pressure at rest \\
\hline$L$ & Length of an element edge \\
\hline$[m]$ & Coordinate matrix \\
\hline$[n]$ & Coordinate matrix \\
\hline$[N]$ & Element shape functions \\
\hline
\end{tabular}




$\begin{array}{ll}{[R]} & \text { Residual force vector } \\ s, t & \text { Local coordinates } \\ u, v & \text { Horizontal and vertical displacement } \\ {[\Delta u]} & \text { Displacement increment vector } \\ W & \text { Weight of an element } \\ \gamma & \text { Unit weight of soil } \\ \{\varepsilon\} & \text { Element strains } \\ v & \text { Poisson's ratio } \\ \{\sigma\} & \text { Element stresses } \\ \left\{\sigma^{s}\right\} & \text { Surface tractions } \\ \sigma_{x}, \sigma_{y} & \text { Stresses along the } x \text { - and } y \text {-axes } \\ \phi & \text { Angle of friction }\end{array}$




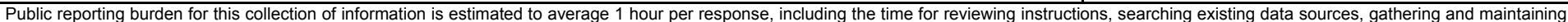

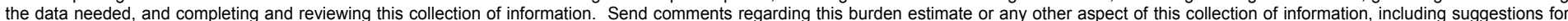

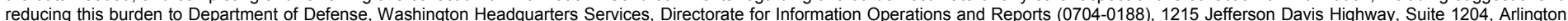

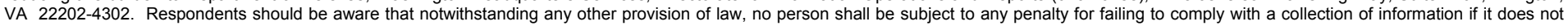
display a currently valid OMB control number. PLEASE DO NOT RETURN YOUR FORM TO THE ABOVE ADDRESS.
1. REPORT DATE (DD-MM-YYYY)
November 2002$$
\text { Final report }
$$

4. TITLE AND SUBTITLE

Numerical Methods to Model Excavation of Soil Adjacent to Retaining Structures
3. DATES COVERED (From - To)

5a. CONTRACT NUMBER

5b. GRANT NUMBER

5c. PROGRAM ELEMENT NUMBER

5d. PROJECT NUMBER

5e. TASK NUMBER

5f. WORK UNIT NUMBER

33272

8. PERFORMING ORGANIZATION REPORT NUMBER

ERDC/ITL TR-02-7

Virginia Polytechnic Institute and State University, Blacksburg, VA 24061;

U.S. Army Engineer Research and Development Center

ERDC/TL TR-02-7

3909 Halls Ferry Road

Vicksburg, MS 39180-6199

9. SPONSORING / MONITORING AGENCY NAME(S) AND ADDRESS(ES)

U.S. Army Corps of Engineers

Washington, DC 20314-1000

10. SPONSOR/MONITOR'S ACRONYM(S)

11. SPONSOR/MONITOR'S REPORT NUMBER(S)

\section{DISTRIBUTION / AVAILABILITY STATEMENT}

Approved for public release; distribution is unlimited.

\section{SUPPLEMENTARY NOTES}

\section{ABSTRACT}

The U.S. Army Corps of Engineers uses SOILSTRUCT-ALPHA to perform soil-structure interaction (SSI) analyses of multianchored or tieback retaining walls. A critical aspect for SSI analyses of such structures is the modeling of the excavation process. The excavation algorithm in SOILSTRUCT was developed in the late 1960s by Clough and Duncan (1969), and it has not been updated since that time, even though improved methods have become available.

In this investigation, a comprehensive literature review of numerical modeling of excavation was performed to determine the suitability of existing excavation algorithms for their use in SOILSTRUCT. It was shown that the existing Clough and Duncan excavation procedure used in SOILSTRUCT-ALPHA yields results that are dependent on the number of excavation stages used in the simulations for linear elastic materials. Of the general methods reviewed, the most appropriate method for implementation, and recommended for implementation in SOILSTRUCT-ALPHA, is the method of force residuals. Information necessary to implement this excavation algorithm in SOILSTRUCT-ALPHA is given in the report.

\section{SUBJECT TERMS}

Earth pressures

Earth retaining structures

16. SECURITY CLASSIFICATION OF:

\begin{tabular}{|l|l|}
\hline $\begin{array}{l}\text { a. } \text { REPORT } \\
\text { UNCLASSIFIED }\end{array}$ & $\begin{array}{c}\text { b. ABSTRACT } \\
\text { UNCLASSIFIED }\end{array}$ \\
\hline
\end{tabular}

c. THIS PAGE

UNCLASSIFIED
Excavation

Finite elements

17. LIMITATION OF ABSTRACT

\section{SOILSTRUCT}

Soil-structure interaction

18. NUMBER $19 a$. NAME OF RESPONSIBLE OF PAGES

105
PERSON

19b. TELEPHONE NUMBER (include area code) 